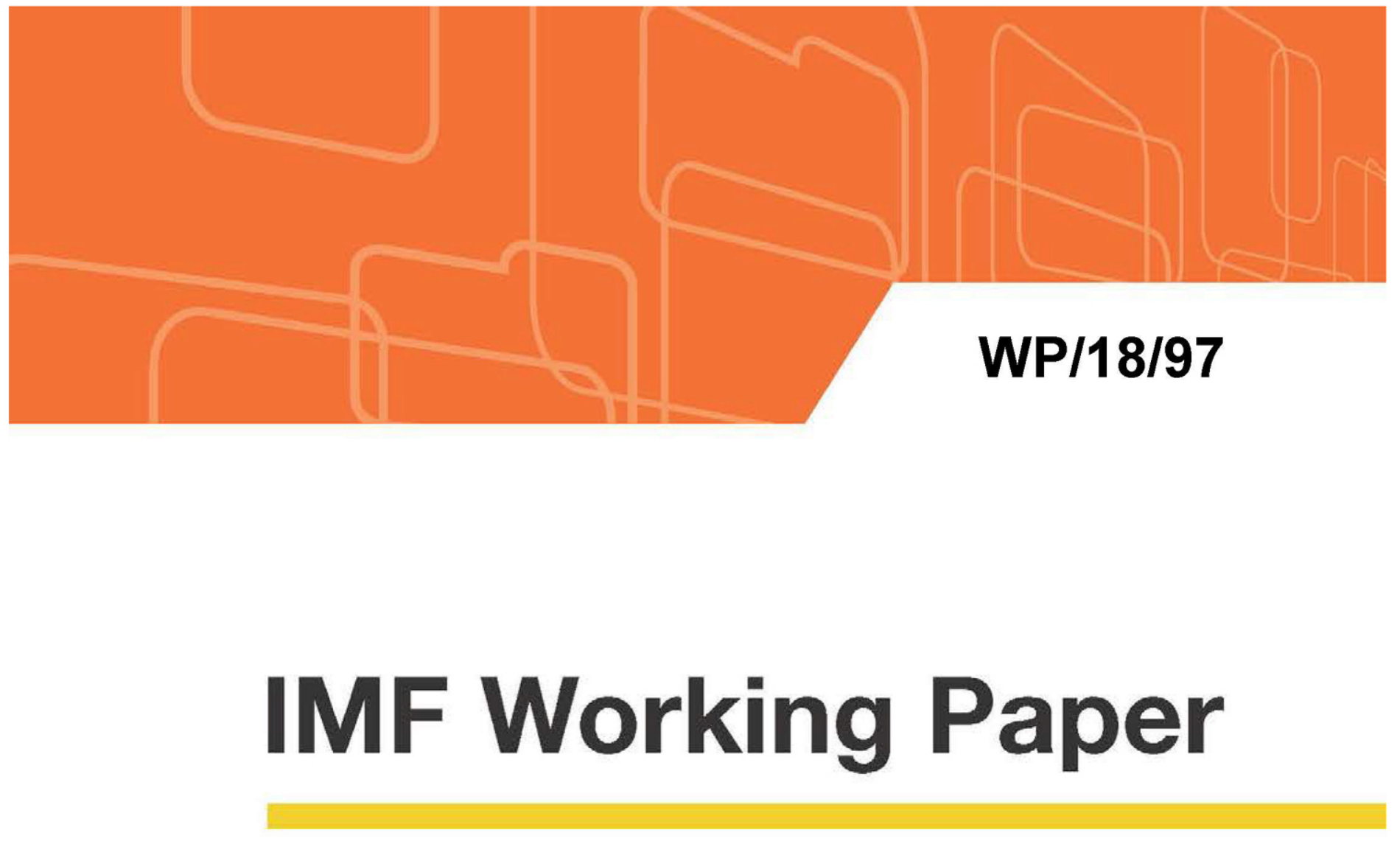

\title{
Foreign Currency Bank Funding and Global Factors
}

by Signe Krogstrup and Cédric Tille

IMF Working Papers describe research in progress by the author(s) and are published to elicit comments and to encourage debate. The views expressed in IMF Working Papers are those of the author(s) and do not necessarily represent the views of the IMF, its Executive Board, or IMF management. 


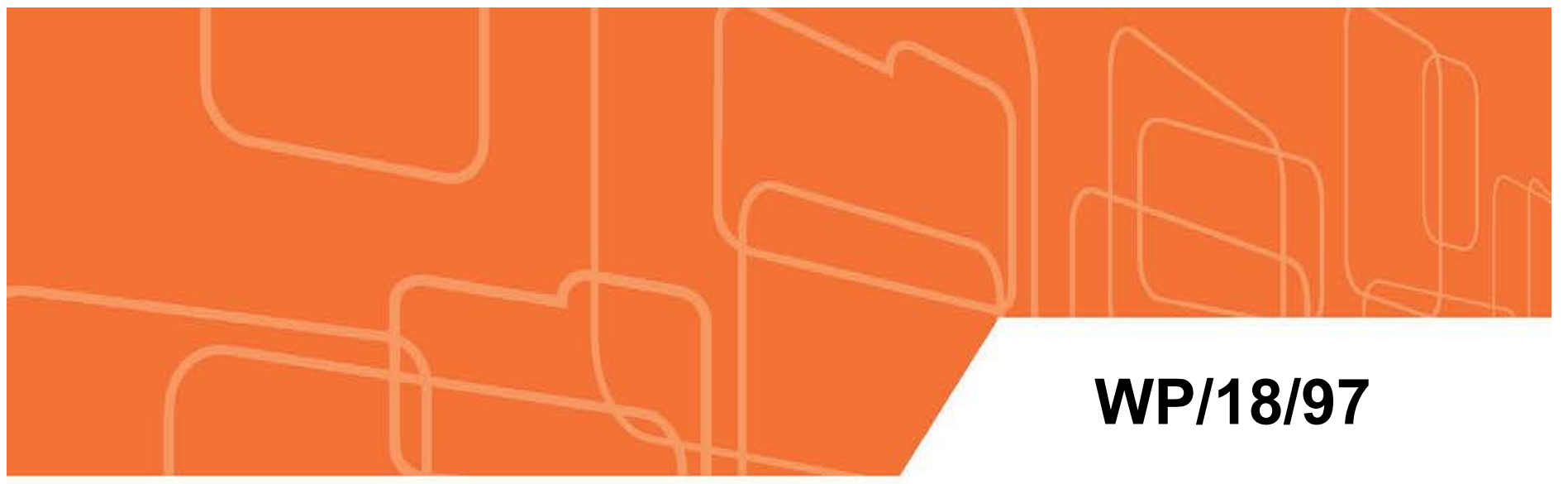

\section{IMF Working Paper}

\section{Foreign Currency Bank Funding and Global Factors}

by Signe Krogstrup and Cédric Tille

IMF Working Papers describe research in progress by the author(s) and are published to elicit comments and to encourage debate. The views expressed in IMF Working Papers are those of the author(s) and do not necessarily represent the views of the IMF, its Executive Board, or IMF management.

I N T E R N A T I O N A L M O N E T A R Y F U N D 


\title{
IMF Working Paper
}

\author{
Research Department
}

\section{Foreign Currency Bank Funding and Global Factors}

Prepared by Signe Krogstrup and Cédric Tille

\author{
Authorized for distribution by Signe Krogstrup
}

May 2018

\section{IMF Working Papers describe research in progress by the author(s) and are published to elicit comments and to encourage debate. The views expressed in IMF Working Papers are those of the author(s) and do not necessarily represent the views of the IMF, its Executive Board, or IMF management.}

\begin{abstract}
The literature on the drivers of capital flows stresses the prominent role of global financial factors. Recent empirical work, however, highlights how this role varies across countries and time, and this heterogeneity is not well understood. We revisit this question by focusing on financial intermediaries' funding flows in different currencies. A concise portfolio model shows that the sign and magnitude of the response of foreign currency funding flows to global risk factors depend on the financial intermediary's pre-existing currency exposure. An analysis of a rich dataset of European banks' aggregate balance sheets lends support to the model predictions, especially in countries outside the euro area.

JEL Classification Numbers: F32, F34, F36.

Keywords: Currency mismatch, capital flows, push factors, spillovers, cross-border transmission of shocks, European bank balance sheets.

Author's E-Mail Address: skrogstrup@,imf.org, cedric.tille@graduateinstitute.ch

The views in this paper are solely the responsibility of the authors and do not necessarily reflect the views of the International Monetary Fund, its Executive Board or Management. We would like to thank Stefan Avdjiev, Giovanni Dell'Ariccia, Oliver Gloede, Linda Goldberg, Patrick McGuire, Alistair Milne, Friederike Niepmann, Maury Obstfeld, Philip Saure, Livio Stracca, Casper de Vries, Adrian van Rixtel, Pinar Yesin, participants at the fall 2017 CEPR-IMF meeting, the fall 2017 SNB research conference, the SNB workshop on foreign currency lending, the Infinity conference, the Konstanz seminar, the German economics society macroeconomics workshop, the annual meeting of the Swiss Society of Economics and Statistics, the SNB brownbag workshop, the BIS SNB research workshop, the IMF Macro-Financial Seminar and the Federal Reserve Board brownbag seminar, for comments and suggestions on the present and earlier versions of this paper. Excellent research assistance was provided by Wenjie Li and Menglu Cai.
\end{abstract}




\section{Introduction}

How do capital flows respond to global risk factors? It is well established in the empirical literature that conditions in global financial markets, such as global risk sentiment, volatility and liquidity, drive cross border capital flows (e.g. Calvo et al. [1996], Forbes and Warnock [2012], Rey [2015], Cerutti et al. [2017a]). Global financial factors have traditionally been viewed as push factors in the literature, impacting capital flows irrespective of the fundamentals of recipient countries. Accordingly, they are usually modelled as having a uniform impact on capital flows over time and across countries. Recent empirical studies point to substantial cross country variation in the response of cross border capital flows to global financial factors, however, and to changes in the sensitivity of capital flows to global factors over time (e.g. Avdjiev et al. [2017], Cerutti et al. [2017b]). These patterns are not just a reflection of differences between emerging markets and advanced economies, as time and cross country variation is also observed within these sets of countries (Goldberg and Krogstrup [2018]). It underscores that country specific features play a role in determining a country's capital flow sensitivity to global factors and, hence, capital flow volatility.

A better understanding of such features can help inform the design of capital flow management measures. The literature on the drivers of capital flow sensitivity to global factors is scarce, however. Two recent empirical studies suggest that the types of foreign investors and domestic financial institutions intermediating a country's cross border capital flows play a role (IMF [2014], Cerutti et al. [2015])), although the exact mechanisms remain unexplored. Cross country comparable data on the financial market structure and the balance sheets of the institutions driving capital flows are limited, and there is, to our knowledge, no theoretical literature investigating institution specific capital flow responses to global risk factors.

This paper contributes to the theoretical as well as the empirical understanding of the drivers of capital flow sensitivity to global factors from a financial intermediary's portfolio balance perspective. As exchange rate risk is a major source of uncertainty in international financial markets, we focus on what drives the intermediary's choice of its portfolio across currencies. Building on the role of financial institutional structure underlined in IMF [2014] and Cerutti et al. [2015], we focus on the role of the balance sheet structure and portfolio optimization behavior of financial institutions residing in host countries. We find that their foreign currency mismatch affects the sign and size of the response of their cross border 
positions to global risk factors. The mechanism is the following. Financial institutions choose their foreign currency exposure to maximize the risk-adjusted return on their total portfolio. When the risk associated with this exposure increases, or the risk appetite decreases, the financial institution reduces its exposure. Reducing foreign currency exposure, however, has different implications for the direction of the resulting cross border flow depending on the sign of the initial foreign currency exposure. If the financial institution has a short foreign currency exposure, e.g. has more foreign currency funding than foreign currency lending, reducing this exposure requires a reduction in foreign currency funding, or an increase of foreign currency lending. This means that if the financial institution is net short foreign currency, it will respond to higher global risk with a capital outflow. The opposite response of cross border flows ensues if the financial institution is initially long in foreign currency exposure, e.g. has more foreign currency lending than foreign currency funding. In this case, reducing the exposure to foreign risks requires a reduction in foreign currency lending or an increase in foreign currency funding, or a capital inflow.

Our model is a portfolio optimization setting for a financial institution's balance sheet with domestic as well as foreign currency positions. The model focuses on the cross border funding flows of a resident financial institution as opposed to those of the foreign counterparties. A previous theoretical literature considering the drivers of bank cross border funding flows has mainly focused on the behavior and incentives of global banks (e.g. Bruno and Shin [2013], Cetorelli and Goldberg [2011]). The global bank perspective has implications for global flows from center to periphery countries, but cannot explain differences in flows across periphery countries. Our model hence offers a new and complementary perspective. We use the model to derive the determinants of the financial institution's choice of net wholesale funding denominated in foreign currency, which we associate with cross border funding. The main source of risk is currency risk. The financial institution maximizes the expected future value of its equity under exchange rate uncertainty, and adjusts its mix of domestic and foreign currency wholesale funding in response to changes in global risk and risk aversion. To keep the model tractable, we assume that the financial institution is small and residing in a small country, and does not take account of the effects of its decisions on global markets and prices. Extensions toward general equilibrium that account for the portfolio optimization behavior of both the domestic and foreign counterparty financial institutions, as well as the interaction 
with the macroeconomic environment, exchange and interest rates, would be desirable but are beyond the scope of this paper.

The solution to the model illustrates how the financial institution trades off the riskiness of a net foreign currency exposure with the return to having such an exposure. The net foreign currency exposure is then an optimal decision based on funding cost differentials across currencies. The sign of the optimal foreign currency exposure depends on differences in cross currency funding costs, and its extent depends on country specific institutional factors such as risk preferences and equity financing, which we treat as exogenous. Given this exposure, the model in turn illustrates how an increase in the perceived riskiness of this exposure leads the financial institution to reduce it. This is achieved through an increase in net foreign currency funding, giving rise to a cross border inflow. Conversely, if the financial institution is net short, it will reduce its exposure, which gives rise to a cross border outflow.

The model delivers a simple expression for net foreign currency funding flows as a function of changes in global risk factors, pre-existing foreign currency balance sheet exposures, and other determinants of the risk and return of funding positions, from which we derive an empirical estimating equation. We test the model predictions for aggregate bank funding flows in foreign currency using a rich dataset of European countries' aggregate banking sector balance sheets, the Swiss Franc Lending Monitor (henceforth the SFLM), compiled by the Swiss National Bank in collaboration with other European central banks. The advantage of investigating bank funding flows specifically is that data on bank balance sheet positions are detailed and available in formats that are comparable across countries, allowing us to compute specific types of flows and associate these directly with measures of balance sheet exposures. Detailed balance sheet data with information on both domestic and foreign positions for nonbanks financial institutions is not available in cross country comparable format. ${ }^{1}$ The SFLM database distinguishes between banks' domestic and foreign counterparties as well as positions in local and foreign currency, the latter being further divided into Swiss francs and other foreign currencies. Cross border foreign currency flows are obtained by valuation adjusting the quarterly changes in outstanding positions using additional country specific data sources on the currency breakdown of positions in non-Swiss franc foreign currencies.

\footnotetext{
${ }^{1}$ For similar reasons, it is not as straightforward to test the predictions of the model for aggregate capital flows directly. Data on balance of payments and international investment positions are not matched with data on domestic balance sheet positions of the sectors or institutions intermediating capital flows. Matching national wealth data with the foreign currency composition within countries could be an interesting future avenue.
} 
A data challenge is the lack of information on off-balance sheet foreign currency exposures, which can be an important part of banks' total foreign currency exposures. We use on-balance sheet foreign currency exposure as a proxy for total exposure, and control empirically for drivers of the use of off-balance sheet foreign currency instruments by including deviations from covered interest parity, as suggested by the model. This source of imprecision could attenuate the results. The findings nevertheless confirm the main predictions of the model. We find that global risk factors are not significant drivers of bank foreign currency funding flows on their own, but become significant when interacted with foreign currency exposure. The effect is most pronounced, and very robust, in countries outside the euro area, while global factors do not significantly explain foreign currency funding flows in euro area countries. This could be related to differences in foreign currency hedging practices across the two samples. We also find that the most consistently empirically relevant measure of the global financial factor is growth in US broker dealer leverage, as proposed notably in Adrian and Shin [2014]. Alternative measures often used in the literature, such as the $V I X$ and measures of US financial conditions, have the right signs but are not as consistently significant across all the specifications that we consider.

The model and empirical evidence indicate that the impact of global factors is heterogeneous across countries and time. Both the size and the sign of a country's capital flow sensitivity to global factors may depend on the constellation of financial institutions involved in intermediating a country's cross border flows, and the portfolio structures and optimization behavior of these institutions. Our empirical results are specific to banks. If these behavioral balance sheet responses can be extended to other types of institutions intermediating cross border capital flows, the findings would suggest that currency mismatches in the balance sheets of a country's institutions may not only increase a country's vulnerability to capital flow volatility, but could directly influence the direction and intensity of the country's capital flows as well as exchange rates. More research and better data are needed to establish the generality of these results for aggregate capital flows and for other sets of countries. ${ }^{2}$

The paper is structured as follows. Section 2 gives an overview of related literature. Section 3 presents the model and derives testable implications. The data and relevant stylized

\footnotetext{
${ }^{2}$ If indeed a country's aggregate foreign currency funding demand responds to a global risk shock, this would either affect the exchange rate or would trigger a policy response from the monetary authorities in case of a peg, and actual capital flows would materialize differently in the two cases, as stressed in Goldberg and Krogstrup [2018]. Considering the role of exchange rate regimes would be an interesting extension.
} 
facts are presented in Section 4, which also presents the variables we consider and the econometric setup. Section 5 presents the econometric results, and the final Section concludes. Supporting materials are provided in the appendix.

\section{Related literature}

Our work ties to three broad streams of literature. The first is the analysis of the drivers of capital flows, and in particular, the role of foreign push factors versus domestic pull factors (Calvo et al. [1996], Forbes and Warnock [2012], Fratzscher [2012], Ghosh et al. [2014], McQuade and Schmitz [2016]). This literature generally finds that push factors such as global financial and economic conditions play an important role in explaining cross border capital flows independently of country specific pull factors. Recent contributions find that the role of push factor is heterogeneous across categories of capital flows. Avdjiev et al. [2017] find that the impact of global risk conditions has changed in recent years. Cerutti et al. [2015] shows that the impact of risk depends on the mix of foreign financial institutions intermediating capital flows, leading to cross country heterogeneity in the impact of push factors. We take a step further and focus on the role of domestic financial institutions. A clean distinction between push and pull factors may be misleading if country specific financial factors explain how global push factors affect a country's capital flows.

The second stream of related literature pertains to the international transmission of shocks through international bank linkages. Several papers stress global bank funding structures and networks as central in the cross border transmission of shocks (Takats [2010], Avdjiev et al. [2012], Bussiere et al. [2016], McCauley et al. [2015], Milesi-Ferretti and Tille [2011]). Claessens and van Horen [2015] point out that the structure of the international banking system has gone through substantial changes in the crisis, which can affect the transmission of shocks. Cetorelli and Goldberg [2011] document the transmission of shocks through crossborder bank lending and operations of banks' local affiliates. Cetorelli and Goldberg [2012] underline the role of banks' internal capital markets, and show that global banks' affiliates in more robust countries can be used as sources of funds for the parent in a crisis. A key aim in this literature is to assess how financial and monetary developments in global financial markets, or in the home country of the foreign funding currency, impact funding conditions in 
other countries (Bruno and Shin [2014], Cerutti [2015] and Cerutti et al. [2017a]). A general finding is that global financial factors, including global financial sentiment typically captured by the VIX, and US monetary and financial conditions, drive bank funding costs in other countries. Avdjiev et al. [2016] find that the role of the VIX in driving global flows has diminished, while the real exchange rate of the USD has gained in prominence as a driver, underlining possible structural changes in funding markets since the crisis (see also Bremus and Fratzscher [2015]). Our results suggest a complementary interpretation of a changing impact of global risk factors since the crisis, in that the response of bank capital flows to global financial factors may be conditional on the structure of bank balance sheets and their risk management behavior, which have changed.

The final line of research that we link to is the analysis of borrowing in foreign currencies. Foreign currency borrowing increased substantially before the crisis in some countries, notably in Eastern Europe where the issuance of foreign currency mortgages increased prior to the crisis, and dropped again after the crisis (Krogstrup and Tille [2017], (Yesin [2013]). Foreign currency borrowing by nonfinancial firms also increased in some countries (Bruno and Shin [2015], Caballero et al. [2015], (Brunnermeier et al. [2009]). Borrowers may have been unaware of the full extent of the risks taken with such loans. Alternatively, taking foreign currency loans can translate into a schedule of payments for the borrower that is more favorable compared to a loan in domestic currency even when the full risk is internalized by the borrower (Dell'Ariccia et al. [2016]). Foreign currency borrowing has often been limited to a few key currencies, giving rise to currency networks in international banking activity (Avdjiev and Takats [2016]), the presence of which opens channels for across border transmission of monetary policy from the home countries of these key currencies (Takats and Temesvary [2016]). A recent line of research related to foreign currency borrowing focuses on the breakdown of covered interest parity. A firm can borrow in a foreign currency and lend in its domestic currency without incurring any exchange risk, if it also takes a position in the forward exchange rate markets. The covered interest parity condition implies that the two options carry the same cost, as otherwise there would be an opportunity for risk-free arbitrage. While covered interest parity conditions generally held empirically before the crisis, we have since seen sizable deviations that may reflect a limited ability of banks to take the leverage required to exploit the arbitrage conditions (see Du et al. [2017], Avdjiev et al. 
[2016] and Borio et al. [2016]). This recent development motivates the inclusion of a forward currency contract, balance sheet costs of holding this contract, and deviations from covered interest parity in our analysis.

\section{A model of wholesale bank funding}

This section presents a simple partial equilibrium model focusing on the currency composition of a financial institution's funding portfolio. We focus on the main elements and results of the model necessary, and leave the derivations to Appendix A. ${ }^{3}$ The model derives the optimal allocation of wholesale funding between the domestic and foreign currency, and also how this allocation is adjusted when the institution's environment shifts, for instance with exogenous shifts in other categories of its balance sheet or shifts in risk and risk tolerance. While we refer to the financial institution as a bank because the subsequent empirical analysis considers bank balance sheet data, the model is more general and applies to financial institutions more broadly.

The emphasis is on the currency composition of net wholesale funding, which can be interpreted as gross wholesale funding net of gross wholesale lending, but the gross wholesale positions are not modelled individually as they are assumed to be perfect substitutes. ${ }^{4}$ Our focus is motivated by the fact that foreign currency wholesale funding is likely to capture the majority of cross border foreign currency flows emanating from banks in the short term. Wholesale funding is the component of the balance sheet that banks can most rapidly adjust. By contrast, changing the composition of loans or deposits takes longer and is less directly under the control of banks, as these balance sheet items can respond autonomously to changes in customer demand for credit and deposits. ${ }^{5}$

\footnotetext{
${ }^{3}$ The model presented here considers exchange rate risk as the only stochastic dimension. A detailed appendix available on request presents a more general version of the model.

${ }^{4}$ This implicitly assumes that the bank can place wholesale lending in the interbank market at the same conditions as it can obtain wholesale funding in that market.

${ }^{5}$ See Christensen and Krogstrup [2016] for an example of how bank deposits can respond autonomously to the portfolio choice of a bank's customers, and Choi and Choi [2016] for how banks tend to adjust wholesale funding to shocks in deposit funding empirically.
} 


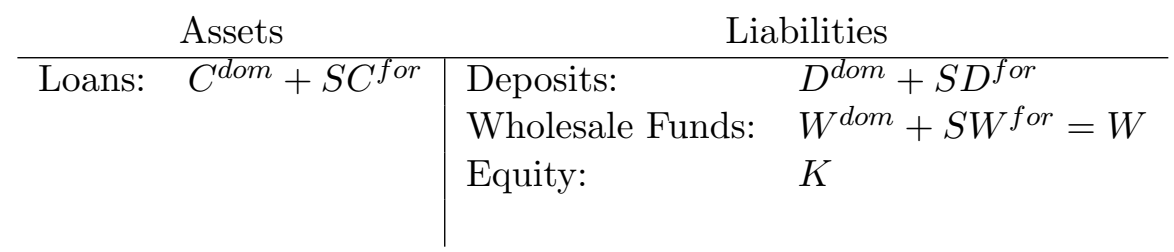

Figure 1: The bank's balance sheet structure

$S$ is the spot exchange rate (domestic per foreign currency units). Superscripts dom and for denote currency of issuance (domestic or foreign currency). $C$ is loans and $D$ is deposits, divided by currency of issuance and exogenous and fixed in the currency of issuance. $K$ is equity and is predetermined. $W$ is total net wholesale funding and is residually determined, given the other exogenous and predetermined balance sheet items. The currency mix of wholesale funding is adjustable. Beyond the balance sheet, the bank also has access to an off-balance sheet currency forward market.

\subsection{Main building blocks}

Figure 3.1 shows the bank balance sheet. The exchange rate between the domestic and the foreign currency, in terms of units of local currency per unit of foreign currency, is denoted by $S$. The bank's assets are loans, $C$, issued either in domestic or in foreign currency. Its liabilities include domestic and foreign currency deposits, $D$, wholesale funding in both currencies, $F$, and equity, $K$. As wholesale funding is net of wholesale lending, it can be negative. In addition to the balance sheet items in Figure 3.1, the bank can take positions in the currency forward market, which we describe further below.

The model covers two periods, $t$ and $t+1$. The exchange rate is written as $S_{t}=\exp \left[s_{t}\right]$ in period $t$ and as $S_{t+1}=\exp \left[s_{t+1}\right]$ in period $t+1$. The values of loans and deposits issued in domestic currency, $C^{d o m}$ and $D^{d o m}$, are assumed to remain constant. Similarly, the values of loans and deposits denominated in foreign currency, $C^{\text {for }}$ and $D^{f o r}$, are fixed in foreign currency. The bank cannot adjust the amount of loans or deposits. ${ }^{6}$

As loans and deposits are exogenous and equity is predetermined, the total value of the bank's wholesale funding in period $t, W_{t}$, is also predetermined. The currency composition of the wholesale funding portfolio, however, can be adjusted by the bank. We denote domestic currency wholesale funding in period $t$ by $W_{t}^{\text {dom }}$. Similarly, the foreign currency value of funding in foreign currency is $W_{t}^{f o r}$. Wholesale funding entails an interest cost that is non-stochastic in the currency of denomination. The gross cost (including principal) is

\footnotetext{
${ }^{6}$ This assumption is relaxed in other contributions. For instance Ivashina and Stein [2015] consider a similar model where the lending currency mix is endogenous to the bank's decisions, in order to study how shocks to the funding currency mix translate into changes in the lending currency mix.
} 
$\exp \left[r_{t+1}^{W, d o m}\right]$ for funding in domestic currency and $\exp \left[r_{t+1}^{W, f o r}\right]$ for funding in foreign currency.

The bank also participates in the foreign currency swap market through a forward exchange rate contract (Fender and McGuire [2010]). The contract pays off the forward rate $F_{t+1}=\exp \left[f_{t+1}\right]$ units of domestic currency per foreign currency in period $t+1$, which is known in period $t$. Purchasing the contract thus entails taking a short position in the spot market in period $t+1$. The covered foreign currency funding position entails no risk, and it is therefore directly comparable to domestic currency funding in its risk profile. If $f_{t+1}-s_{t}<r_{t+1}^{W, d o m}-r_{t+1}^{W, f o r}$, the cost of swapped funding is lower than the cost of domestic wholesale funding. In the absence of other costs, this implies an unlimited risk-free arbitrage opportunity, and the only equilibrium would be for the cost of domestic and covered foreign funding sources to be equalized. There are, however, occasionally large and persistent deviations from covered interest parity, in particular since the global financial crisis. The fact that banks do not take unlimited positions in response suggests the presence of additional costs in foreign currency swap markets (Ivashina and Stein [2015]). Such costs could be time varying risk premiums of specific financial institutions or sectors, constraints on the balance sheet capacity of swap market participants, and constraints on counterparty risk taking (Du et al. [2017], Borio et al. [2016], Avdjiev et al. [2016]). We include such costs in the model by assuming that positions in the forward contract entail a balance sheet cost which is quadratic in the amount of positions the bank takes. Specifically, the total payoff in period $t+1$ of buying $G^{\text {for }}$ units of the forward contract is:

$$
G^{f o r}\left(F_{t+1}-S_{t+1}\right)-\frac{\alpha_{t+1}}{2} F_{t+1}\left(G^{f o r}\right)^{2}
$$

\subsection{Solution of the model}

\subsubsection{Optimality conditions}

The bank is initially endowed with an equity position $K_{t}$ in domestic currency. ${ }^{7}$ It chooses the currency composition of wholesale funding, $W_{t}^{d o m}$ and $W_{t}^{f o r}$, to maximize its expected ${ }^{7} K_{t}=C^{d o m}-D^{d o m}-W_{t}^{d o m}+S_{t}\left[C^{f o r}-D^{\text {for }}-W_{t}^{f o r}\right]$ 
valuation of equity in period $t+1$, denoted by $K_{t+1}$ :

$$
\begin{aligned}
K_{t+1}= & C^{\text {dom }}-D^{\text {dom }}-W_{t}^{\text {dom }} R_{t+1}^{W, d o m}+S_{t+1}\left(C^{\text {for }}-D^{\text {for }}-W_{t}^{\text {for }} R_{t+1}^{W, f o r}\right) \\
& +G^{\text {for }}\left(F_{t+1}-S_{t+1}\right)-\frac{\alpha_{t+1}}{2}\left(G^{f o r}\right)^{2}
\end{aligned}
$$

We assume that the bank values its future equity using a CRRA utility function: $u=$ $\left(1-\gamma_{t}\right)^{-1}\left(K_{t+1}\right)^{1-\gamma_{t}} .{ }^{8} \mathrm{~A}$ bank chooses its exposure to currency risk according to a specific risk management framework, such as a Value-At-Risk framework as discussed in Adrian and Shin [2014], in addition to regulatory constraints on risk taking and other factors. A detailed modeling of such factors goes beyond the scope of our paper, and we instead consider a convex valuation as a shorthand for limits on the bank's risk exposure.

The optimization takes place subject to the constraint that overall wholesale funding is given initially. Combining the first-order conditions with respect to the wholesale funding in domestic and foreign currency, we get the standard result that the bank will choose uncovered foreign currency funding to the point where the expected discounted excess returns between the domestic and foreign currency funding are zero:

$$
0=E\left(K_{t+1}\right)^{-\gamma_{t}}\left[\frac{S_{t+1}}{S_{t}} R_{t+1}^{W, \text { or }}-R_{t+1}^{W, d o m}\right]
$$

The first-order condition with respect to the holdings of the forward contract implies that the bank will choose covered foreign currency funding to the point where the expected discounted excess returns between the forward and spot exchange rate offset the expected discounted marginal cost of holding the contract:

$$
0=E\left(K_{t+1}\right)^{-\gamma_{t}}\left(F_{t+1}-S_{t+1}-\alpha_{t+1} F_{t+1} G^{\text {for }}\right)
$$

\subsubsection{Solution in two steps}

The optimal funding portfolio boils down to the two optimality conditions (1) and (2). As these are highly non-linear, we compute the solution by taking a Taylor expansion. Specifically, we rely on quadratic and cubic approximations. The solution requires keeping track of terms that are proportionnal to innovations (so-called "first order"), proportional to the

\footnotetext{
${ }^{8}$ The appendix presents the derivation for a general utility function.
} 
square of innovations (so-called "second-order"), and so on, following Tille and van Wincoop [2014]. As the technical steps are complex, we leave them to Appendix A and instead focus on the underlying intuition.

The solution proceeds in two steps. We first derive the value of the wholesale funding in foreign currency and the position in the forward contract in a baseline environment. The environment consists of exogenous values of loans and deposits, interest rates, expected exchange rate movements, and the moments of baseline shocks (i.e. risk). We can think of the resulting baseline portfolio as a steady state value. ${ }^{9}$

Once we have solved for the baseline solution, we compute the values for the portfolio in a shifted environment. In this shifted environment the values of loans, deposits, interest rates, exchange rates, risk, and risk aversion shift away from baseline values. This step allows us to assess the impact of, for instance, an unusually large amount of loans, an unusually large expected exchange rate movement, or an unusual amount of risk, on the bank's portfolio choice. ${ }^{10}$ We denote variables in the baseline and shifted environment by base and shift subscripts.

\subsubsection{Baseline portfolio}

It is useful to define two measures of baseline exchange rate exposures. $N e t_{\text {base }}^{O B S}$ reflects the on-balance sheet exposure, and is the value of foreign currency loans net of that of deposits and wholesale funding. ${ }^{11}$ Net $_{\text {base }}^{T O T}$ reflects the total exposure that also includes the position in the forward contract:

$$
\begin{aligned}
& N e t_{\text {base }}^{\text {OBS }}=C_{\text {base }}^{f o r}-D_{\text {base }}^{f o r}-W_{\text {base }}^{f o r} \\
& N e t_{\text {base }}^{\text {TOT }}=\text { Net }_{\text {base }}^{\text {OBS }}-G_{\text {base }}^{\text {for }}
\end{aligned}
$$

We also define deviations from uncovered and covered interest parity in baseline and in

\footnotetext{
${ }^{9}$ More accurately, it is the value of foreign currency funding and the forward contract position when exchange rate risk gets very close to zero.

${ }^{10}$ An unusual amount of foreign currency loans (a shift away from baseline) should not be interpreted as a dynamic change between the amount of loans in period $t$ and period $t+1$. Instead, it refers to a deviation from the baseline value of loans which can apply to both periods.

${ }^{11}$ For simplicity the baseline value of the exchange rate is set to unity, without loss of generality.
} 
the shifted environment, where $k=$ base, shift:

$$
u i p_{k}=r_{t+1, k}^{W, f o r}+s_{t+1, k}-s_{t, k}-r_{t+1, k}^{W, d o m} \quad ; \quad \operatorname{cip}_{k}=p_{k}+u i p_{k}
$$

where $p$ is the difference between the forward exchange rate and the expected spot exchange rate. Positive values of deviations from the interest parities indicate that funding in foreign currency is more expensive than funding in the domestic currency. This can reflect interest rate spreads, expected exchange rate movements, and, in the case of the covered interest parity, differences between the forward rate and the expected spot rate (the forward premium).

Using this notation, the baseline portfolio is:

$$
G_{\text {base }}^{\text {for }}=\frac{\text { cip }_{\text {base }}}{\alpha_{\text {base }}} \quad ; \quad N e t_{\text {base }}^{\text {TOT }}=K_{\text {base }} \frac{\text { uip } p_{\text {base }}}{\gamma_{\text {base }} \cdot \sigma_{\text {fx,base }}^{2}}
$$

where $\alpha_{\text {base }}$ is the baseline cost of holding the forward contract, $K_{\text {base }}$ is equity, $\gamma_{\text {base }}$ is the baseline coefficient of risk aversion, and $\sigma_{f x, b a s e}^{2}$ is the baseline variance of exchange rate shocks.

The position in the forward contract, $G_{\text {base }}^{\text {for }}$, reflects the deviation from covered interest parity adjusted for the marginal cost of holding the contract. It is unaffected by risk aversion or risk because the forward contract in combination with spot funding positions offers risk-free arbitrage. Given $G_{\text {base }}^{\text {for }}, W_{\text {base }}^{\text {for }}$ follows from $N e t_{\text {base }}^{T O T}$. The total exchange rate exposure reflects the deviation from uncovered interest parity, adjusted by the exchange rate risk and risk aversion. Absent any deviation from uncovered interest parity, the bank would fully hedge its position. If funding is relatively expensive in foreign currency (uip base $>0$ ) the bank accepts some long exchange rate exposure, because fully covering it would be expensive. Note that expressions (4) and (5) illustrate that on-balance sheet and total foreign currency exposures are linked through the deviation from covered interest parity. Intuitively, deviations from covered interest parity offer an incentive to use the forward currency market for arbitrage, and therefore a greater distance between on-balance sheet and off-balance sheet foreign currency exposure. We use this observation to estimate total currency exposure for a robustness test, as described in Section 4.4. 


\subsubsection{Shifted portfolio}

We now assess the sensitivity of the funding choice to shifts in the various elements of the environment. This sensitivity is measured by the first-order deviations of funding positions from the zero-order allocation (5).

The holdings of the forward contract adjust in response to shift in the deviation from covered interest parity or the cost of holding the contract:

$$
g_{\text {shift }}^{\text {for }}=\frac{\text { cip }_{\text {shift }}}{\text { cip }_{\text {base }}}-\frac{\alpha_{\text {shift }}}{\alpha_{\text {base }}}
$$

The wholesale funding position adjust to shifts in several variables:

$$
\begin{aligned}
W_{\text {shift }}^{\text {for }}= & \text { Net } t_{\text {base }}^{\text {TOT }}\left[\sigma_{\text {fx,shift }}^{2}+\gamma_{\text {shift }}\right] \\
& + \text { Net } t_{\text {base }}^{\text {TOT }} \cdot s_{t, \text { shift }}-N e t_{\text {base }}^{\text {OBS }} \cdot \frac{N_{\text {base }}^{\text {TOT }}}{K_{\text {base }}} \cdot s_{t, \text { shift }} \\
& +C_{\text {shift }}^{\text {for }}-D_{\text {shift }}^{\text {for }} \\
& -K_{\text {base }} \frac{\text { uip } p_{\text {shift }}}{\gamma_{\text {base }} \cdot \sigma_{\text {fx,base }}^{2}}-G_{\text {base }}^{\text {for }} \cdot g_{\text {shift }}^{\text {for }}
\end{aligned}
$$

The first term in the first line in expression (7) is the focus of this paper, as it captures the bank's foreign currency funding response to changes in risk conditions. Specifically, higher exchange rate risk $\left(\sigma_{f x, \text { shift }}^{2}>0\right)$ and higher risk aversion $\left(\gamma_{\text {shift }}>0\right)$ both lead the bank to reduce its exposure to exchange rate risk. How this translates into its funding position depends on its baseline exposure, $N e t_{\text {base }}^{T O T}$. If the bank is normally long in foreign currency $\left(N_{\text {base }}^{T O T}>0\right)$, reducing risk exposure requires an increase in foreign currency wholesale funding. By contrast, foreign currency wholesale funding is reduced if the bank has a short exposure.

Expression (7) also shows that the bank adjusts its foreign currency funding position $\left(W_{\text {shift }}^{\text {for }}>0\right)$ for a range of other reasons. The first term in the second line reflects a standard portfolio rebalancing result (e.g. Hau and Rey [2008]). Funding adjusts to rebalance the direct impact of the exchange rate on the currency exposure. If the foreign currency is stronger than in the baseline environment $\left(s_{t, \text { shift }}>0\right)$, a bank holding a long currency exposure $\left(N e t_{\text {base }}^{T O T}>0\right)$ sees the value of its long position increase when expressed in domestic currency. The bank offsets this through an increase in funding in foreign currency. 
The second term in the second line reflects a risk-taking channel similar in spirit but not identical to the one stressed by Bruno and Shin [2013]. Interestingly, this channel depends on the cross-product of on-balance sheet and overall currency exposures. Consider a situation where the foreign currency is stronger than in the baseline environment $\left(s_{t, s h i f t}>0\right)$. This translates into a capital gain for a bank that has a long exposure on-balance sheet $\left(N e t_{b a s e}^{O B S}>\right.$ 0). ${ }^{12}$ With a convex utility valuation of equity, this capital gain driven increase in the banks' utility reduces the marginal utility associated with future equity. The bank is thus willing to take on more risk. If the baseline foreign currency exposure is long $($ Net base $>0),{ }^{T 3}$ taking extra risk is achieved through an increase in exposure and hence a reduction of foreign currency funding $\left(W_{\text {shift }}^{\text {for }}<0\right)$.

The terms in the third line reflect shifts in foreign currency loans and deposits. When the bank is faced with more loans or fewer deposits then usual $\left(C_{\text {shift }}^{\text {for }}>0\right.$ or $\left.D_{\text {shift }}^{\text {for }}<0\right)$, its exchange rate exposure increases. This is offset through higher funding in foreign currency.

The first term in the last line reflects the cost of funding. If the extra cost of foreign currency funding (over domestic currency) is larger than in the baseline situation (uip $p_{\text {shift }}>$ 0) the bank reduces its reliance on the expensive form of funding. The final term reflects the position in the forward contract, which is an alternative way for the banks to change its currency exposure.

Our model considers that the return on bank loans is constant. This abstracts from the potential indirect currency risk exposure of the bank through the credit risk of clients, if clients are exposed to a currency mismatch. ${ }^{14}$ Banks are likely to factor such exposures into their portfolio decisions as well, and in an appendix available on request, we develop a richer version of the model that includes this indirect exposure. In this richer version, the solution for foreign currency funding is similar, except that the net exposure now include all direct and indirect channels.

\footnotetext{
${ }^{12}$ The on-balance sheet exposure matters instead of the total exposure because the difference between the two reflects the position in the forward contract. As a shift in the current value of the exchange rate $s_{t, s h i f t}$ does not affect the spread between the forward exchange rate and the expected spot rate in period $t+1$, it has no valuation effect via the position in the forward contract.

${ }^{13}$ Exposure to exchange rate risk reflects positions in wholesale funding as well as the position in the forward contract, and thus the total exposure is the relevant measure.

${ }^{14}$ For example, banks in many European countries have issued foreign currency mortgages to clients and in turn partly hedged these on their own balance sheet, while clients have often not been hedged.
} 


\subsubsection{An empirical specification}

To derive an empirical estimating equation from expression (7), we first divide all terms by the total domestic currency value of the bank's assets in the baseline $A_{\text {base }}$. This provides us with ratios that are comparable across countries. We then take first differences, which cancels out baseline values in many, but not all, terms. This facilitates our analysis. Estimating the baseline portfolio is problematic given the relatively short sample. These two steps yield the following expression:

$$
\begin{aligned}
\frac{d W_{t, i}^{f o r}}{A_{i}}= & \operatorname{Net}_{i}\left(d \gamma_{t, i}+d \sigma_{f x, t, i}^{2}\right)+\left(N_{e}\right) d s_{t, i} \\
& -\frac{A_{i}}{K_{i}}\left(N e t_{i}\right)^{2} d s_{t, i}+\frac{d C_{t, i}^{f o r}}{A_{i}}-\frac{d D_{t, i}^{f o r}}{A_{i}} \\
& -\frac{K_{i}}{A_{i} \cdot \gamma_{i}} \frac{d u i p_{t, i}}{\sigma_{f x, i}^{2}}-\frac{d c i p_{t, i}-G_{i} \cdot d \alpha_{t, i}}{A_{i} \cdot \alpha_{i}}
\end{aligned}
$$

where we have omitted the base and shift subscript for clarity. Instead, variables without time subscript refer to country specific baseline values, variables with time and country subscripts refer to shifted variables, and variables without country subscript refer to global time-varying variables. Moreover, we have used the simpler notation $d W_{t, i}^{f o r}=W_{\text {shift }, t, i}^{f o r}-W_{\text {shift }, t-1, i}^{\text {for }}$, with $d C_{t, i}^{f o r}$ and $d D_{t, i}^{f o r}$ defined similarly, and evaluated at the baseline value of the exchange rate. $N e t_{i}$ is an empirical measure of net foreign currency exposure, the nature of which we discuss in more detail in Section 4.4.

We then make a series of simplifying assumptions and adjustments in order to take it to the data. First, because we cannot distinguish between risk and risk aversion empirically, we test for both jointly, and distinguish instead between a global financial factor $(G F)$ and a local one $(L F)$. The $G F$ captures risk and risk aversion related to global conditions in bank funding markets, as in Forbes and Warnock [2012] and Rey [2015], while LF captures country specific foreign currency risk and risk aversion. Higher values of $G F$ and $L F$ denote higher risk or higher risk aversion. Following the theoretical results, we include these risk factors on their own and interacted with net currency exposure in the estimating equation.

Second, the model indicates that the parameters for the risk taking channel and those of uip and cip depend on country specific features (banking sector leverage and country 
specific average risk factors). We restrict them to be the same across countries in the baseline specification for simplicity, but check robustness of the main findings to allowing the parameter estimates to vary across countries.

Third, the cost of engaging in foreign exchange swap contracts, $\alpha$, is not empirically observable and is hence not included in the regressions. $\alpha$ is likely to be correlated with cip as in Ivashina and Stein [2015]. If indeed we were to allow $\alpha$ to be proportional to cip in the model, the two terms would collapse into one with a different parameter. This interpretation of what cip is capturing in the regression should be kept in mind when interpreting the results. Moreover, to the extent that the balance sheet cost is common across countries, we can capture it with time fixed effects that pick up all factors that are common across countries but vary over time. As a robustness text, we hence also run the regressions with time fixed effects instead of the global factor on its own, but still including the interaction between the global factor and net currency exposure.

Finally, we add country fixed effects to capture all time invariant country specific factors affecting foreign currency funding decisions. Taking into account all these assumptions and adjustments yields our main empirical estimating equation:

$$
\begin{aligned}
d \tilde{W}_{t, i}^{f o r}= & \beta_{0}+\beta_{1} \cdot \operatorname{dlog}\left(G F_{t-1}\right)+\beta_{2} \cdot N e t_{i} \cdot \operatorname{dlog}\left(G F_{t-1}\right) \\
& +\beta_{3} \cdot \operatorname{dlog}\left(L F_{t-1}\right)+\beta_{4} \cdot N e t_{i} \cdot \operatorname{dlog}\left(L F_{t-1}\right) \\
& +\beta_{5} \cdot \operatorname{dlog}\left(S_{i, t-1}\right)+\beta_{6} \cdot N e t_{i} \cdot \operatorname{dlog}\left(S_{i, t-1}\right)+\beta_{7} \cdot N e t_{i}^{2} \cdot \operatorname{dlog}\left(S_{i, t-1}\right) \\
& +\beta_{8} \cdot N e t_{i}+\beta_{9} \cdot N e t_{i}^{2}+\beta_{10} \cdot d \tilde{C}_{t, i}^{f o r}+\beta_{11} \cdot d \tilde{D}_{t, i}^{f o r} \\
& +\beta_{12} \cdot \operatorname{duip}_{i, t-1}+\beta_{13} \cdot d c i p_{i, t-1}+\mu_{i}+\epsilon_{i, t}
\end{aligned}
$$

where $d \tilde{W}_{t, i}^{f o r}=S_{i, t-1} d W_{t, i}^{f o r} / A_{i, t}$ is the valuation adjusted change in net foreign currency wholesale funding as a share of total bank assets, $d \tilde{C}_{t, i}^{f o r}=S_{i, t-1} d C_{t, i}^{f o r} / A_{i, t}$ is the valuation adjusted change in foreign currency assets net of wholesale assets as a share of total bank assets, and $d \tilde{D}_{t, i}^{\text {for }}=S_{i, t-1} d D_{t, i}^{\text {for }} / A_{i, t}$ is the valuation adjusted change in foreign currency liabilities net of wholesale liabilities as a share of total bank assets.

The model analyzes the bank's demand for foreign currency wholesale funding, taking the supply side as well as domestic and global prices of funding as exogenous. It is possible that 
changes in demand also affect prices and supply, giving rise to endogeneity, a common problem in the literature. We follow the standard approach of lagging all explanatory variables by one quarter (e.g. Cerutti et al. [2017a]). Given that there is some persistence in bank balance sheet dynamics and in the explanatory variables, one should bear in mind that lagging may not fully alleviate endogeneity concerns.

The model implies that $\beta_{1}, \beta_{2}, \beta_{4}, \beta_{6}$ and $\beta_{10}$ are positive, and $\beta_{7}, \beta_{11}, \beta_{12}$ and $\beta_{13}$ are negative. There are no priors for the signs of the remaining parameter estimates.

\section{The Data and Stylized Facts}

The main data source for bank balance sheet positions is the Swiss Franc Lending Monitor (SFLM), containing end-of-quarter bank balance sheet positions. Other sources include Datastream, Bloomberg, the US Financial Accounts and national statistical agencies and central banks. Details and data formatting of the individual series used are described in Appendix B. The date series we consider and some key stylized facts are presented below.

\subsection{Bank Balance Sheet Data}

Testing the portfolio balance predictions requires data on the portfolio structure of banks across currencies. Such data are available in the Swiss National Bank's Swiss Franc Lending Monitor database of country-level bank balance sheets. The SFLM contains aggregate bank balance sheet data collected from 20 participating European central banks. ${ }^{15}$ We consider 16 of these countries which have sufficiently complete data. ${ }^{16}$ Most of the data are publicly available through national data sources. The advantage of the SFLM is that it is all merged in a cross-country consistent way. The SFLM was initiated in 2009, but some participating countries provide data for earlier quarters as well and we use an unbalanced sample that starts in the first quarter of 2007. ${ }^{17}$ This allows us to cover a part of the financial crisis period. We check robustness throughout to excluding data prior to Q2 2009, which turns

\footnotetext{
${ }^{15}$ Austria, Bulgaria, Czech Republic, Croatia, Denmark, Estonia, France, Germany, Greece, Hungary, Iceland, Italy, Latvia, Luxembourg, Poland, Romania, Serbia, Slovenia, Slovakia, and the United Kingdom.

${ }^{16}$ We exclude Iceland and France due to insufficient data coverage. Luxembourg is excluded as an outlier, and Poland is excluded due to incomplete data on the asset side of the balance sheet. We include data for Estonia from 2011 when it joined the euro. Estonia is hence considered a euro area country. In contrast, we include data for Latvia only until 2014, when it joined the euro, and we hence consider Latvia a non-euro area country in this sample.

${ }^{17}$ The individual country charts in the appendix reflect the period covered for each country.
} 
out to be important. The SFLM provides quarterly data on various components of resident banks' balance sheet positions, aggregated at the country level. ${ }^{18}$ All positions are broken down by currency of issuance, namely across positions in local currency, positions in Swiss francs, and positions in foreign currencies other than the Swiss franc. The latter category is not broken further down into individual currencies. Assets are split between lending and other assets, while liability positions are split between deposits (including repo and interbank borrowing), own securities issuance and other liabilities. Lending and deposits are further divided across counterparties, separating positions into claims on and liabilities to resident banks and non-banks, and non-resident banks and non-banks. ${ }^{19}$ The dataset is comparable in structure to the BIS locational banking statistics, but with a different coverage across time and countries. Specifically, the division of bank balance sheets by currencies in the SFLM covers a broader set of European countries, and in particular includes a comprehensive set of eastern European countries not reporting to the BIS locational statistics. A disadvantage of the SFLM compared to the BIS locational statistics is that it does not include data on flows. These have to be computed by adjusting positions for valuation changes from exchange rates, as discussed below.

\subsection{Foreign Currency Wholesale Funding}

The variable of interest is the change in net wholesale funding in foreign currency (evaluated at constant exchange rates) relative to total bank assets net of domestic interbank positions. ${ }^{20,21}$ We measure foreign currency wholesale funding as the difference between foreign currency liabilities to non-resident bank counterparties, minus foreign currency denominated claims on non-resident bank counterparties. The SFLM reveals substantial variation in the degree to which banking systems rely on foreign currency funding. Figure 2(a) shows the net wholesale funding position in foreign currency at the beginning and the end of the sample period. A

\footnotetext{
${ }^{18}$ The data thus includes subsidiaries of foreign banks, but not foreign bank branches. Subsidiaries of foreign banks, especially European ones, account for a very large share of the market, particularly in some Eastern European countries.

${ }^{19}$ Resident non-bank counterparties are further divided by households, non-bank corporations and government. The data does not divide positions with foreign bank counterparties by foreign parent bank and unrelated foreign bank.

${ }^{20}$ To focus on changes in positions between the domestic banking sector and the rest of the economy, we exclude domestic interbank positions from total bank assets throughout.

${ }^{21}$ Including non-bank foreign claims and liabilities does not affect the results, as these positions are relatively small.
} 
positive value indicates that the country has net wholesale liabilities in foreign currency (in line with the model definition of $W$ as a net liability). Most banking systems in the sample countries were net debtors in wholesale funding in foreign currency at the beginning of the sample (black bars). Moreover, most countries with a large initial share of net foreign currency funding had substantially reduced it by the end of the sample period (grey bars), which may reflect efforts to reduce leverage and/or risk exposures in the aftermath of the global financial crisis. Bulgaria went from being a wholesale debtor to being a wholesale creditor in foreign currency. ${ }^{22}$

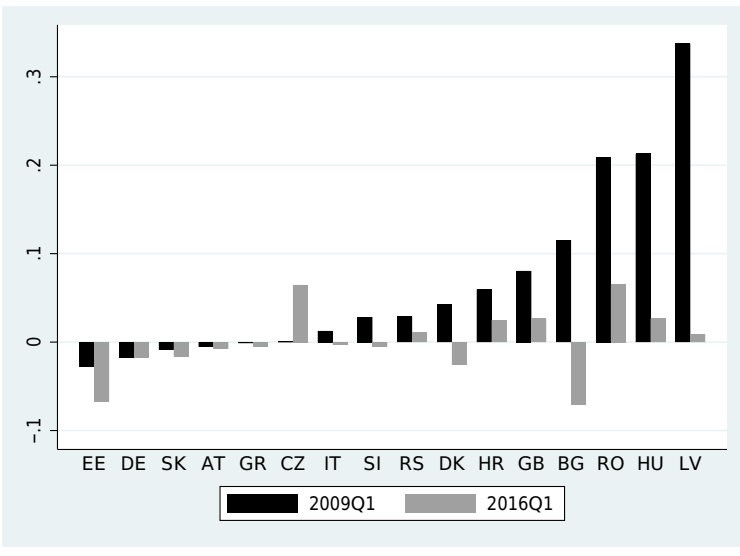

(a) Foreign Currency Wholesale Funding Stocks

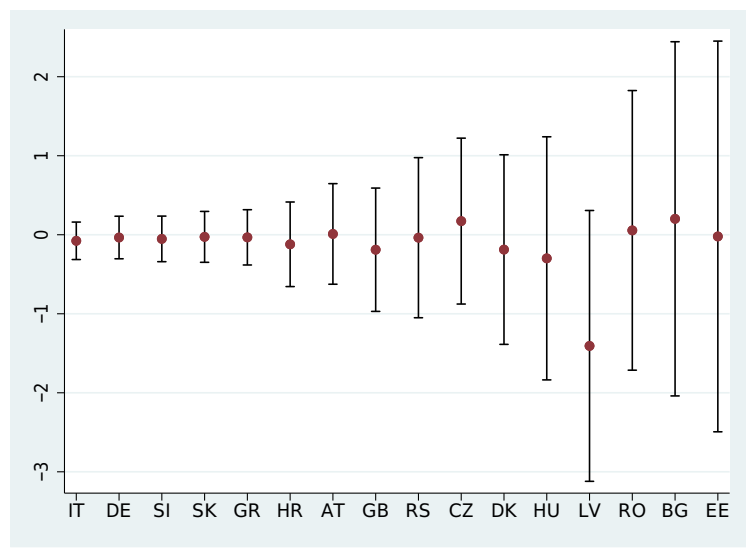

(b) Foreign Currency Wholesale Funding Flows

Figure 2: Foreign Currency Wholesale Funding

Panel (a): Net FX wholesale funding share of liabilities is calculated as FX deposits from foreign banks less FX lending to foreign banks as a share of the sum of net FX wholesale funding and all other funding. The Figure depicts levels in 2009Q1 and 2016Q1 with the following exceptions: Croatia starts in 2010Q1, Estonia starts in 2011Q1, Latvia in 2013Q3, Italy starts in 2009Q2 and ends in 2015Q4, Slovakia ends in 2015Q4. Panel (b): The dot depicts the country specific sample mean net FX wholesale funding flow (valuation adjusted quarterly change in stock). The bars depict one country specific standard deviation on each side of the mean. Source: SFLM.

As the SFLM quotes the positions in domestic currency, we adjust changes in positions for the direct valuation impact of exchange rate movements when computing flows associated with foreign currency denominated positions. This is easily done for positions in Swiss francs, which are quoted separately in the SFLM. It is more challenging for other foreign currency positions that are not quoted separately. For the currency breakdown of these positions, we

\footnotetext{
${ }^{22}$ These changes over time can have been obtained through outright foreign currency funding flows, through changes in the size of total funding relative to FX funding (growth), or through valuation changes (depreciating domestic currencies). Possible underlying time trends in flows are allowed for and controlled for in our empirical specification by introducing country fixed effects.
} 
rely on country specific data sources. The steps and the sources used for valuation adjusting changes in positions are described Appendix C.

Appendix D contains time series plots of the resulting net foreign funding flows in foreign currency to bank counterparties as well as cross-border flows in domestic currency for individual sample countries. We observe substantial variation across countries and time in net foreign currency wholesale funding flows, summarized in Figure 2(b). A pattern of particular interest is that foreign currency bank flows have smaller amplitudes in euro area countries than in non-euro countries, relative to the total assets of their banking systems. Indeed, the sorting of countries by the standard deviation of flows in Figure 2(b) cleanly separates the sample into euro countries with low variation in flows to the left, and non-euro countries with high variation in flows to the right. ${ }^{23}$ This pattern partly reflects that cross border flows in euro countries are to a larger extent denominated in local currency, the shared euro. ${ }^{24}$ We therefore carry out all regressions splitting the sample into euro and non-euro area countries, a distinction that turns out to be important.

\subsection{Risk Factors}

To investigate the response of wholesale funding flows to global and local factors, we need measures of risk factors. The literature proposes a host of empirical proxies for global risk factors capturing different aspects of global sentiment. There is no consensus on which measure is most appropriate or accurate. We therefore take an agnostic approach and consider a range of these. We present the main results based on quarterly growth in US broker dealer leverage as a global risk factor, following Adrian et al. [2014]. Higher leverage growth among US broker dealers has been shown to be associated with lower global risk aversion and higher liquidity within global wholesale funding markets (see for instance Bruno and Shin [2013]). This measure is particularly relevant for risk sentiment specific to international banking flows. Our robustness checks show that while the results using growth in US broker dealer leverage are very robust, this is not the case for other types of global risk measures.

In the empirical specification, we multiply broker dealer leverage growth by -1 so that an

\footnotetext{
${ }^{23}$ We cluster standard errors on countries in our regressions for this reason.

${ }^{24}$ Our focus is on flows relative to the size of the balance sheet of the domestic banking sector. Absolute nominal foreign currency flows may well be large for some euro countries given the size of their economies and banking sectors.
} 


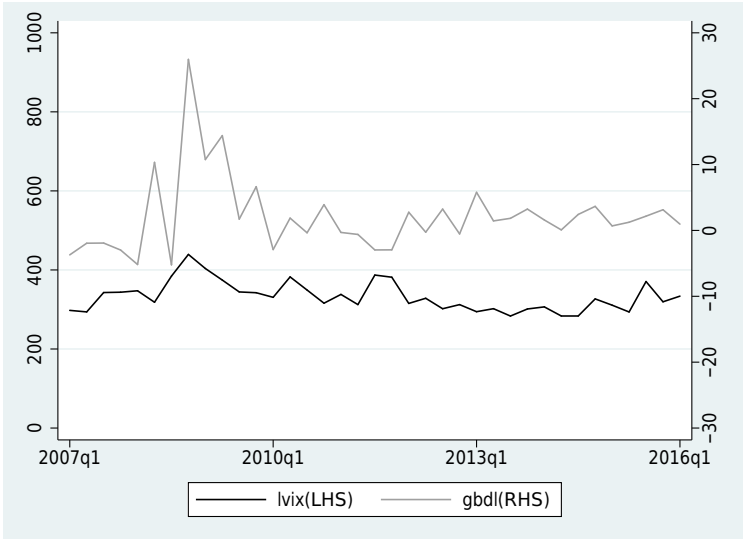

Figure 3: $g b d l$ and the $V I X$

$g b d l$ is the quarterly growth in US broker dealer leverage multiplied by minus one. lvix is the $\log$ of the highest realized value of daily realizations of the VIX over the quarter. See Appendix B for sources.

increase denotes a higher level of risk aversion or more restrictive global financial conditions, comparable to how we interpret other global risk measures. We refer to this measure as $g b d l$. Other measures considered include the log of the VIX (Forbes and Warnock [2012], Rey [2015], Goldberg and Krogstrup [2018]), which we refer to as lvix, the relative change in the US real and nominal effective exchange rates following recent work by Avdjiev et al. [2016], and other different measures of US financial and monetary conditions further described in Section 5.3. Figure 4.3 shows that while $g b d l$ and lvix comove over the sample period, this is far from a one-for-one movement in the quarterly frequency. As we do not have similar proxies for the local risk factors for all sample countries, we proxy for the local risk using the realized intra-quarter volatility of the daily exchange rate vis-à-vis the US dollar.

\subsection{Net Foreign Currency Exposure}

As our model predicts that the sensitivity of bank foreign currency funding flows to global risk factors is conditional on banks' net foreign currency exposure, we need a measure of the latter. Section 3 defines the relevant measure as the financial institutions' total currency exposure, including off-balance sheet positions. The SFLM, however, does not report offbalance sheet exposures, and we are not aware of other sources of data that do so consistently across countries and time. We instead rely on the on-balance sheet foreign currency mismatch, which is directly observable in the SFLM. Specifically, we measure $N e t_{i}$ in expression (9) as 
total foreign currency assets minus total foreign currency liabilities, divided by total bank assets. $^{25}$ Net $_{i}$ can conceptually range from -1 (if all liabilities and no assets are in foreign currency) to 1 (if all assets but no liabilities are in foreign currency). A positive value indicates that the banking sector of country $i$ has a long foreign currency exposure on its balance sheet. We rely on the lagged $N e t_{i}$ in the regressions. ${ }^{26}$

Figure 4(a) depicts country specific sample average foreign currency exposures for each country and their standard deviation. Figures 8 to 10 in Appendix D provide more detailed evidence and show the times series of $N e t_{i}$ for each sample country. We see that with the exception of Estonia, Greece and Austria, euro countries have had a relatively small net foreign currency exposure on average over the sample, with very little variation, consistent with bank regulation tending to require very low currency exposures. With the exception of Romania, non-euro countries tend to have more persistently positive net currency exposures (i.e. they tend to be net long), with more variation in the exposure over time.

Our model assumes that banks use the currency mix of their wholesale funding to absorb excessive foreign currency exposures in the other components of their balance sheet that they cannot adjust as rapidly. The net currency exposures in our data set are consistent with this use of wholesale funding. The net on-balance sheet exposure can be decomposed into the exposure within wholesale funding positions and the exposure within the other components of the balance sheet. Figure 4(b) contrasts the currency exposure in wholesale funding with the exposure in the other components. The country-specific average exposure excluding net wholesale funding is shown on the horizontal axis, while the exposure in the wholesale funding position is shown on the vertical axis. If banks first decide on a net currency exposure and then divide this evenly across different instruments, we should observe a positive association between the exposure in wholesale and non-wholesale positions. Conversely, if banks instead use the currency mix of wholesale funding to offset the exposure in other positions, in line with our model, the dots would line up on a negative line (the 45 degrees line if exposures were fully off-set). Figure 4(b) shows a very clear negative association, consistent with banks

\footnotetext{
${ }^{25}$ Total bank assets exclude domestic interbank positions. Austria, Denmark and the Czech Republic do not report other assets and liabilities. For these countries, we instead proxy the foreign currency mismatch by the mismatch reflected in total lending and total deposits only.

${ }^{26}$ We cannot assess the theoretical concept of the long-term underlying structural value of the currency exposure empirically given the short sample. The country specific mean would reflect pressures to manage risk in the aftermath of the global financial crisis and would not be accurate. The lagged time varying net exposure allows us to take advantage of the time variation in addition to the cross country variation in exposures.
} 


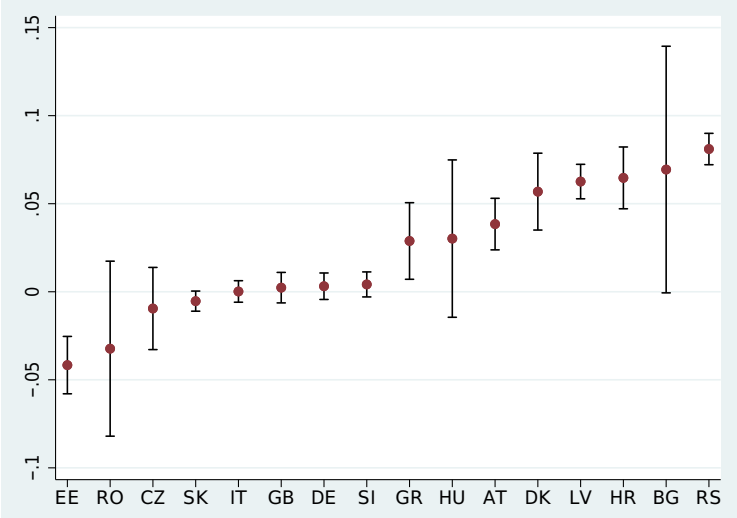

(a) Net Foreign Currency Exposure

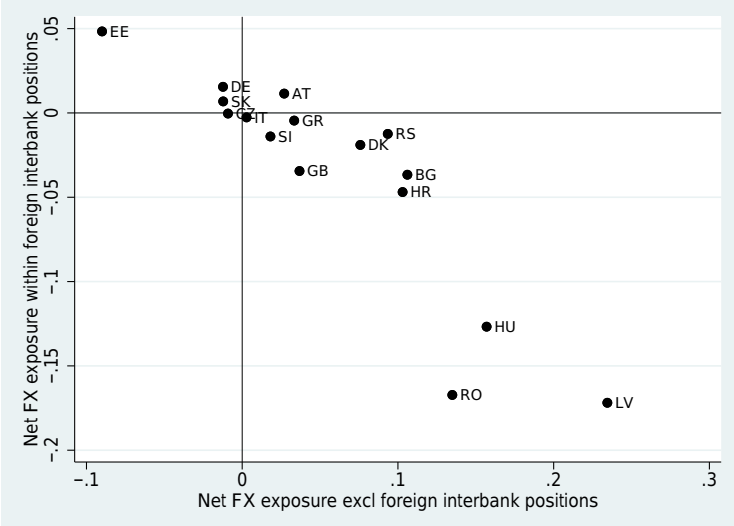

(b) FX Exposure in Wholesale and Other Positions

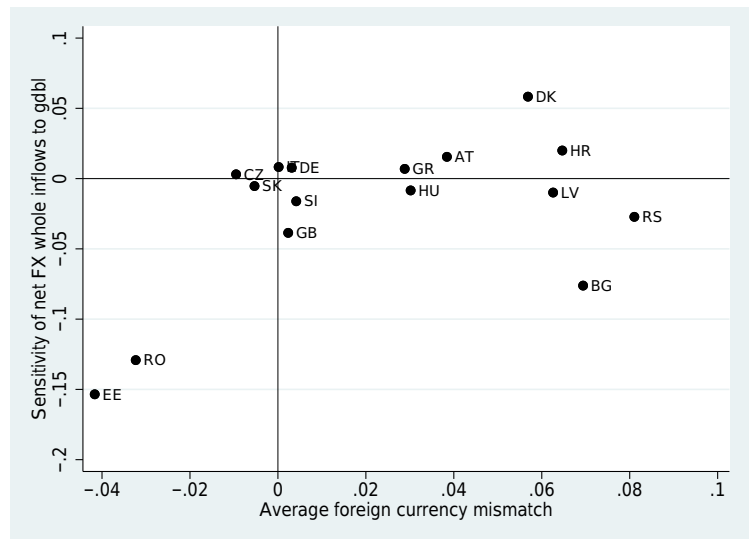

(c) FX Funding Sensitivity to Global Factor and Net Exposure

Figure 4: Net FX Exposure and Global Factors

Panel (a): The dot depicts the country specific mean net FX exposure, bars reflect one standard deviation on each side of the mean. Net FX exposure: FX assets less FX liabilities divided by total bank assets net of domestic interbank positions. Panel (b): Country sample means. Net FX exposure within foreign wholesale positions is computed as FX lending to foreign banks less FX deposits from foreign banks divided by total assets net of domestic interbank. Net FX exposure excl. foreign wholesale positions is computed as FX assets net of FX lending to foreign banks less FX liabilities net of FX deposits from foreign banks, divided by total assets net of domestic interbank assets. Panel (c): The vertical axis reflects the regression coefficient from country-specific simple OLS regressions of foreign currency wholesale funding inflows in percent of total assets on lagged $g d b l$ and a constant, for the sample from 2007Q1 to 2016Q2. The horizontal axis reflects country mean FX exposure. Sources: SFLM, the Federal Reserve and authors' own calculations.

responding to the foreign currency exposure in their non-wholesale portfolio by adjusting positions in the wholesale funding market.

To assess whether there is an association between net currency exposure and the unconditional correlation of bank funding flows and global factors, Figure 4(c) plots the country 
specific regression coefficients from simple country-by-country regressions of net wholesale foreign currency funding inflows in percent of total assets on lagged $g b d l$ and a constant, against the country's average net foreign currency exposure. The variation in both size and sign on the vertical axis reflects substantial heterogeneity in the unconditional correlation of funding flows with global factors. Some countries tend to see inflows associated with a rise in global risk conditions, while other countries tend to see outflows. The figure also suggests a positive association between banking systems that are short foreign currency and a negative association of funding inflows with global risk factors. Two countries in particular drive this association, namely Estonia and Romania, while some other countries exhibit the opposite pattern, such as Bulgaria. The regression analysis in Section 5 confirms this pattern when controlling for other factors and taking into account time variation.

A key question is the extent to which the on-balance sheet foreign currency exposure reflects the banking sector's actual total exposure. If banks use off-balance sheet instruments to fully hedge foreign currency risk, the true exposure would be zero and we should not find any effect of the variables interacted with the on-balance sheet exposure (which would be meaningless). Instead, the regressions produce the expected significant sign for the interaction between on-balance sheet currency mismatch and the global factor, as shown below. This suggests that on-balance sheet exposures do contain relevant information about total exposures, at least for some countries. In addition, the potential imprecision due to the omission of off-balance sheet exposures could lead to attenuation bias of the parameter estimates, suggesting that actual associations could be even stronger.

As an alternative approach to measuring currency exposure, we note that Expressions (4) and (5) describe the relationship between the on-balance sheet exposure and the total exposure as a function of the deviation from covered interest parity, or $N e t_{\text {base }}^{O B S}=N e t_{\text {base }}^{T O T}+\frac{\text { cip base }_{\text {base }}}{\alpha_{\text {base }}}$. Assuming that $\alpha$ is a constant or linearly proportional to cip, we then regress the net onbalance sheet exposure on the deviations from covered interest parity. The residuals from that regression are, in turn, used as an alternative proxy for the total balance sheet exposure:

$$
\hat{N e t} t_{i, t}^{T O T}=\varepsilon_{i, t}
$$

where $\varepsilon_{i, t}$ are the residuals from the panel regression $N e t_{i, t}^{O B S}=\beta c i p_{i, t}+\varepsilon_{i, t}{ }^{27}$ As this ${ }^{27}$ Note that $\varepsilon_{i, t}$ contains a constant term.

\section{CInternational Monetary Fund. Not for Redistribution}


approach relies on data on deviations from covered interest parity which are quite volatile (see below), and because other factors not included in the model that could influence the net total currency exposure of banks, such as bank regulation of risk exposures, we use this measure of total exposure only as a robustness check, and not as our main measure of currency exposure. $^{28}$

\subsubsection{Other explanatory variables}

We control for the other explanatory variables suggested by the empirical specification derived from the model (Equation 9). We briefly discuss these variables here, and leave a more detailed description of definitions and sources (as well as information on additional data used in robustness tests) to Appendix B.

In the main specification, the foreign exchange rate is measured against the US dollar, $d U S D$, with a positive value indicating an appreciation of the dollar during the quarter. The US dollar is the most prominent bank foreign funding currency, but euros could also be important in the sample of countries outside the euro area. Robustness tests discussed below using the euro as foreign funding currency for this set of countries show that USD results are more significant and robust.

We compute the flows of new loans and deposits in foreign currency, $d \bar{C}^{F X}$ and $d \bar{D}^{F X}$ based on the SFLM positions adjusted for the valuation effect of exchange rates. Relative funding costs in domestic and foreign currency are proxied by deviations from uncovered interest parity, $d U I P$, computed as the simple interest differential, and deviations from covered parity, $d C I P$, explained in more detail in Appendix B. ${ }^{29}$

Summary statistics of all the main variables included in the regressions are provided in Table 1.

\footnotetext{
${ }^{28}$ In robustness tests using the level of deviations from uip unadjusted for equity or risk as a proxy for net foreign currency exposure, we get very similar results. Not shown, but results are available upon request.

${ }^{29}$ Currency swap markets are not necessarily liquid for all these countries, giving rise to rather volatile deviations, notably for Latvia (which accounts for the max and min observations of the $d C I P$ recorded in Table 1, Romania and Serbia. In robustness tests not reported here, we have used averages of the last month of the quarter instead of the last week of the quarter in order to average out some of the volatility. The regression results are largely the same, however, and deviations from covered interest parity are rarely significant in any case.
} 
(a) All Sample Countries

\begin{tabular}{lcccccc}
\hline \hline & Mean & Median & Max & Min & Std. Dev & Obs \\
\hline$d \hat{F}^{F X}$ & -0.10 & -0.10 & 7.13 & -5.66 & 1.24 & 482 \\
$d \hat{F}^{l}$ & -0.02 & -0.02 & 8.50 & -7.86 & 1.16 & 510 \\
Net & 0.02 & 0.01 & 0.16 & -0.15 & 0.05 & 519 \\
lvol & -1.33 & -1.34 & 1.37 & -3.24 & 0.79 & 576 \\
$d U S D$ & 3.03 & 0.08 & 90.98 & -66.12 & 22.55 & 576 \\
$d \hat{C}^{F X}$ & 0.07 & -0.06 & 9.02 & -15.37 & 1.66 & 496 \\
$d \hat{D}^{F X}$ & 0.11 & -0.02 & 8.92 & -4.80 & 1.41 & 494 \\
$d U I P$ & 0.00 & 0.03 & 7.91 & -8.04 & 1.08 & 583 \\
$d C I P$ & -0.00 & -0.01 & 4.15 & -3.85 & 0.57 & 536 \\
\hline \hline
\end{tabular}

(b) Non-Euro European countries

\begin{tabular}{lcccccc}
\hline \hline & Mean & Median & Max & Min & Std. Dev & Obs \\
\hline$d \hat{F}^{F X}$ & -0.15 & -0.18 & 7.13 & -4.49 & 1.48 & 276 \\
$d \hat{F}^{l}$ & 0.05 & 0.03 & 3.42 & -2.50 & 0.76 & 298 \\
Net & 0.03 & 0.04 & 0.16 & -0.15 & 0.05 & 303 \\
lvol $^{U S D}$ & -1.23 & -1.21 & 1.37 & -3.24 & 0.82 & 324 \\
$d U S D$ & 3.55 & 0.38 & 90.98 & -66.12 & 24.36 & 324 \\
$d \hat{C}^{F X}$ & 0.17 & -0.02 & 9.02 & -15.37 & 2.04 & 290 \\
$d \hat{D}^{F X}$ & 0.24 & 0.08 & 8.92 & -4.80 & 1.77 & 290 \\
$d U I P$ & 0.02 & 0.05 & 7.91 & -8.04 & 1.39 & 324 \\
$d C I P$ & 0.00 & -0.01 & 4.15 & -3.85 & 0.70 & 294 \\
\hline \hline
\end{tabular}

(c) Euro Countries

\begin{tabular}{lcccccc}
\hline \hline & Mean & Median & Max & Min & Std. Dev & Obs \\
\hline$d \hat{F}^{F X}$ & -0.03 & -0.06 & 5.30 & -5.66 & 0.81 & 206 \\
$d \hat{F}^{l}$ & -0.10 & -0.09 & 8.50 & -7.86 & 1.55 & 212 \\
Net & 0.01 & 0.00 & 0.06 & -0.08 & 0.03 & 216 \\
lvol ${ }^{U S D}$ & -1.47 & -1.43 & 0.20 & -3.24 & 0.74 & 252 \\
$d U S D$ & 2.35 & -0.59 & 45.50 & -39.35 & 20.02 & 252 \\
$d \hat{C}^{F X}$ & -0.08 & -0.06 & 4.94 & -5.59 & 0.86 & 206 \\
$d \hat{D}^{F X}$ & -0.08 & -0.05 & 1.91 & -2.26 & 0.55 & 204 \\
$d U I P$ & -0.02 & 0.01 & 1.20 & -2.10 & 0.48 & 259 \\
$d C I P$ & -0.01 & -0.01 & 1.24 & -1.38 & 0.36 & 242 \\
\hline \hline
\end{tabular}

(d) Global Factors

\begin{tabular}{ccccccc}
\hline \hline & & & & & & \\
& Mean & Median & Max & Min & Std. Dev & Obs \\
\hline gbdl & 2.11 & 1.44 & 25.96 & -5.22 & 5.83 & 37 \\
lvix & 332.36 & 326.77 & 439.27 & 283.38 & 37.25 & 37 \\
\hline \hline
\end{tabular}

\section{Table 1: Data and descriptive statistics}

Non-euro countries include Bulgaria, Croatia, Czech Republic, Denmark, Hungary, Latvia (before joining the euro), Romania, Serbia and the UK. Euro area countries include Austria, Estonia (post euro), Germany, Greece, Slovakia and Slovenia. lvol_USD, $d U S D, d C I P$ and $d U I P$ are the same for all euro area countries and the number of independent observations of each would be 39 in the euro area sample. All variables are expressed in percentage or percentage points, except for $N e t$, which is expressed as a ratio of total bank assets. The sample is unbalanced and runs from Q1 2007 to Q1 2016. The appendix presents data sources, definitions and computations in more detail. 


\section{$5 \quad$ Results}

\section{$5.1 \quad$ Full sample}

We first run the regression on the whole sample of European countries, with the results of different specifications shown in the columns of Table 2. All specifications rely on growth in US broker dealer leverage as the global factor. We consider alternative measures of the global factor in Section 5.3.

Column I shows that the global factor is not significant when it enters on its own and without other risk factors. It becomes significant when interacted with net foreign currency exposure (Column II). A higher value of the risk factor, as measured by an increase in $g b d l$, raises foreign currency funding for banks that have a long exposure to foreign currency, and reduces it for banks with a short exposure, in line with the theoretical predictions.

Turning to the other explanatory variables predicted to matter by the model, their role is less robust. The volatility of the bilateral USD exchange rate, as a measure of local risk factors, is neither significant alone nor when interacted with net foreign currency exposure. Global risk factors seem to be more important in driving perceived foreign currency risk than local factors, for the banking sectors in our sample.

Realized exchange rate movements are only significant, and with the right sign, when interacted with net exposure (offset of the valuation effect) and through the risk taking channel (interacted with the square of net exposure). Column VIII shows that this exchange rate effect is driven mainly by Estonia and Romania, however. We also find that wholesale funding reacts to the flows of loans granted in foreign currency, with the positive coefficient indicating a partial offsetting of new exchange rate exposure. This effect is driven mainly by the variation in the financial crisis period, and is not significant in the post-crisis sample (column VI). No such offset is seen in response to movements in deposits. We find no evidence

that funding reacts consistently across countries to deviations from interest parity, with the coefficients on changes in uip and cip deviations both insignificant.

The salient result from Table 2 is the significance of $g b d l$ interacted with exchange rate exposure. Consider a one standard deviation increase in $g b d l$ (an increase of about 6). Using the estimates of column $\mathrm{V}$, this will lead to a predicted increase in foreign currency wholesale funding, and hence a funding inflow, of $0.5 \%$ of total bank assets in a country with an initial 


\begin{tabular}{|c|c|c|c|c|c|c|c|c|c|c|}
\hline & $\overline{\mathrm{I}}$ & II & III & IV & $\mathrm{V}$ & VI & VII & VIII & IX & $\mathrm{X}$ \\
\hline$g b d l_{-1}$ & -0.009 & -0.021 & -0.018 & -0.017 & -0.032 & -0.012 & -0.004 & & -0.002 & -0.026 \\
\hline Net $_{-1} \cdot g b d l_{-1}$ & & $1.113^{* * *}$ & $0.960 * *$ & $1.145^{* * *}$ & $1.569^{* *}$ & $1.015^{* * *}$ & $0.827^{*}$ & $1.263^{* * *}$ & 0.459 & $1.833^{* *}$ \\
\hline $\operatorname{lvol}_{-1}^{U S D}$ & & & -0.096 & -0.097 & 0.015 & -0.119 & -0.116 & 0.195 & -0.087 & 0.028 \\
\hline Net $_{-1} \cdot \operatorname{lvol}_{-1}^{U S D}$ & & & 0.464 & 1.184 & -1.283 & 2.578 & 1.763 & 0.511 & -0.236 & -1.902 \\
\hline$d U S D_{-1}$ & & & -0.000 & -0.000 & -0.001 & -0.001 & -0.002 & -0.009 & -0.000 & -0.002 \\
\hline Net $_{-1} \cdot d U S D_{-1}$ & & & $0.332^{* * *}$ & $0.345^{* * *}$ & $0.207^{* *}$ & $0.323^{* * *}$ & 0.296 & $0.281^{* * *}$ & $0.224^{*}$ & $0.204^{* * *}$ \\
\hline$N e t_{-1}^{2} \cdot d U S D_{-1}$ & & & $-2.922^{* * *}$ & $-3.229 * * *$ & -1.443 & $-3.009 * * *$ & -2.487 & $-2.815^{* * *}$ & -1.479 & -1.011 \\
\hline Net-1 & -3.796 & -5.065 & -3.541 & -2.377 & 0.185 & -3.640 & -6.603 & -2.488 & -3.693 & -0.714 \\
\hline$N e t_{-1}^{2}$ & 0.352 & -3.215 & -2.510 & -10.297 & -23.050 & 21.836 & 40.694 & -9.124 & 4.146 & -24.770 \\
\hline$\tilde{C}_{-1}^{F X}$ & $0.208^{* * *}$ & $0.200 * * *$ & $0.181^{* *}$ & $0.164^{* *}$ & 0.070 & $0.120^{* *}$ & $0.114^{* *}$ & $0.141^{*}$ & $0.187^{* * * *}$ & 0.065 \\
\hline$\tilde{D}_{-1}^{F X}$ & -0.030 & -0.020 & 0.017 & 0.011 & -0.100 & 0.045 & 0.038 & -0.002 & 0.003 & -0.083 \\
\hline$d U I P_{-1}$ & -0.083 & -0.029 & $-0.046^{*}$ & -0.032 & -0.024 & -0.027 & -0.021 & 0.010 & $-0.079 *$ & -0.004 \\
\hline$d C I P_{-1}$ & 0.035 & -0.006 & -0.002 & -0.018 & -0.098 & -0.014 & -0.106 & -0.061 & -0.008 & -0.079 \\
\hline Constant & -0.014 & -0.003 & -0.171 & -0.166 & -0.193 & -0.197 & -0.174 & 1.964 & -0.202 & -0.193 \\
\hline$R^{2}$ & 0.111 & 0.129 & 0.164 & 0.161 & 0.044 & 0.181 & 0.139 & 0.221 & 0.133 & 0.047 \\
\hline$R^{2}$ adjusted & 0.097 & 0.113 & 0.139 & 0.136 & 0.011 & 0.155 & 0.110 & 0.200 & 0.108 & 0.015 \\
\hline Nobs & 452 & 452 & 452 & 452 & 391 & 434 & 405 & 452 & 452 & 391 \\
\hline No.cross sections & 16 & 16 & 16 & 16 & 16 & 15 & 14 & 16 & 16 & 16 \\
\hline Sample period & Full & Full & Full & Full & $\mathrm{PC}$ & Full & Full & Full & Full & $\mathrm{PC}$ \\
\hline Fixed effects & Yes & Yes & No & Yes & Yes & Yes & Yes & Yes & Yes & Yes \\
\hline Time effects & No & No & No & No & No & No & No & Yes & No & No \\
\hline
\end{tabular}

Table 2: Main regression for the full set of countries

The Table shows results from regressions of valuation adjusted bank wholesale funding flows in percent of total assets. The country included in the panel are listed under Table 1. The full sample runs from Q1 2007 to Q1 2016 and the post financial crisis sample (PC) starts in 2009Q2. Results in Specifications VI and VII exclude Estonia, and Estonia and Romania, respectively. Specifications X and XI are based on the alternative net exposure measure given by expression (10). Asterisks $*, * *$ and $* * *$ indicate significance at the 10,5 percent and 1 percent levels using white cross section standard errors and covariances. 
net long foreign currency exposure of $10 \%$ of assets, ${ }^{30}$ but a predicted contraction of foreign currency wholesale funding of $0.7 \%$ of total assets if the country initially has a net short exposure of $10 \%{ }^{31}$

The significance of the interaction with net exposure is very robust to changes in the specification; notably to whether fixed and time effect are included (columns IV and IX); to using the alternative net exposure measure given by Equation (10) (columns X and XI points to significance in the post-crisis sample $)^{32}$; to allowing for the parameter estimates of deviations from interest parity conditions to vary across countries (Table 6 in the appendix) ${ }^{33}$; to using the euro exchange rate for computing the exchange rate appreciation and volatility terms and for the interest rate parities for the non-euro countries (Table 9 in the appendix shows that the interaction term remains significant, although less so); and to the inclusion of a number of additional control variables such as inflation, growth and US financial and monetary variables, as shown in Table 7 in the appendix. The effect of $g b d l$ interacted with net currency exposure is stronger when the crisis period is omitted (column $\mathrm{V}$ and $\mathrm{X}$ in Table 2). Columns VI and VII in Table 2 show that the result is not driven by Estonia and Romania alone, the two countries with the most clearly negative association between foreign currency exposure and the country specific unconditional sensitivity of net foreign currency funding to gbdl in Figure 4(c), although the parameter estimate becomes smaller without these countries in the sample. The specific sample of countries matters, however, and we consider this next.

\subsection{Euro area vs. other European countries}

As pointed out above, euro area countries and non-euro countries differ strongly in the currency denomination of cross border bank funding flows and net currency exposures. We therefore run our regressions separately for these two sub-samples. The results are displayed in Table 3, where we again focus on the growth in broker dealer leverage as a proxy for the global factor, and include country fixed effects in all specifications.

The global factor is not significant for either group when entered alone (columns I and

$30-0.017 \cdot 6+1.145 \cdot 0.1 \cdot 6=0.46 \%$

${ }^{31}-0.013 \cdot 6+1.145 \cdot(-0.1) \cdot 6=-0.68 \%$

${ }^{32}$ The results are also robust to using the lagged value of the level of the deviation from uip as an alternative measure of net foreign currency exposure, following expression (5). Not shown but results are available on request.

${ }^{33}$ In robustness tests not shown, we also allow the parameter estimates of the risk taking term for foreign currency appreciation to vary across countries, with no implications for the results. 
VII). It is however significant when interacted with the net foreign currency exposure for noneuro countries (column II), but not for euro countries (column VIII). The significance of the interacted global factor is robust to the inclusion of additional controls for countries outside the euro area (columns III and IV) and to using the euro as the foreign currency (Table 10 in the appendix). It is also robust to the countries included in the sample. Excluding Romania (column VI) reduces significance somewhat but the results remain, and jointly excluding Denmark and the UK, or sequentially excluding any other country, does not change the sign and significance of the interaction term (not shown).

The pattern is quite different in the sample of euro area countries. Estonia is an outlier that strongly affects the regression results and fit, and we therefore exclude it from the main euro sample in columns VII to X, whereas columns XI and XII illustrate the results including Estonia. The interaction term of the global factor with net currency exposure is never significant in the euro area sample. This is quite robust: only in the post-crisis sample and excluding Estonia (column X) is it marginally significant, but with the wrong sign.

As already noted, on-balance sheet net foreign currency funding is a marginal activity at the country aggregate level for euro-area countries, both in terms of level and first-differences. The cross-border on-balance sheet net flows of these countries are predominantly denominated in domestic currency, and these domestic currency flows are not included in the main specification. For completeness, we also run the regressions using net wholesale funding flows denominated in domestic currency, shown in the appendix, Table 8. The change in currency denomination of cross border flows leads, as expected, to a lower fit of the regression. Moreover, the global factor remains insignificant as a driver of local currency flows in the euro area. $^{34}$

Other drivers of foreign currency funding inflows also behave differently across euro and non-euro countries. There is some evidence of a role for the local risk factor (exchange rate volatility), as well as of the use of wholesale funding as a way to offset the change in exposure due to realized exchange rate movements (positive coefficient on $N e t \cdot d U S D$ ) and additional

\footnotetext{
${ }^{34}$ Interestingly, it is significant and with the right sign when interacted with exchange rate exposure in the non-euro sample. The regressions show other interesting results that are not the focus of this paper. For example, the coefficient on the deviation from uncovered interest parity is significant and negative in the full and euro sub-samples, which is not the case for foreign currency flows. Deviations from covered interest parity are significant and positive in full sample, indicating perhaps some substitution effects between foreign and domestic currency wholesale funding.
} 
(a) Non-Euro Area Countries

\begin{tabular}{|c|c|c|c|c|c|c|}
\hline & I & II & III & IV & $\overline{\mathrm{V}}$ & VI \\
\hline$g b d l_{-1}$ & -0.015 & -0.033 & -0.020 & $-0.077^{* *}$ & -0.043 & $-0.078^{* *}$ \\
\hline $\mathrm{Net}_{-1} \cdot g b d l_{-1}$ & & $1.148^{* * *}$ & $1.078^{* *}$ & $2.127^{* * *}$ & $1.503^{*}$ & $2.279^{* * *}$ \\
\hline$l v o l_{-1}^{U S D}$ & & & $-0.255^{*}$ & -0.020 & -0.156 & -0.010 \\
\hline $\mathrm{Net}_{-1} \cdot \mathrm{lvol}_{-1}^{U S D}$ & & & 3.479 & 0.960 & 2.149 & 1.956 \\
\hline$d U S D_{-1}$ & & & -0.001 & -0.005 & $-0.007^{*}$ & $-0.007^{* *}$ \\
\hline Net $_{-1} \cdot d U S D_{-1}$ & & & $0.302^{* *}$ & $0.223^{* *}$ & $0.368^{* *}$ & $0.181^{* *}$ \\
\hline$N e t_{-1}^{2} \cdot d U S D_{-1}$ & & & $-2.691^{* *}$ & -1.250 & $-2.673^{* *}$ & -0.685 \\
\hline $\mathrm{Net}_{-1}$ & $-7.335^{*}$ & $-8.359^{* *}$ & -3.251 & $-9.003^{*}$ & -6.181 & $-9.085^{*}$ \\
\hline$N e t_{-1}^{2}$ & 29.042 & 23.284 & 24.638 & 63.450 & 67.820 & 69.559 \\
\hline$\tilde{C}_{-1}^{F X}$ & $0.179^{* * *}$ & $0.174^{* * *}$ & $0.133^{* *}$ & 0.062 & 0.035 & 0.063 \\
\hline$\tilde{D}_{-1}^{F X}$ & 0.005 & 0.015 & 0.036 & -0.056 & -0.050 & -0.104 \\
\hline$d U I P_{-1}$ & -0.089 & -0.034 & -0.038 & -0.042 & -0.021 & 0.072 \\
\hline$d C I P_{-1}$ & 0.039 & -0.017 & -0.023 & -0.048 & -0.100 & 0.123 \\
\hline$R^{2}$ & 0.15 & 0.17 & 0.21 & 0.11 & 0.09 & 0.12 \\
\hline$R^{2}$ adjusted & 0.13 & 0.15 & 0.17 & 0.05 & 0.02 & 0.06 \\
\hline Nobs & 253 & 253 & 253 & 215 & 191 & 197 \\
\hline No.cross sections & 9 & 9 & 9 & 9 & 8 & 8 \\
\hline Sample period & Full & Full & Full & $\mathrm{PC}$ & $\mathrm{PC}$ & $\mathrm{PC}$ \\
\hline Fixed effects & Yes & Yes & Yes & Yes & Yes & Yes \\
\hline
\end{tabular}

(b) Euro Area Countries

\begin{tabular}{|c|c|c|c|c|c|c|}
\hline & 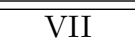 & $\overline{\text { VIII }}$ & IX & $\overline{\mathrm{X}}$ & $\overline{\mathrm{XI}}$ & $\overline{\mathrm{XII}}$ \\
\hline$g b d l_{-1}$ & 0.004 & 0.005 & 0.005 & 0.013 & 0.000 & 0.012 \\
\hline $\mathrm{Net}_{-1} \cdot g b d l_{-1}$ & & -0.319 & -0.264 & $-0.656^{*}$ & -0.265 & -0.624 \\
\hline $\operatorname{lvol}_{-1}^{U S D}$ & & & -0.014 & -0.017 & -0.060 & -0.028 \\
\hline Net $_{-1} \cdot \operatorname{lvol}_{-1}^{U S D}$ & & & 0.858 & 0.320 & 2.574 & 1.335 \\
\hline$d U S D_{-1}$ & & & 0.001 & 0.001 & 0.001 & 0.001 \\
\hline Net $_{-1} \cdot d U S D_{-1}$ & & & 0.488 & 0.436 & 0.073 & 0.038 \\
\hline$N e t_{-1}^{2} \cdot d U S D_{-1}$ & & & -9.522 & -8.887 & -0.090 & -0.471 \\
\hline $\mathrm{Net}_{-1}$ & 4.489 & 5.427 & 6.611 & 6.192 & $37.699^{* * *}$ & $40.894^{* *}$ \\
\hline$N e t_{-1}^{2}$ & -117.662 & -125.061 & -119.153 & -108.566 & $-813.861^{* * *}$ & $-814.873^{* * *}$ \\
\hline$\tilde{C}_{-1}^{F X}$ & -0.071 & -0.071 & -0.078 & $-0.131^{*}$ & -0.107 & -0.151 \\
\hline$\tilde{D}_{-1}^{F X}$ & -0.097 & -0.097 & -0.050 & -0.022 & -0.102 & -0.135 \\
\hline$d U I P_{-1}$ & $-0.145^{*}$ & $-0.146^{*}$ & $-0.180^{*}$ & 0.014 & -0.108 & 0.179 \\
\hline$d C I P_{-1}$ & -0.090 & -0.082 & -0.056 & -0.169 & 0.037 & -0.005 \\
\hline$R^{2}$ & 0.06 & 0.06 & 0.10 & 0.12 & 0.13 & 0.13 \\
\hline$R^{2}$ adjusted & 0.02 & 0.01 & 0.03 & 0.04 & 0.07 & 0.06 \\
\hline Nobs & 181 & 181 & 181 & 158 & 199 & 176 \\
\hline No.cross sections & 6 & 6 & 6 & 6 & 7 & 7 \\
\hline Sample period & Full & Full & Full & $\mathrm{PC}$ & Full & $\mathrm{PC}$ \\
\hline Fixed effects & Yes & Yes & Yes & Yes & Yes & Yes \\
\hline
\end{tabular}

Table 3: Main regression for euro and non-euro samples separately

The tables shows results from regressions of valuation adjusted bank wholesale funding flows in percent of total assets. Country sub-samples are listed under Table 1. The full sample runs from Q1 2007 to Q1 2016 and the post financial crisis sample (PC) starts in 2009Q2. Specification VI and VII exclude Romania and Latvia respectively, specifications VIII-X exclude Estonia. Asterisks $*, * *$ and $* * *$ indicate significance at the 10, 5 percent and 1 percent levels, respectively, using white cross section standard errors and covariances. 
foreign currency loans (positive coefficient on $d \bar{C}^{F X}$ ) in non-euro countries. These effects, however, lose significance once we exclude the crisis period (column IV). Euro area net foreign currency funding inflows respond significantly to exchange rate changes interacted with net currency exposure, and to interest rate differentials as captured by $d U I P$ in line with theory. These findings are sensitive to sample period as well as sample countries included, however. Table 6 in the appendix shows that funding costs matter significantly in many countries when these are allowed to differ across countries.

Why are the results so different for euro and non-euro countries? One difference could be in the use of off-balance sheet hedging practises, and hence the information contents of on-balance sheet net foreign currency exposure as a proxy for total foreign currency exposure. Euro area banks can use the euro dollar forward market, which is likely to be a substantially deeper and more liquid market than many of the bilateral forward markets for non-euro area currencies. The foreign currency funding strains experienced by European banks during the global financial crisis suggest that these banks were indeed exposed to foreign currency risk to a greater degree than what the on-balance sheet measures we have access to suggest. If so, our net foreign currency measure may be more informative about actual exposures in non-euro area countries. ${ }^{35}$

Overall, the regressions indicate that the on-balance sheet foreign currency mismatch affects the response of cross border bank funding flows to global risk factors, especially in non-euro area countries. Omitting the interaction with exposure affects the estimates of the impact of global risk factors in some countries. The result suggests that changing balance sheet features of financial intermediaries could change the sensitivity of these intermediaries' capital flows to global risk factors, at least in some areas of the world.

\subsection{Alternative global factor measures}

As discussion in Section 4, the literature considers a number of alternative measures of global financial factors as drivers of capital flows. Table 7 in the appendix shows that controlling for such measures in the baseline regression does not affect the results for $g b d l$. Table 4 shows the results for the regressions when including alternative global factor measures in place of $g b d l$, for the sample of all countries.

\footnotetext{
${ }^{35}$ In future extensions, this conjecture would be investigated by looking at data for the depth and liquidity of forward markets across currencies.
} 
As alternative global factor measures, we consider the log of the VIX, the quarterly change in the short-term US real interest rate (3-month money market rate less inflation) ${ }^{36}$, and the appreciation rate of the real and nominal effective US dollar. We also considered the quarterly change in the term spread (10-year treasury yield less the 3-month money market rate), the growth rate in the US monetary base and the change in the US shadow federal funds rate estimated in $\mathrm{Wu}$ and Xia [2016] as measures of changes in the US monetary policy stance taking into account the ZLB period with unconventional monetary policy measures, but none of these were significant in any regressions.

Table 4 illustrates the regression results with the alternative global factor measures with significant parameter estimates in some specifications. We find that the log of the VIX, the change in the US real interest rate and the US real and nominal exchange rates all exhibit similar significant effects on foreign currency funding flows when interacted with net exposure, as predicted by theory. However, in contrast to the results for $g b d l$, none of the interaction terms with alternative global factors are robustly significant when the full set of control variables are included. Including the crisis period, or splitting the sample into euro and non-euro countries do not change our findings (not shown).

The less than robust role of the $V I X$ is particularly interesting, as this is the most frequently used measure of global risk factors in the literature. The result could reflect that the $V I X$, being derived from US equity prices, is not a close proxy for global conditions in banking markets. While the VIX has been found to be an important indicator of global risk and risk aversion in the literature, it may not be the most important indicator of the type of global risk factor that matters for foreign currency wholesale bank funding in European banks outside the euro area.

\footnotetext{
${ }^{36}$ We also tried specifying the short-term real interest rate as the shadow federal funds rate of Wu and Xia [2016] less inflation, with no difference in the results, despite the finding that this measure is much more correlated with $g b d l$ in our sample.
} 


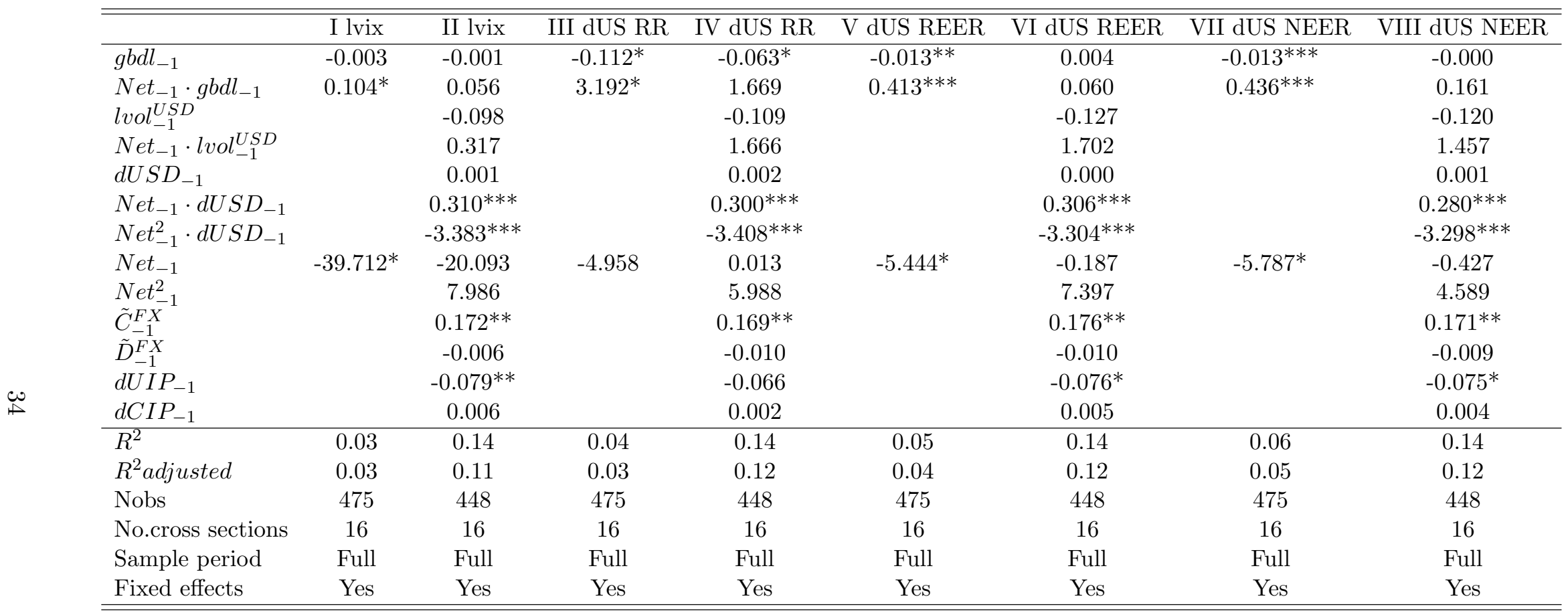

\section{Table 4: Alternative global factors}

The Table shows results from regressions of valuation adjusted bank net wholesale funding flows in percent of total assets for all sample countries. The sample period (Full) runs from Q1 2007 to Q1 2016. Asterisks *, ** and *** indicate significance at the 10, 5 percent and 1 percent levels, respectively, using white cross section standard errors and covariances. lvix is the log of the VIX, $d U S R R$ is the change in the US real interest rate, $d U S R E E R$ and $d U S N E E R$ are the relative change in the real and nominal equilibrium exchange rates respectively, defined in more detail in the appendix (B). 


\section{Conclusion}

This paper offers a new perspective on the sensitivity of financial institutions' foreign currency funding activity to global risk factors. It is often presumed that an increase in global risk aversion or volatility will result in a reduction in banks and other financial institutions' use of foreign currency funding, which is seen as more risky than domestic currency funding. We argue that there is no clear unidirectional link between global risk factors and foreign currency funding, neither conceptually nor empirically. Rather, we make the simple point that the sign

and size of the response of foreign currency funding flows to global risk factors depends on the nature of financial institutions' foreign currency exposure, i.e. whether financial institutions are initially net long or net short in foreign currency.

We first derive this point conceptually from a simple portfolio model of a financial institution's wholesale funding currency choice. We then test it empirically using cross border bank funding flows and bank balance sheet positions in 16 European countries. We find that the sign and size of the effect of global risk factors on wholesale funding flows indeed depend on the pre-existing foreign currency exposure of banks, in line with the theory.

The findings are driven mainly by European countries that are not part of the euro area. In contrast, the relatively small foreign currency funding positions on the balance sheets of euro area banking sectors are not sensitive to the risk factors we consider. This could reflect different off-balance sheet hedging practises, making the on-balance sheet foreign currency exposure measure that we use less accurate in the case of euro area banking sectors. More research is needed to confirm this.

We also show that the most consistently relevant empirical global risk factor for European foreign currency wholesale funding is growth in US broker dealer leverage. Other measures used in the literature, such as the $V I X$, weakly confirm the role of net currency exposures in determining the response of foreign funding, but are less robustly significant as drivers of funding flows in the sample we consider.

We have viewed the response of banks to global risks through the prism of portfolio risk management behavior. Other factors may be at play, such as regulatory rules regarding foreign currency exposures. Moreover, we have focused empirically on bank net funding flows, for which comprehensive balance sheet data exist that are comparable across countries. Similar comprehensive data are not readily available for other types of financial institutions inter- 
mediating an important share of cross border capital flows, such as institutional investors. Other institutions and sectors may respond differently to global factors, and aggregate responses across sectors can elicit macroeconomic responses that in turn may attenuate the initial capital flow pressures. We therefore cannot generalize our results to total cross border capital flows. More research and better data would help further our understanding of the link between domestic financial market structure and regulation on the one hand, and capital flow sensitivity to global risk and hence volatility, on the other.

Our results suggest that different financial institutions may respond differently to changes in global risk conditions, and hence affect aggregate capital flows differently. A better understanding of such portfolio optimization and financial structural drivers of capital flows could help inform the design and targeting of capital flow management measures to reduce capital flow volatility.

\section{References}

Tobias Adrian and Hyun Song Shin. Procyclical leverage and value-at-risk. Review of Financial Studies, 27(2):373-403, 2014.

Tobias Adrian, Erkko Etula, and Tyler Muir. Financial intermediaries and the cross-section of asset returns. forthcoming, The Journal of Finance, 2014.

Stefan Avdjiev and Elod Takats. Monetary policy spillovers and currency networks in crossborder bank lending. BIS Working Papers 549, Bank for International Settlements, March 2016.

Stefan Avdjiev, Zsolt Kuti, and Elod Takats. The euro area crisis and cross-border lending to emerging markets. Bank for International Settlements quarterly review, pages 37-47, 2012.

Stefan Avdjiev, Wenxin Du, Catherine Koch, and Hyun Song Shin. The dollar, bank leverage and the deviation from covered interest parity. Working Papers 592, BIS, 2016.

Stefan Avdjiev, Leonardo Gambacorta, Linda Goldberg, and Stefano Schiaffi. The shifting drivers of international capital flows. Staff Reports 819, Federel Reserve Bank of New York, Jul 2017. 
Claudio Borio, Robert Neil McCauley, Patrick McGuire, and Vladyslav Sushko. Covered interest parity lost: understanding the cross-currency basis. BIS Quarterly Review, September 2016.

Franziska Bremus and Marcel Fratzscher. Drivers of structural change in cross-border banking since the global financial crisis. Journal of International Money and Finance, 52:32 - 59, 2015.

Martin Brown and Helmut Stix. The euroization of bank deposits in Eastern Europe. paper presented at the 59th panel meeting of economic policy, 2014.

Markus K. Brunnermeier, Stefan Nagel, and Lasse H. Pedersen. Carry Trades and Currency Crashes. In NBER Macroeconomics Annual 2008, Volume 23, NBER Chapters, pages 313-347. National Bureau of Economic Research, Inc, April 2009.

Valentina Bruno and Hyun Song Shin. Capital flows and the risk-taking channel of monetary policy. Working Paper 18942, National Bureau of Economic Research, April 2013.

Valentina Bruno and Hyun Song Shin. Cross-border banking and global liquidity. BIS Working Papers 458, Bank for International Settlements, Aug 2014.

Valentina Bruno and Hyun Song Shin. Global dollar credit and carry trades: a firm-level analysis. BIS Working Papers 510, Bank for International Settlements, August 2015.

Matthieu Bussiere, Julia Schmidt, and Natacha Valla. International Financial Flows in the New Normal: Key Patterns (and Why We Should Care). CEPII Policy Brief 2016-10, CEPII research center, March 2016.

Julian Caballero, Ugo Panizza, and Andrew Powell. The second wave of global liquidity: Why are firms acting like financial intermediaries? CEPR Discussion Papers 10926, C.E.P.R. Discussion Papers, November 2015.

Guillermo A. Calvo, Leonardo Leiderman, and Carmen M. Reinhart. Inflows of Capital to Developing Countries in the 1990s. Journal of Economic Perspectives, 10(2):123-139, Spring 1996.

Eugenio Cerutti. Drivers of cross-border banking exposures during the crisis. Journal of Banking \& Finance, 55(C):340-357, 2015. 
Eugenio Cerutti, Stijn Claessens, and Lev Ratnovski. Global liquidity and cross-border bank flows. Economic Policy, 32(89):81-125, 2017a.

Eugenio Cerutti, Stijn Claessens, and Andrew K Rose. How Important is the Global Financial Cycle? Evidence from Capital Flows. CEPR Discussion Papers 12075, C.E.P.R. Discussion Papers, June 2017b.

Eugenio M Cerutti, Stijn Claessens, and Damien Puy. Push Factors and Capital Flows to Emerging Markets; Why Knowing Your Lender Matters More Than Fundamentals. IMF Working Papers 15/127, International Monetary Fund, June 2015.

Nicola Cetorelli and Linda Goldberg. Global banks and international shock transmission: evidence from the crisis. International Monetary Fund Economic Review, 59:41-46, 2011.

Nicola Cetorelli and Linda Goldberg. Follow the money: Quantifying domestic effects of foreign bank shocks in the Great Recession. American Economic Review Papers and Proceedings, 2012.

Dong Boem Choi and Hyun-Soo Choi. The effect of monetary policy on bank wholesale funding. Staff Reports 759, Federal Reserve Bank of New York, January 2016.

Jens H. E. Christensen and Signe Krogstrup. A Portfolio Model of Quantitative Easing. Working Paper Series 2016-12, Federal Reserve Bank of San Francisco, July 2016.

Stijn Claessens and Neeltje van Horen. The impact of the global financial crisis on banking globalization. DNB Working Papers 459, Netherlands Central Bank, Research Department, February 2015.

Giovanni Dell'Ariccia, Luc Laeven, and Robert Maquez. Financial Frictions, Foreign Currency Borrowing, and Systemic Risk. Manuscript, IMF, Dec 2016.

Wenxin Du, Alexander Tepper, and Adrien Verdelhan. Deviations from covered interest rate parity. Working Paper 23170, National Bureau of Economic Research, February 2017.

ECB. The International Role of the Euro. Technical report, The European Central Bank, 2014. 
Ingo Fender and Patrick McGuire. Bank structure, funding risk and the transmission of shocks across countries: concepts and measurement. BIS Quarterly Review, September 2010.

Kristin Forbes and Francis Warnock. Capital flow waves: Surges, stops, flight, and restrenchment. Journal of International Economics, 88:235 - 251, 2012.

Marcel Fratzscher. Capital flows, push versus pull factors and the global financial crisis. Journal of International Economics, 88(2):341-356, 2012.

Atish R. Ghosh, Mahvash S. Qureshi, Jun Il Kim, and Juan Zalduendo. Surges. Journal of International Economics, 92(2):266-285, 2014.

Linda Goldberg and Signe Krogstrup. International Capital Flow Pressures. IMF Working Papers 18/30, International Monetary Fund, Feb 2018.

Harald Hau and Helene Rey. Global portfolio rebalancing under the microscope. Technical report, National Bureau of Economic Research, 2008.

IMF. How Do Changes in the Investor Base and Financial Deepening Affect Emerging Market Economies? Chapter 2, Global Financial Stability Report, International Monetary Fund, Apr 2014.

David S. Scharfstein Ivashina, Victoria and Jeremy C. Stein. Dollar Funding and the Lending Behavior of Global Banks. Quarterly Journal of Economics, 130(3):1241-1281, Aug 2015.

Signe Krogstrup and Cédric Tille. On the Roles of Different Foreign Currencies in European Bank Lending, chapter in "International Currency Exposure". CESifo Seminar Series. MIT Press, 1 edition, July 2017.

Robert McCauley, Patrick McGuire, and Vladyslav Sushko. Global dollar credit: links to US monetary policy and leverage. Working Paper 483, Bank for International Settlements, January 2015.

Peter McQuade and Martin Schmitz. The great moderation in international capital flows: a global phenomenon? Working Paper Series 1952, European Central Bank, August 2016.

Gian-Maria Milesi-Ferretti and Cédric Tille. The great retrenchment: International capital flows during the global financial crisis. Economic Policy, 66:285-330, 2011. 
Hélène Rey. Dilemma not Trilemma: The global Financial Cycle and Monetary Policy Independence. Working Paper 21162, National Bureau of Economic Research, May 2015.

Elod Takats. Was it credit supply? Cross-border bank lending to emerging market economies during the financial crisis. Bank for International Settlements Quarterly Review, pages 49-56, 2010.

Elod Takats and Judit Temesvary. The Currency Dimension of the Bank Lending Channel in International Monetary Transmission. BIS Working Papers 600, Bank for International Settlements, December 2016.

Cédric Tille and Eric van Wincoop. Solving DSGE portfolio choice models with dispersed private information. Journal of Economic Dynamics and Control, 40(C):1-24, 2014.

Jing Cynthia Wu and Fan Dora Xia. Measuring the Macroeconomic Impact of Monetary Policy at the Zero Lower Bound. Journal of Money, Credit and Banking, 48(2-3):253-291, 032016.

Pinar Yesin. Foreign currency loans and systemic risk in Europe. Federal Reserve Bank of St Louis Review, pages 219-235, 2013. 
Appendices for Online Publication 


\section{A Theoretical model}

\section{A.1 Building blocks}

\section{A.1.1 General approach}

This appendix presents our model and the main technical derivations. We focus on exchange rate risk for brevity, and leave a more general variant of the model to a detailed appendix available on request.

We consider a bank active over two periods, $t$ and $t+1$. Its assets consist of risk-free loans in domestic and foreign currency. Its liabilities are made of risk-free deposits in both currencies, wholesale funding in domestic and foreign currency, and equity. The emphasis is on the portfolio choice of wholesale funding across the two currencies. Portfolio choice is driven by the volatility of shocks and the covariance across various variables, as well as changes in these moments. We follow the approach of Tille and van Wincoop [2014] and split variables across their components of various orders. Orders differ through their linkage to the shocks in the model. Specifically, zero-order components are not proportional to innovations. First-order components are linearly proportional to innovations. Second-order components are linearly proportional to the square product of innovations. Third-order components are linearly proportional to the cubic product of innovations. For a variable $x_{t}$ the component of order $n$ is denoted by $x_{t}(n)$, so that: $x_{t}=x_{t}(0)+x_{t}(1)+x_{t}(2)+x_{t}(3) \ldots$

We first solve a baseline (zero-order) portfolio which reflects exogenous terms in the bank balance sheet, interest rates, expected exchange rate movements, and the moments of stochastic variables. We then solve for the (first-order) deviations of the portfolio from that baseline, which reflect how the various drivers differ from their values in the baseline.

\section{A.1.2 Exchange rates}

The exchange rate in terms of units of local currency per unit of foreign currency is denoted by $S$. The exchange rate in period $t$ is written as $S_{t}=S(0) \exp \left[s_{t}\right]$, where $S(0)$ is the zero-order component that we set to 1 for simplicity. $s_{t}$ includes components of first-, second-, and third-order: $s_{t}=s_{t}(1)+s_{t}(2)+s_{t}(3)$. Similarly, $S_{t+1}=\exp \left[s_{t+1}\right]$ where $s_{t+1}$ is also affected by a shock $\varepsilon_{t+1}^{S}$ of mean zero and variance including second-and third-order terms:

$$
\begin{aligned}
s_{t+1} & =s_{t+1}(1)+s_{t+1}(2)+s_{t+1}(3)-\frac{1}{2} \sigma_{f x}^{2}\left[1+\nu_{t+1}^{\sigma}(1)\right]+\varepsilon_{t+1}^{S} \\
E_{t}\left(\varepsilon_{t+1}^{S}\right) & =0 \\
\operatorname{Var}_{t}\left(\varepsilon_{t+1}^{S}\right) & =\sigma_{f x}^{2}\left[1+\nu_{t+1}^{\sigma}(1)\right]
\end{aligned}
$$

The bank can invest in a forward exchange rate contract. The forward exchange rate, $F_{t+1}=\exp \left[f_{t+1}\right]$, differs from the expected future spot rate by a forward premium $p_{t+1}$ that has second- and third-order components:

$$
\exp \left[f_{t+1}\right]=\exp \left[p_{t+1}(2)+p_{t+1}(3)+s_{t+1}(1)+s_{t+1}(2)+s_{t+1}(3)\right]
$$

\section{A.1.3 Components of the bank's balance sheet}

The bank holds exogenous amounts of loans in both currencies. For simplicity, we consider that the interest rate is not stochastic for loans in either currency and set the gross interest rate to 1 , so the value of loans is constant in the currency of denomination. The value of loans are written as:

$$
C^{d o m}=C^{d o m}(0) \exp \left[c^{d o m}\right] \quad ; \quad C^{f o r}=C^{f o r}(0) \exp \left[c^{f o r}\right]
$$


where dom and for denotes position denominated in domestic and foreign currency respectively. The bank also holds exogenous deposits in both currencies which are written along similar lines:

$$
D^{d o m}=D^{d o m}(0) \exp \left[d^{d o m}\right] \quad ; \quad D^{f o r}=D^{f o r}(0) \exp \left[d^{f o r}\right]
$$

The bank can get wholesale funding in both currencies. Funding in domestic currency carries a risk-free interest cost equal to $\exp \left[r_{t+1}^{W, d o m}\right]$. The value of the wholesale position in domestic currency in the two periods is then:

$$
W_{t}^{d o m}=W^{d o m}(0) \exp \left[w^{d o m}\right] \quad ; \quad W_{t+1}^{d o m}=W^{d o m}(0) \exp \left[w^{d o m}\right] \exp \left[r_{t+1}^{W, d o m}\right]
$$

The value of the foreign currency wholesale position is defined similarly:

$$
W_{t}^{\text {for }}=W^{\text {for }}(0) \exp \left[w^{\text {for }}\right] \quad ; \quad W_{t+1}^{\text {for }}=W^{\text {for }}(0) \exp \left[w^{\text {for }}\right] \exp \left[r_{t+1}^{W, f o r}\right]
$$

The interest rates include second-, and third-order components (for simplicity we abstract from first-order components):

$$
\begin{aligned}
r_{t+1}^{W, \text { dom }} & =r_{t+1}^{W, \text { dom }}(2)+r_{t+1}^{W, d o m}(3) \\
r_{t+1}^{W, \text { for }} & =r_{t+1}^{W, \text { for }}(2)+r_{t+1}^{W, \text { for }}(3)
\end{aligned}
$$

We define the uip deviation as the gap between the expected cost of domestic and foreign currency funding (for $r=1,2,3$ ):

$$
\operatorname{uip}_{t+1}(r)=r_{t+1}^{W, \text { for }}(r)+s_{t+1}(r)-s_{t}(r)-r_{t+1}^{W, d o m}(r)
$$

Similarly, the cip deviation is $\left(p_{t+1}(1)=0\right)$ :

$$
\operatorname{cip}_{t+1}(r)=p_{t+1}(r)+u i p_{t+1}(r)
$$

One unit of the forward foreign exchange contract purchased in period $t$ requires that the bank delivers one unit of foreign currency in period $t+1$ and receives $F_{t+1}$ units of domestic currency in exchange. Holding the contract thus implies a short exposure to the future spot exchange rate. The bank buys $G^{f o r}=G^{f o r}(0) \exp \left[g^{f o r}\right]$ units of the contract. Holding the contract also entails a quadratic friction, so the ex-post payoff of holding $G_{t}^{\text {for }}$ units is:

$$
G^{f o r}\left(F_{t+1}-S_{t+1}\right)-\frac{\alpha_{t+1}}{2} F_{t+1}\left(G^{f o r}\right)^{2}
$$

The terms $\alpha_{t+1}$ allows for deviations from covered interest parity without going to corner solutions.

Using the building blocks above, the equity of the bank in period $t$ is:

$$
\begin{aligned}
K_{t}= & C^{d o m}-D^{d o m}-W_{t}^{d o m}+S_{t}\left(C^{\text {for }}-D^{\text {for }}-W_{t}^{\text {for }}\right) \\
= & C^{d o m}(0) \exp \left[c^{d o m}\right]-D^{d o m}(0) \exp \left[d^{d o m}\right]-W^{d o m}(0) \exp \left[w^{d o m}\right] \\
& +C^{\text {for }}(0) \exp \left[s_{t}+c^{\text {for }}\right]-D^{\text {for }}(0) \exp \left[s_{t}+d^{\text {for }}\right]-W^{\text {for }}(0) \exp \left[s_{t}+w^{\text {for }}\right]
\end{aligned}
$$

The equity in period $t+1$ is: 


$$
\begin{aligned}
& K_{t+1}=C^{d o m}-D^{d o m}-W_{t}^{d o m} R_{t+1}^{W, d o m}+S_{t+1}\left(C^{\text {for }}-D^{f o r}-W_{t}^{f o r} R_{t+1}^{W, f o r}\right) \\
& +G^{\text {for }}\left(F_{t+1}-S_{t+1}\right)-\frac{\alpha_{t+1}}{2}\left(G^{\text {for }}\right)^{2} \\
& =C^{d o m}(0) \exp \left[c^{d o m}\right]-D^{d o m}(0) \exp \left[d^{d o m}\right] \\
& +C^{\text {for }}(0) \exp \left[s_{t+1}+c^{\text {for }}\right]-D^{\text {for }}(0) \exp \left[s_{t+1}+d^{\text {for }}\right] \\
& -W^{d o m}(0) \exp \left[w^{d o m}+r_{t+1}^{W, d o m}\right]-W^{f o r}(0) \exp \left[s_{t+1}+w^{\text {for }}+r_{t+1}^{W, f o r}\right] \\
& +G^{\text {for }}(0) \exp \left[g^{\text {for }}\right]\left(\exp \left[f_{t+1}\right]-\exp \left[s_{t+1}\right]\right) \\
& -\frac{\alpha_{t+1}}{2}\left(G^{\text {for }}(0)\right)^{2} \exp \left[2 g^{\text {for }}+f_{t+1}\right]
\end{aligned}
$$

\section{A.2 Optimal funding portfolio}

\section{A.2.1 Utility and constraint}

We now turn to the optimization in period $t$. The bank maximizes the expected utility of future equity: $E_{t} u\left(K_{t+1}, \gamma_{t}\right)$, where $\gamma_{t}$ is a parameter (e.g. a risk aversion coefficient) known at time $t$. We split that parameter between zero- and higher-order components: $\gamma_{t}=\gamma(0) \exp [\hat{\gamma}]$. The optimization is subject to the constraint of overall wholesale funding at period $t$ :

$$
\bar{W}_{t}=W_{t}^{d o m}+S_{t} W_{t}^{\text {for }}=W^{\text {dom }}(0) \exp \left[w^{\text {dom }}\right]+W^{\text {for }}(0) \exp \left[s_{t}+w^{\text {for }}\right]
$$

The Lagrangian is:

$$
E_{t} u\left(K_{t+1}, \gamma_{t}\right)+\phi_{t}\left[W^{d o m}(0) \exp \left[w^{d o m}\right]+W^{\text {for }}(0) \exp \left[s_{t}+w^{f o r}\right]\right]
$$

The first-order conditions with respect to $W_{t}^{d o m}$, and $W_{t}^{\text {for }}$ are:

$$
\begin{aligned}
\phi_{t} & =E_{t} u_{K}\left(K_{t+1}, \gamma_{t}\right) \exp \left[r_{t+1}^{W, \text { dom }}\right] \\
\phi_{t} \exp \left[s_{t}\right] & =E_{t} u_{K}\left(K_{t+1}, \gamma_{t}\right) \exp \left[s_{t+1}+r_{t+1}^{W, \text { for }}\right]
\end{aligned}
$$

Combining these leads to the first portfolio Euler equation:

$$
\begin{aligned}
0 & =E_{t} u_{K}\left(K_{t+1}, \gamma_{t}\right)\left[\frac{S_{t+1}}{S_{t}} R_{t+1}^{W, \text { for }}-R_{t+1}^{W, d o m}\right] \\
0 & =E_{t} u_{K}\left(K_{t+1}, \gamma_{t}\right)\left[\exp \left[s_{t+1}-s_{t}+r_{t+1}^{W, f o r}\right]-\exp \left[r_{t+1}^{W, d o m}\right]\right]
\end{aligned}
$$

The first-order conditions with respect to the forward contract $G^{\text {for }}$ is:

$$
\begin{aligned}
0 & =E_{t} u_{K}\left(K_{t+1}, \gamma_{t}\right)\left[F_{t+1}-S_{t+1}-\alpha_{t+1} F_{t+1} G^{\text {for }}\right] \\
0 & =E_{t} u_{K}\left(K_{t+1}, \gamma_{t}\right)\left[\begin{array}{c}
\left(\exp \left[f_{t+1}\right]-\exp \left[s_{t+1}\right]\right) \\
-\alpha_{t+1} G^{\text {for }}(0) \exp \left[g^{\text {for }}+f_{t+1}\right]
\end{array}\right]
\end{aligned}
$$

The optimality conditions (13) and (14) are highly non-linear and we need to take approximations around the zero-order allocation. 
A quadratic expansion captures risk and provides us with the zero-order solution for $W_{t}^{f o r}$ and $G^{\text {for }}$. Capturing shifts in risk, which is necessary for the first-order solution for $W_{t}^{\text {for }}$ and $G^{\text {for }}$, requires a cubic approximation of the equations.

\section{A.2.2 Expansion of the Euler conditions}

\section{Zero-and first-order components}

It is useful to first focus on the zero- and first-order components of (13)-(14), which are:

$$
0=u_{K} \alpha_{t+1}(0) G^{f o r}(0)
$$

where $u_{K}=u_{K}\left(K_{t+1}(0), \gamma(0)\right)$. The zero-order components of excess returns is zero, as otherwise there would be no interior solution. The zero-order component of the quadratic cost is also zero, $\alpha_{t+1}(0)=0$.

The first-order component is obtained from the linear approximation of (13)-(14):

$$
\begin{aligned}
0 & =\operatorname{uip}_{t+1}(1) \\
0 & =\alpha_{t+1}(0)\left[g^{f o r}(1)+s_{t+1}(1)\right]+\alpha_{t+1}(1)=\alpha_{t+1}(1)
\end{aligned}
$$

The uip holds to a first-order. The first-order component of the quadratic cost is zero. $\alpha_{t+1}(1)=0$. In other words, the holding cost is of the same order as the forward premium, which has components of order two and above.

We define two measures of the zero-order components of exchange rate exposure in period $t+1$. The first, $N e t^{O B S}$, reflects the on-balance sheet exposure. The second, $N e t^{T O T}$, indicates the overall exposure including the position in the forward contract:

$$
\begin{aligned}
& N e t^{O B S}(0)=C^{f o r}(0)-D^{f o r}(0)-W^{\text {for }}(0) \\
& N e t^{T O T}(0)=N e t^{O B S}(0)-G^{f o r}(0)
\end{aligned}
$$

Notice that the first-order shifts in loans and deposits that are not driven by exchange rate valuation effects have to be mirrored by shifts in wholesale funding:

$$
\begin{aligned}
0= & C^{d o m}(0) c^{d o m}(1)-D^{d o m}(0) d^{d o m}(1)-W^{d o m}(0) w^{d o m}(1) \\
& +C^{f o r}(0) c^{f o r}(1)-D^{f o r}(0) d^{f o r}(1)-W^{f o r}(0) w^{\text {for }}(1)
\end{aligned}
$$

In addition, only valuation effects from the exchange rate affect the initial equity:

$$
K_{t}(0) k_{t}(1)=\left[C^{f o r}(0)-D^{f o r}(0)-W^{f o r}(0)\right] s_{t}(1)=N e t^{O B S}(0) \cdot s_{t}(1)
$$

\section{Expansion of first Euler equation}

The expansion of (13) takes the form:

$$
0=\operatorname{linear}_{A}+\frac{1}{2} \text { quadratic }_{A}+\frac{1}{6} \text { cubic }_{A}
$$


The linear term is the only one with a first-order component, which implies that uip holds to a first order. The second- and third-order components of the linear term are:

$$
\begin{aligned}
\operatorname{linear}_{A}(2) & =u_{K}\left(\text { uipt+1 }_{t+1}(2)-\frac{1}{2} \sigma_{f x}^{2}\right) \\
\operatorname{linear}_{A}(3) & =u_{K}\left(\text { uip }_{t+1}(3)-\frac{1}{2} \sigma_{f x}^{2} \nu_{t+1}^{\sigma}(1)\right)
\end{aligned}
$$

The quadratic term has second- and third-order components:

$$
\begin{aligned}
\text { quadratic }_{A}(2)= & u_{K} \sigma_{f x}^{2}+2 u_{K K} N_{e t}^{T O T}(0) \sigma_{f x}^{2} \\
\text { quadratic }_{A}(3)= & 2 u_{K K}\left(\text { uip }_{t+1}(2)-\frac{1}{2} \sigma_{f x}^{2}\right) N_{e t_{t+1}^{O B S} s_{t}(1)} \\
& +2 u_{K K} N e t^{T O T}(0) \sigma_{f x}^{2} \nu_{t+1}^{\sigma}(1)+2 u_{K \gamma}\left(u i p_{t+1}(2)-\frac{1}{2} \sigma_{f x}^{2}\right) \gamma(0) \hat{\gamma}(1) \\
& +u_{K}\left[2 r_{t+1}^{W, d o m}(1)\left(u i p_{t+1}(2)-\frac{1}{2} \sigma_{f x}^{2}\right)+\sigma_{f x}^{2} \nu_{t+1}^{\sigma}(1)\right]
\end{aligned}
$$

The cubic term only has a third-order component:

$$
\begin{aligned}
\operatorname{cubic}_{A}(3)= & 6 u_{K K K} N e t^{O B S}(0) N^{T O T} t^{T O T}(0) s_{t}(1) \sigma_{f x}^{2} \\
& +3\left[u_{K K \gamma}+u_{K \gamma K}\right] N e t^{T O T}(0) \gamma(0) \hat{\gamma}(1) \sigma_{f x}^{2}+3 u_{K K} N e t^{O B S}(0) s_{t}(1) \sigma_{f x}^{2} \\
& +6 u_{K K} r_{t+1}^{W, d o m}(1) N e t^{T O T}(0) \sigma_{f x}^{2} \\
& +6 u_{K K}\left[\begin{array}{c}
C^{f o r}(0) c^{f o r}(1)-D^{f o r}(0) d^{f o r}(1) \\
-W^{f o r}(0)\left(w^{f o r}(1)+r_{t+1}^{W, f o r}(1)\right) \\
+N e t^{T O T}(0) s_{t+1}(1)-G^{f o r}(0) g^{f o r}(1)
\end{array}\right] \sigma_{f x}^{2} \\
& +3 u_{K} r_{t+1}^{W, d o m}(1) \sigma_{f x}^{2}+3 u_{K \gamma} \gamma(0) \hat{\gamma}(1) \sigma_{f x}^{2}
\end{aligned}
$$

\section{Expansion of second Euler equation}

The expansion of (13) takes the form:

$$
0=\operatorname{linear}_{B}+\frac{1}{2} q u a d r a t i c_{B}+\frac{1}{6} \text { cubic }_{B}
$$

The linear term has second- and third-order components:

$$
\begin{aligned}
\operatorname{linear}_{B}(2) & =u_{K}\left[p_{t+1}(2)+\frac{1}{2} \sigma_{f x}^{2}-G^{\text {for }}(0) \alpha_{t+1}(2)\right] \\
\operatorname{linear}_{B}(3) & =u_{K}\left[p_{t+1}(3)+\frac{1}{2} \sigma_{f x}^{2} \nu_{t+1}^{\sigma}(1)-G^{f o r}(0) \alpha_{t+1}(3)\right]
\end{aligned}
$$

The quadratic term has second- and third-order components: 


$$
\begin{aligned}
\text { quadratic }_{B}(2)= & -u_{K} \sigma_{f x}^{2}-2 u_{K K} N e t^{T O T}(0) \sigma_{f x}^{2} \\
\text { quadratic }_{B}(3)= & u_{K}\left(2 s_{t+1}(1)\left(p_{t+1}(2)+\frac{1}{2} \sigma_{f x}^{2}\right)-\sigma_{f x}^{2} \nu_{t+1}^{\sigma}(1)\right) \\
& -2 u_{K} G^{f o r}(0)\left(g^{f o r}+f_{t+1}\right) \alpha_{t+1}(2)-2 u_{K K} N e t^{T O T}(0) \sigma_{f x}^{2} \nu_{t+1}^{\sigma}(1) \\
& +2 u_{K \gamma}\left[p_{t+1}(2)+\frac{1}{2} \sigma_{f x}^{2}-G^{f o r}(0) \alpha_{t+1}(2)\right] \gamma(0) \hat{\gamma}(1) \\
& +2 u_{K K}\left[p_{t+1}(2)+\frac{1}{2} \sigma_{f x}^{2}-G^{f o r}(0) \alpha_{t+1}(2)\right] N e t^{O B S}(0) s_{t}(1)
\end{aligned}
$$

The cubic term only has a third-order component:

$$
\begin{aligned}
\operatorname{cubic}_{B}(3)= & -3 u_{K} s_{t+1}(1) \sigma_{f x}^{2}-6 u_{K K} s_{t+1}(1) N e t^{T O T}(0) \sigma_{f x}^{2} \\
& -6 u_{K K K} N e t^{O B S}(0) N e t^{T O T}(0) s_{t}(1) \sigma_{f x}^{2} \\
& -3\left[u_{K \gamma K}+u_{K K \gamma}\right] N e t^{T O T}(0) \gamma(0) \hat{\gamma}(1) \sigma_{f x}^{2}-3 u_{K K} N e t^{O B S}(0) s_{t}(1) \sigma_{f x}^{2} \\
& -6 u_{K K}\left[\begin{array}{c}
C^{f o r}(0) c^{f o r}(1)-D^{f o r}(0) d^{f o r}(1) \\
-W^{f o r}(0)\left(w^{f o r}(1)+r_{t+1}^{W, f o r}(1)\right) \\
+N e t^{T O T}(0) s_{t+1}(1)-G^{f o r}(0) g^{f o r}(1)
\end{array}\right] \sigma_{f x}^{2} \\
& -3 u_{K \gamma} \gamma(0) \hat{\gamma}(1) \sigma_{f x}^{2}
\end{aligned}
$$

\section{A.2.3 Portfolio solution}

Combining the second-order components of (13) implies:

$$
N e t^{T O T}(0)=K(0) \frac{u_{K}}{-u_{K K} K} \frac{u i p_{t+1}(2)}{\sigma_{f x}^{2}}
$$

The second-order components of (14) give the solution for the forward contract:

$$
G^{f o r}(0)=\frac{\operatorname{cip}_{t+1}(2)}{\alpha_{t+1}(2)}
$$

This corresponds to the baseline solution (5) in the main text, with $G_{\text {base }}^{f o r}=G^{f o r}(0), N_{\text {base }}^{T O T}=N e t^{T O T}(0), K_{\text {base }}^{T O}=K_{(0)}$, uip $_{\text {base }}=$ uip $_{t+1}(2), \gamma_{\text {base }}=\left(-u_{K K} K\right) / u_{K}, \sigma_{f x, b a s e}^{2}=\sigma_{f x}^{2}, \operatorname{cip}_{\text {base }}=\operatorname{cip}_{t+1}(2), \alpha_{\text {base }}=\alpha_{t+1}(2)$.

The third-order components of (13) give the first-order component of the foreign currency wholesale funding and forward contract position:

$$
\begin{aligned}
& W^{f o r}(0) w^{f o r}(1)+G^{f o r}(0) g^{f o r}(1) \\
= & -K(0) \frac{u_{K}}{-K u_{K K}} \frac{u i p_{t+1}(3)}{\sigma_{f x}^{2}} \\
& +N e t^{T O T}(0)\left[\nu_{t+1}^{\sigma}(1)+\left(\frac{-u_{K \gamma}}{u_{K}}+\frac{1}{2} \frac{u_{K K \gamma}+u_{K \gamma K}}{u_{K K}}\right) \gamma(0) \hat{\gamma}(1)\right] \\
& +N e t^{T O T}(0) s_{t+1}(1)+C^{f o r}(0) c^{f o r}(1)-D^{f o r}(0) d^{f o r}(1) \\
& +\left[\frac{-u_{K K}}{u_{K}}+\frac{u_{K K K}}{u_{K K}}\right] N e t^{O B S}(0) N e t^{T O T}(0) s_{t}(1)
\end{aligned}
$$

The third-order components of (14) give the first-order component of the forward contract: 


$$
g^{f o r}(1)=\frac{c i p_{t+1}(3)}{c i p_{t+1}(2)}-\frac{\alpha_{t+1}(3)}{\alpha_{t+1}(2)}
$$

The firs-order shifts in the forward contract reflect third-order shifts in the covered interest parity and in the holding cost.

(18) corresponds to the shifted solution (??) in the text, with $G_{s h i f t}^{\text {for }}=G^{\text {for }}(0) g^{\text {for }}(1), \operatorname{cip}_{\text {shift }}=\operatorname{cip}_{t+1}(3), \alpha_{\text {shift }}=\alpha_{t+1}(3)$. Similarly, (??) corresponds to (7) in the text with $W_{\text {shift }}^{\text {for }}=W^{\text {for }}(0) w^{\text {for }}(1), \sigma_{\text {fx,shift }}^{2}=\nu_{t+1}^{\sigma}(1), \gamma_{\text {shift }}=\gamma(0) \hat{\gamma}(1), s_{t, s h i f t}=$ $s_{t+1}(1), C_{\text {shift }}^{\text {for }}=C^{\text {for }}(0) c^{\text {for }}(1), D_{\text {shift }}^{\text {for }}=D^{\text {for }}(0) d^{\text {for }}(1)$, uip $_{\text {shift }}=u i p_{t+1}(3)$.

A particular case is the CRRA utility function $\left(u=(K)^{1-\gamma}(1-\gamma)^{-1}\right)$, where (??) becomes:

$$
\begin{aligned}
& W^{\text {for }}(0) w^{\text {for }}(1)+G^{\text {for }}(0) g^{\text {for }}(1) \\
= & -K(0) \frac{u i p_{t+1}(3)}{\gamma \sigma_{f x}^{2}}+N e t^{T O T}(0)\left[\nu_{t+1}^{\sigma}(1)+\hat{\gamma}(1)\right] \\
& +N e t^{T O T}(0) s_{t}(1)+C^{f o r}(0) c^{f o r}(1)-D^{f o r}(0) d^{f o r}(1) \\
& -N e t^{O B S}(0) \frac{N e t^{T O T}(0)}{K(0)} s_{t}(1)
\end{aligned}
$$

\section{B Data}

The main data source for bank balance sheet positions is the Swiss Franc Lending Monitor (SFLM), containing end-of-quarter bank balance sheet positions. Other sources include Datastream, Bloomberg, the US Financial Accounts and national statistical agencies and central banks. Details and data formatting of the individual series used are described below:

- $d \bar{W}^{F X}$ : quarterly change in net foreign currency wholesale funding (adjusted for exchange rate valuation) in percent of total bank assets (Appendix C provides more details on the adjustment for exchange rate valuation). Net wholesale funding for the banking sector as a whole is proxied by lending to and deposits from foreign banks. For Austria, Czech Republic and Denmark, data on total assets is not reported. We have instead used total lending for these countries. Source: SFLM.

- $d \bar{W}^{l}$ : quarterly change in net domestic currency wholesale funding in percent of total bank assets. Net wholesale funding for the banking sector as a whole is proxied by lending to and deposits from foreign banks. For Austria, Czech Republic and Denmark, data on total assets is not reported. We have instead used total lending for these countries. Source: SFLM.

- Net: total foreign currency assets less total foreign currency liabilities, as a share of total assets. For Austria, Czech Republic and Denmark, data on total assets and liabilities is not reported. We have instead used total lending and total deposits plus own securities instead of assets and liabilities respectively for these countries. Source: SFLM.

- $d \tilde{C}^{F X}$ : quarterly change in foreign currency assets other than wholesale assets (adjusted for exchange rate valuation) in percent of total bank assets (Appendix C provides more details on the adjustment for exchange rate valuation). For Austria, Czech Republic and Denmark, data on total assets is not reported. We have instead used total lending for these countries. Source: SFLM.

- $d \tilde{D}^{F X}$ : quarterly change in foreign currency liabilities other than wholesale liabilities (adjusted for exchange rate valuation) in percent of total bank assets (Appendix C provides more details on the adjustment for exchange rate valuation). For Austria, Czech Republic and Denmark, data on total assets is not reported. We have instead used total lending for these countries. Source: SFLM.

- lvix: $\log$ of the VIX option-based expected stock price volatility based on the S\&P 500, calculated by the CBOE. Highest daily realized value of quarter (end of quarter has been used alternatively). Source: Datastream. 
- gbdl: quarterly percentage growth in US Broker Dealer Leverage as defined in Adrian et al. [2014], page 9, multiplied by minus one. Quarterly, based on end-of-quarter accounts.

Source: US Financial Accounts (http://www.federalreserve.gov/datadownload/Build.aspx?rel=Z1).

- $l v o l^{U S D}: \log$ of the quarterly average of squared daily percentage changes of the nominal exchange rate of the local currency against the USD (quarterly mean of $\left(100 * d \log \left(S_{t}\right)\right)^{2}$, where $S_{t}$ is the USD exchange rate. Source: Datastream.

- $d U S D$ : percentage nominal appreciation of the US dollar over the quarter. The exchange rate is measured as the average of daily exchange rates of the local currency per foreign currency unit in the last week of the quarter. Exchange rate data (for other foreign currencies) are also used to adjust for valuation effects, as well as directly in the regressions. Bank balance sheet positions are recorded end of quarter, and to match the exchange rate but avoiding most of the volatility of daily data, we use the average daily rate in the last week of the quarter. Due to an abnormal move in the exchange rate for Romania between last quarter of 2014 and first quarter of 2015, we exclude these observations for Romania. Source: Datastream

- dUIP: quarterly changes in deviations from uncovered interest parity. They are computed as changes in the simple USDdomestic interest differential based on 3-month money market interest rates, with the underlying assumption that expected appreciation is zero. 3-month Libor interest rates in all currencies are annualized. We use the average of the daily observations over the last week of the quarter in the regressions. Source: Bloomberg

- dCIP: quarterly changes in deviations from covered interest parity. They are computed daily based on data for 3-month forward premiums and spot rates against the USD, as well as 3-month Libor rates. Interest rates are annualized and the average for the last week of the quarter is used in the regressions. Du et al. [2017] show that there is a spike in the deviations from covered interest parity in the last days of the quarter for a sample of European countries, which they link to regulation related balance sheet constraints. These spikes are mainly found for shorter maturity deviations (overnight and one-week deviations), however. We have verified that such spikes are not observable in our data, which allows us to use the average the last week of the quarter as representative (using the second to last week of quarter does not change results). Source: Bloomberg.

- $d U S R R$ : US short-term real interest rate. 3-month USD money market interest rate, average for the last week of the quarter, less US realized annualized inflation rate as defined below, annualizeda. Source: Bloomberg and National Statistical Authorities or central banks (see specific agencies under growth below).

- $d U S R E E R$ : quarterly percentage change (annualized) in the real effective exchange rate of the USD. Last month of quarter. Source: IFS.

- $d U S N E E R$ : quarterly percentage change (annualized) in the nominal effective exchange rate of the USD. Last month of quarter. Source: IFS.

- Inflation: percentage change in the consumer price index between last month of quarter and same quarter the previous year. Sources: National Statistical Authorities or Central Banks (see specific agencies under growth below).

- Growth: percentage change between quarterly real GDP and the same quarter the previous year. Source: National Statistical Authorities (Austrian Institute of Research, Banque Nationale de Belgique, Danmarks Statistik, Institut National de la Statistique France, Deutsche Bundesbank, Hellenic Statistical Authority (ELSTAT), Istituto Nazionale di Statistica Italy, National Statistical Institute Bulgaria, Croatian Bureau of Statistics, Czech Statistical Office, Statistical Office of Estonia, Central Statistical Office Hungary, Central Statistical Bureau of Latvia, Central Statistical Office Poland, Instit National de Statistica si Studii Economice Romania, Statistical Office of the Republic of Serbia, Statistical Office of the Slovak Republic, Statistical Office of the Republic of Slovenia.) 


\section{Adjusting bank positions for exchange rate valuation effects}

Changes in net funding positions across currencies are adjusted for the valuation effect from exchange rate movements, based on the data available from the Swiss Franc Lending Monitor and other sources. Consider the wholesale funding position of country $c$ in a foreign currency $j$. We denote its value in domestic currency at the end of period $t$ by $L_{t}^{c, j}$. The total change in the value of the position between periods $t-1$ and $t$ consists of the active change in that position, $W_{t}^{c, j}$, and the valuation impact of the exchange rate. We denote the exchange rate in terms of units of local currency per unit of foreign currency as $S_{t}^{c, j}$ (so an increase is an appreciation of the foreign currency). The dynamics of the position are then:

$$
L_{t}^{c, j}=L_{t-1}^{c, j}+W_{t}^{c, j}+L_{t-1}^{c, j} d \ln \left(S_{t}^{c, j}\right)
$$

Which we rewrite as:

$$
\dot{l}_{t}^{c, j}=w_{t}^{c, j}+\dot{s}_{t}^{c, j}
$$

where $i_{t}^{c, j}=d L_{t}^{c, j} / L_{t-1}^{c, j}, w_{t}^{c, j}=W_{t}^{c, j} / L_{t-1}^{c, j}$ and $\dot{s}_{t}^{c, j}=d \ln \left(S_{t}^{c, j}\right)$. There is one such relation for positions in CHF and one for positions in other foreign currencies. The latter is a weighted sum across various currencies, where $\varpi^{c, j}$ is the share of foreign currency $j$ in the other foreign currency positions (i.e. foreign currency positions excluding Swiss franc positions):

$$
\begin{aligned}
i_{t}^{c, C H} & =w_{t}^{c, C H}+\dot{s}_{t}^{c, C H} \\
i_{t}^{c, F X} & =w_{t}^{c, F X}+\sum_{j} \varpi^{c, j} \dot{s}_{t}^{c, j}
\end{aligned}
$$

where $w_{t}^{c, F X}=\sum_{j} \varpi^{c, j} w_{t}^{c, j}$ and $i_{t}^{c, F X}=\sum_{j} \varpi^{c, j} i_{t}^{c, j}$.

The Swiss franc lending monitor provides us with the changes in positions, $i_{t}^{c, C H}$ and $i_{t}^{c, F X}$, but not the individual $i_{t}^{c, j}$. We also observe exchange rates $\dot{s}_{t}^{c, C H}$ and the various $\dot{s}_{t}^{c, j}$. While we can directly back out the active portfolio changes in CHF positions $f_{t}^{c, C H}$, we need to estimate these for positions in other foreign currencies, $w_{t}^{c, F X}$. To do this, we construct empirical estimates of the weights $\varpi^{c, j}$. We rely on three sources. The first is the ECB annual report on the international role of the euro (ECB [2014]). This publication gives the composition of overall deposits and bank loans for selected countries. It suggests that in many cases, one currency (primarily the euro) plays a overwhelming role, and in these cases, we assume that the non-CHF positions in foreign currencies are in that currency.

The second source is the results from regression analyses, where we assume that exchange rate movements immediately affect the local currency value of the positions denominated in foreign currencies, but affect outright flows only with a lag. Regressing $l_{t}^{c, F X}$ on the various $\dot{s}_{t}^{c, j}$ then gives estimates for the coefficients $\varpi^{c, j}$ in (20). We run such a regression for each country, considering the euro, US dollars, British pounds and yen as foreign currencies. The coefficients are re-scaled to add up to one, giving us estimates for $\varpi^{c, j}$. When the regression results provide a good fit for the composition across several currencies, we rely on them. In some cases the regression results are problematic, for instance when the country has a peg against the euro. In these cases, we rely on a third source, namely information on web sites of the European Central Bank and a number of the national central banks of the sample countries. Table 5 lists the approach taken to select weights, as well as the chosen weights, for each of the sample countries. The weights apply to non-Swiss franc foreign currency positions and sum to one. When only one set of weights is provided, it means that we apply the same set of weights to both assets and liabilities positions. For some countries, data availability or regression results allows us to apply weights specific to assets and liabilities respectively, and in these cases, the table clearly distinguishes these.

Finally, we acknowledge that currency weights may have changed across the sample. Data does not allow us such detail. The potential for changing currency compositions across the sample suggests a source of inaccuracy that we cannot account for. 


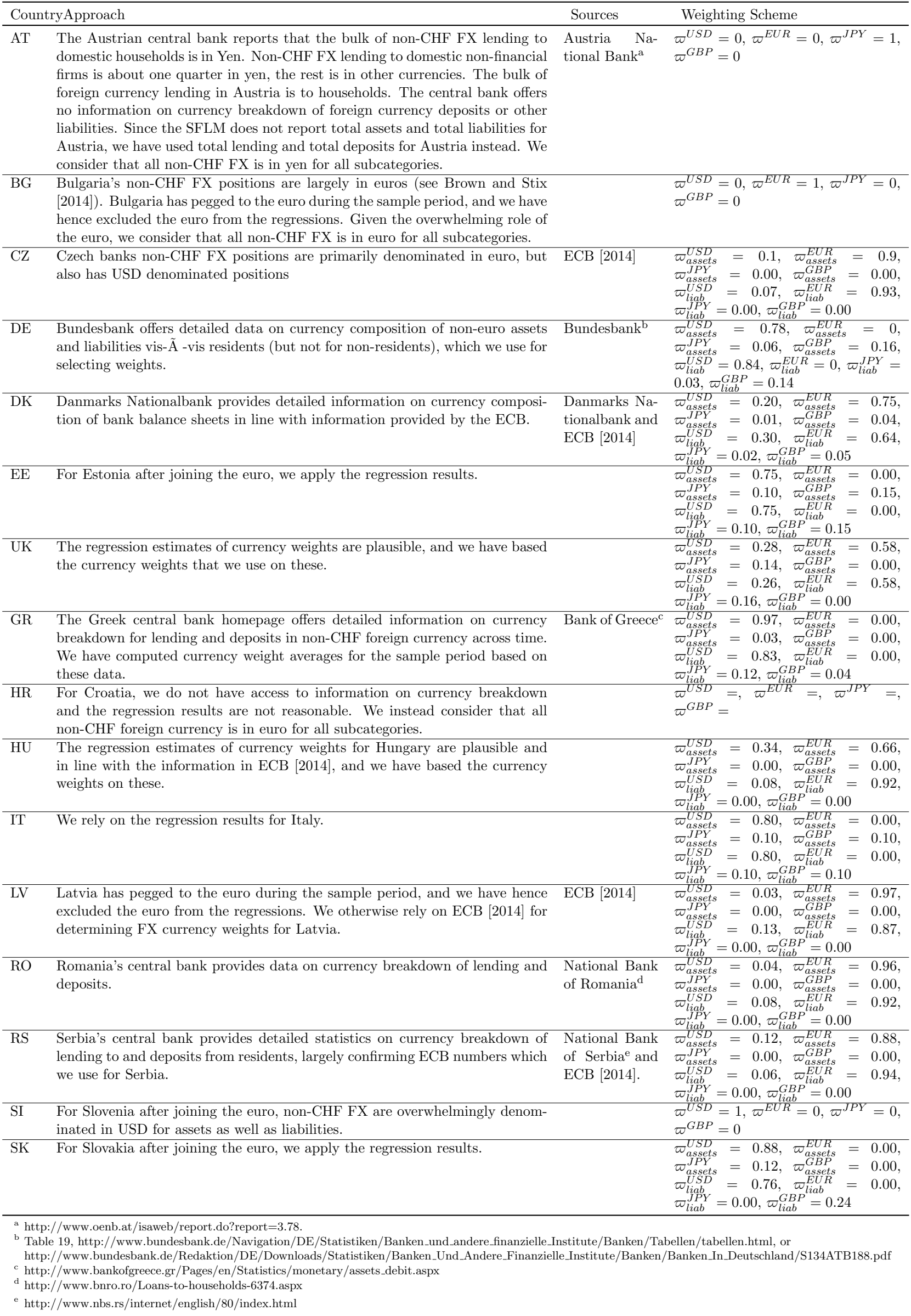

Table 5: Estimates of currency weights in non-Swiss franc FX bank positions

51

\section{(C)International Monetary Fund. Not for Redistribution}




\section{Appendix Figures}

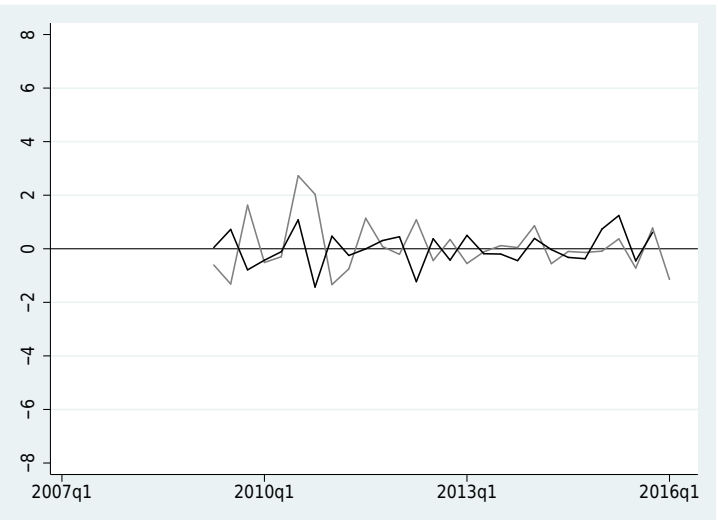

(a) Austria

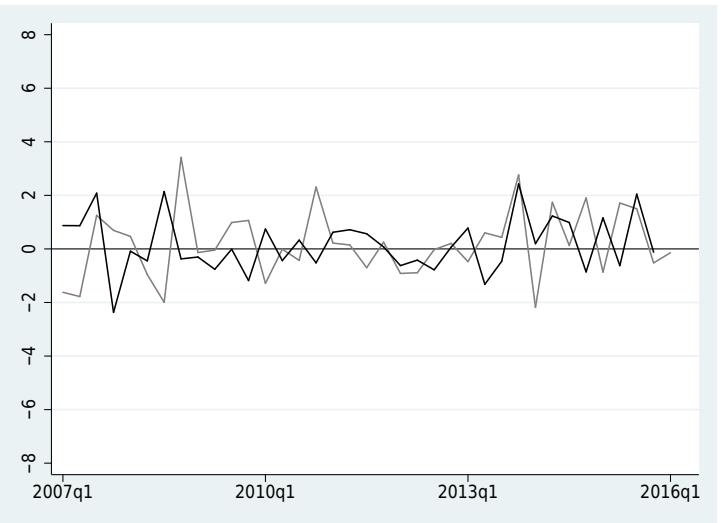

(c) Czech Republic

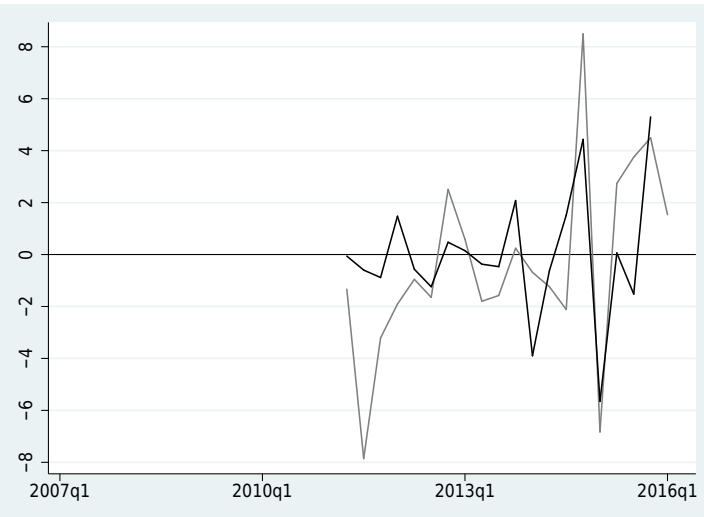

(e) Estonia

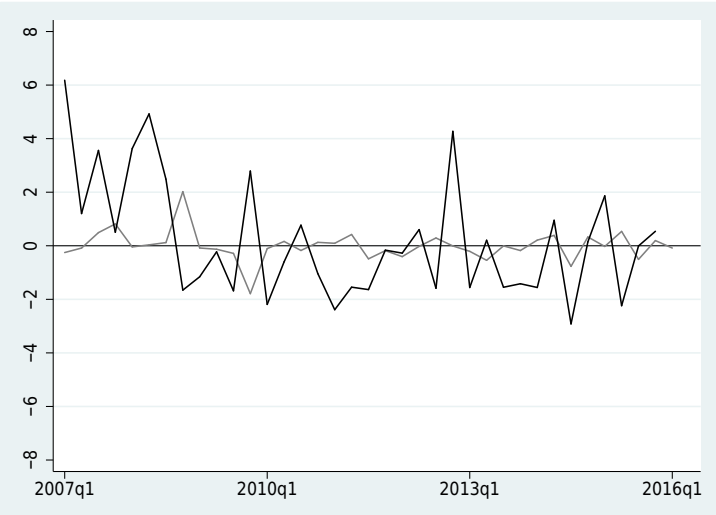

(b) Bulgaria

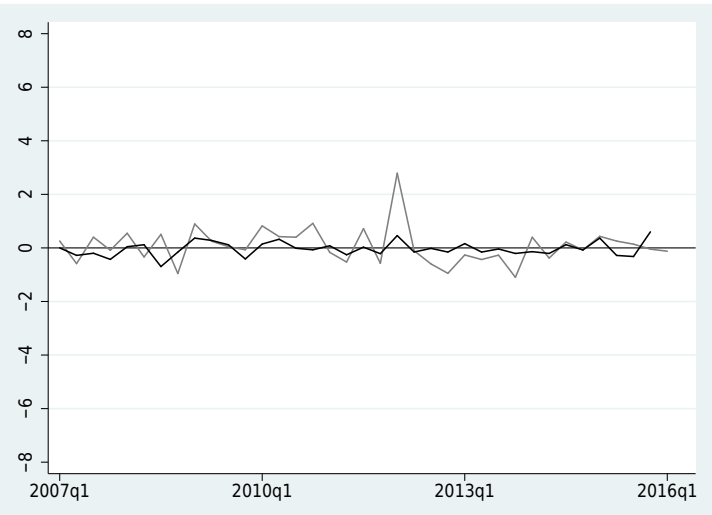

(d) Germany

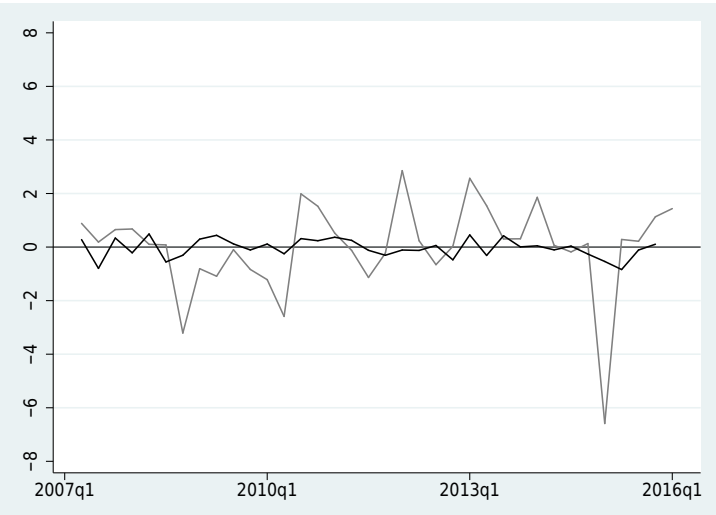

(f) Greece

\section{Figure 5: Net foreign currency and domestic currency wholesale funding inflows}

The black line is quarterly valuation adjusted change in foreign currency interbank funding less foreign currency interbank lending, divided by total bank assets. The gray line is quarterly domestic currency foreign interbank funding less domestic currency foreign interbank lending, divided by total bank assets. Valuation adjusted described in Appendix C. Source: The Swiss Franc Lending Monitor, SNB 


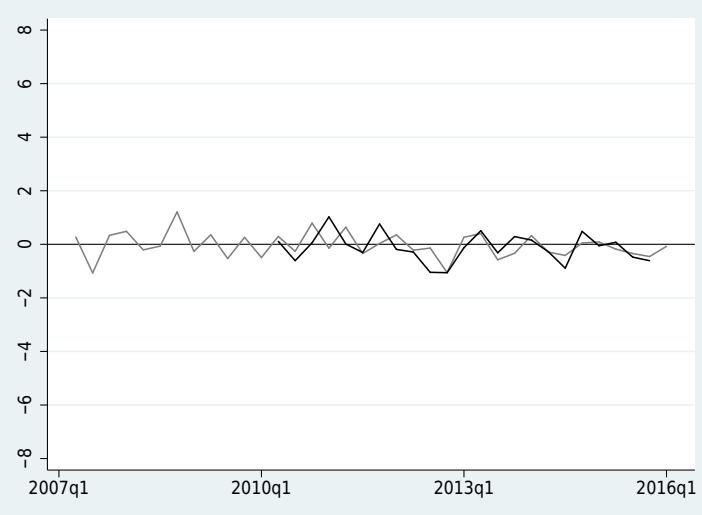

(a) Croatia

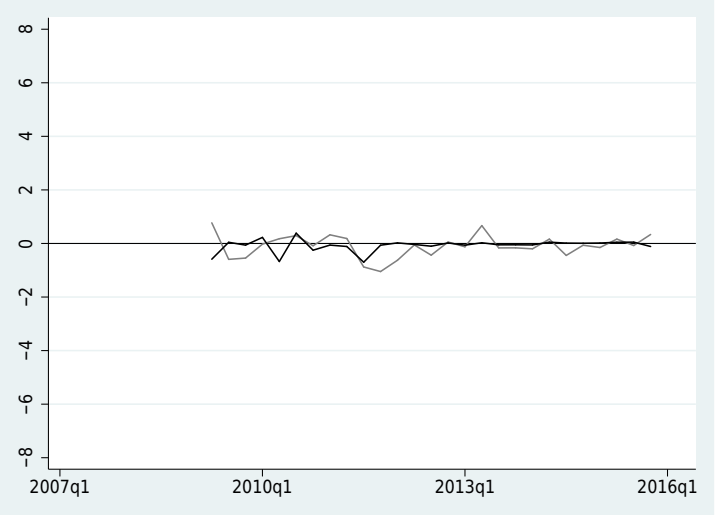

(c) Italy

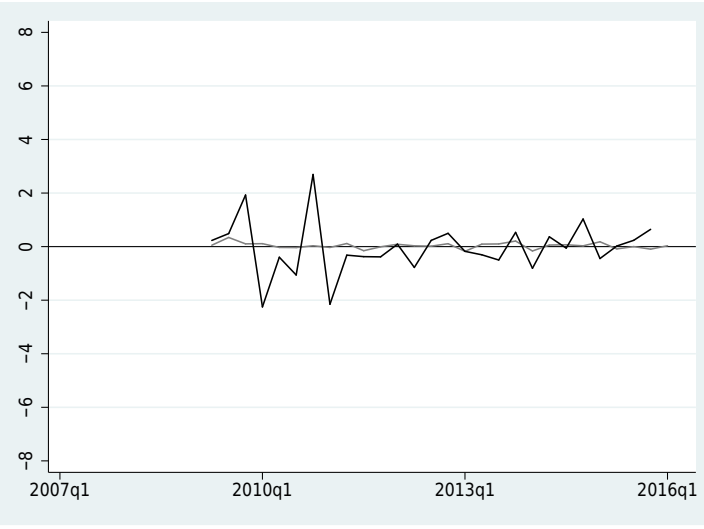

(e) Serbia

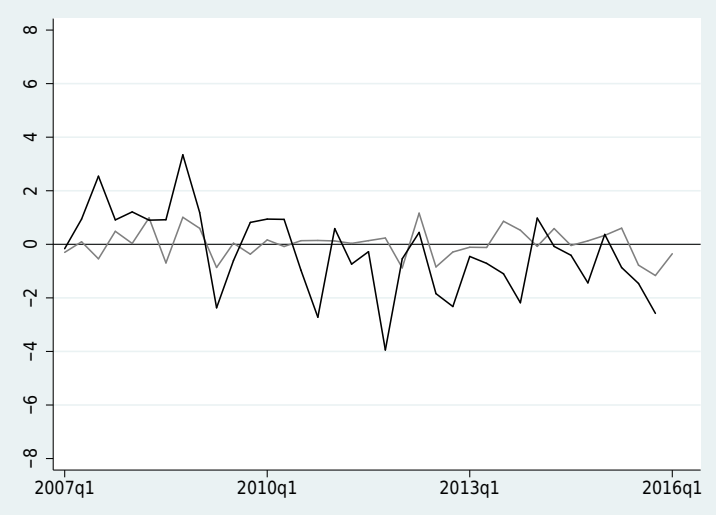

(b) Hungary

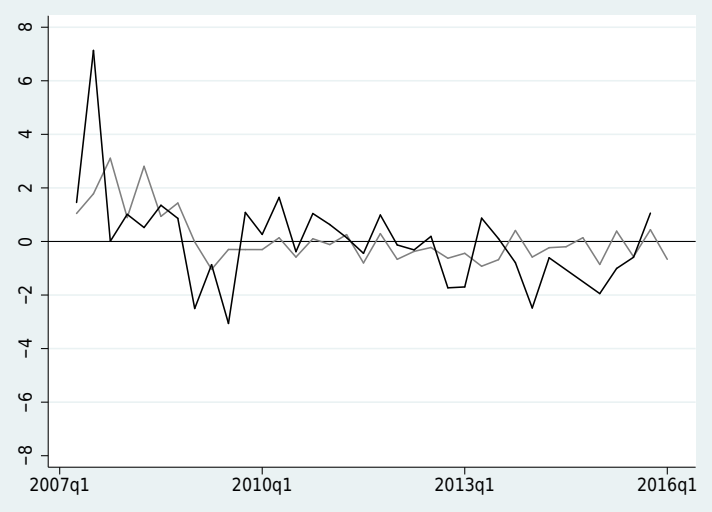

(d) Romania

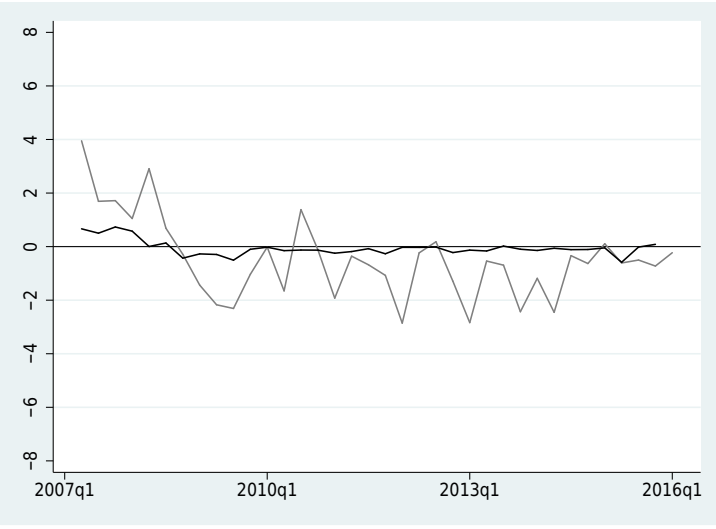

(f) Slovenia

Figure 6: Net foreign currency and domestic currency wholesale funding inflows

The black line is quarterly valuation adjusted change in foreign currency interbank funding less foreign currency interbank lending, divided by total bank assets. The gray line is quarterly domestic currency foreign interbank funding less domestic currency foreign interbank lending, divided by total bank assets. Valuation adjusted described in Appendix C. Source: The Swiss Franc Lending Monitor, SNB 


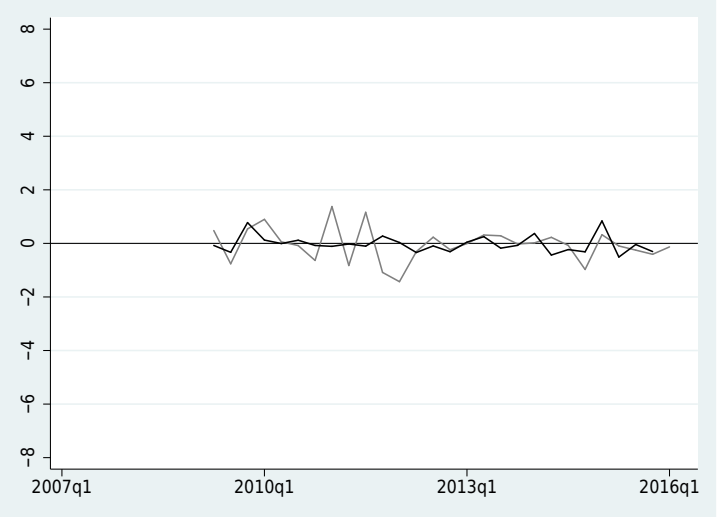

(a) Slovakia

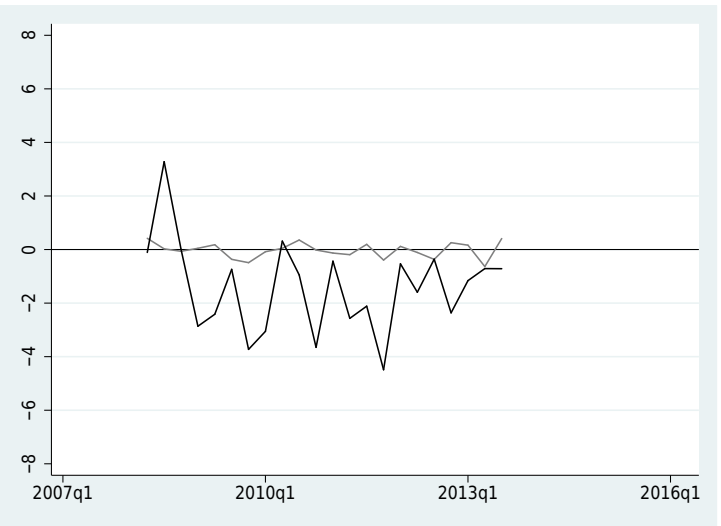

(c) Latvia

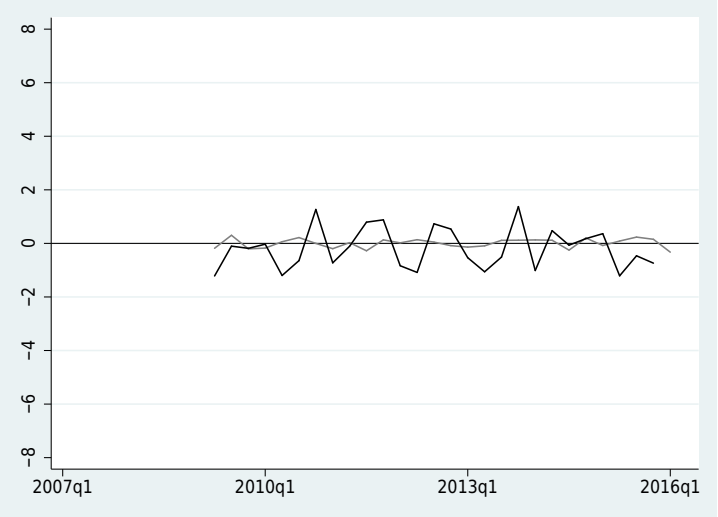

(b) United Kingdom

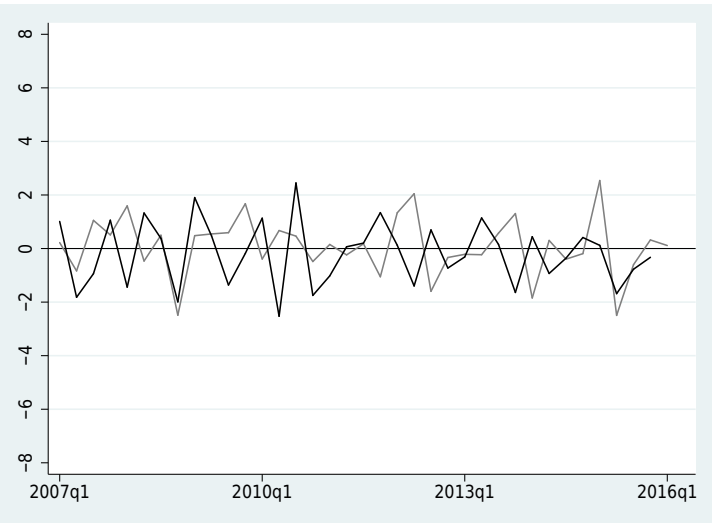

(d) Denmark

Figure 7: Net foreign currency and domestic currency wholesale funding inflows

The black line is quarterly valuation adjusted change in foreign currency interbank funding less foreign currency interbank lending, divided by total bank assets. The gray line is quarterly domestic currency foreign interbank funding less domestic currency foreign interbank lending, divided by total bank assets. Valuation adjusted described in Appendix C. Source: The Swiss Franc Lending Monitor, SNB 


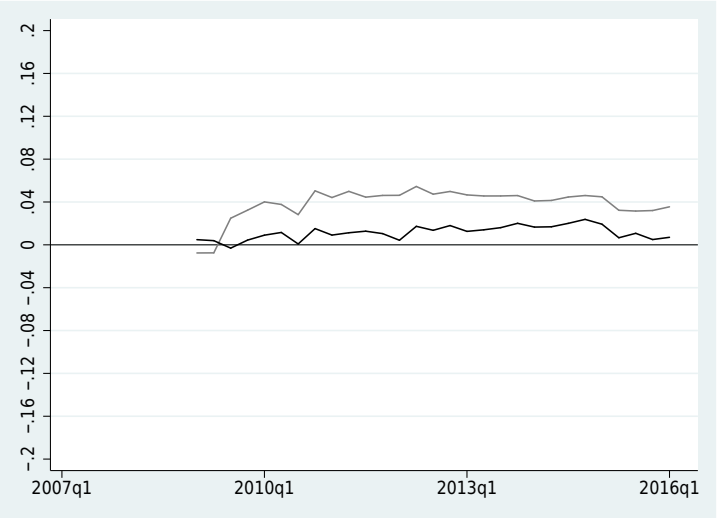

(a) Austria

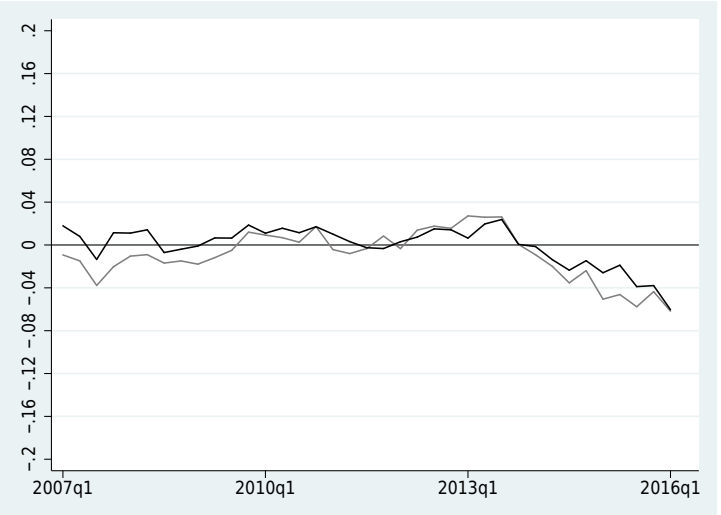

(c) Czech Republic

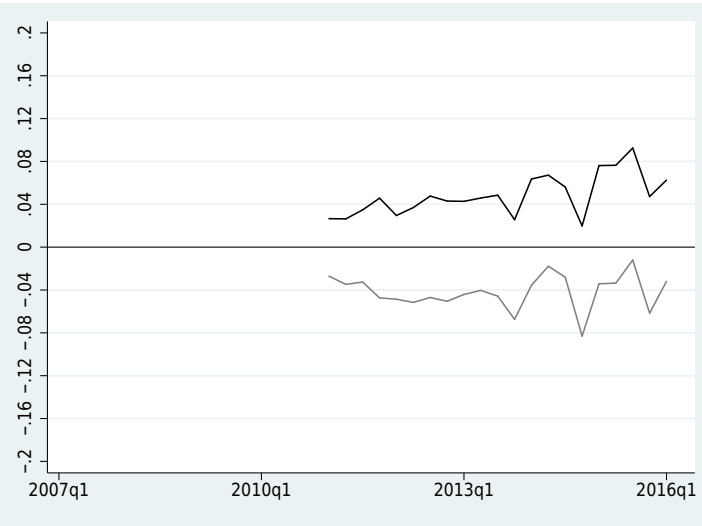

(e) Estonia

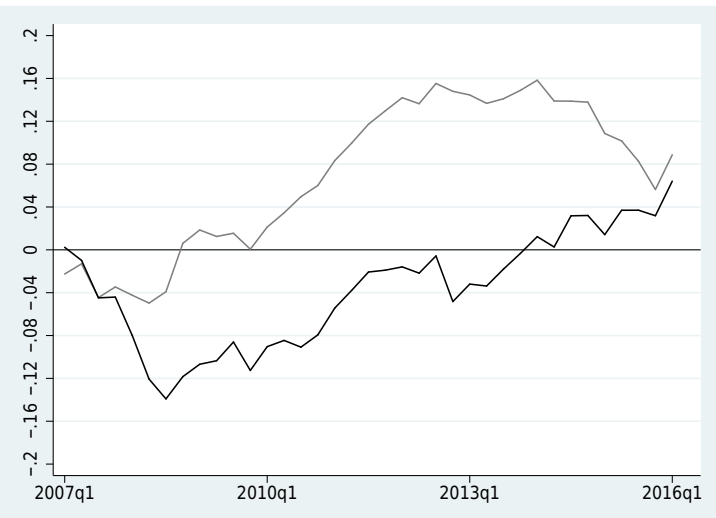

(b) Bulgaria

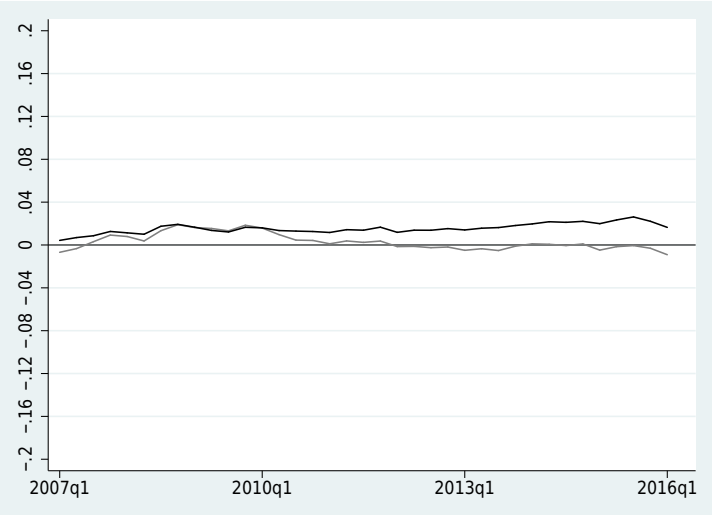

(d) Germany

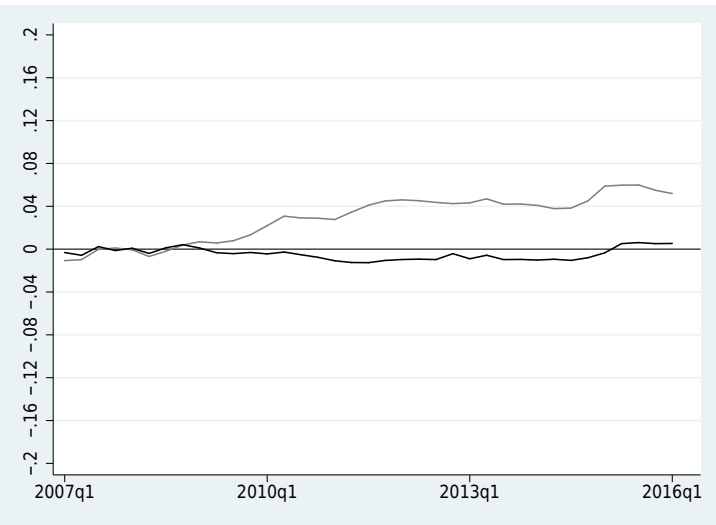

(f) Greece

Figure 8: Net foreign currency exposure.

The black line is the difference between foreign currency assets and foreign currency liabilities as a share of total bank assets. The gray line is foreign currency interbank cross border lending less similarly defined funding, as a share of total bank assets. Source: The Swiss Franc Lending Monitor, SNB. 


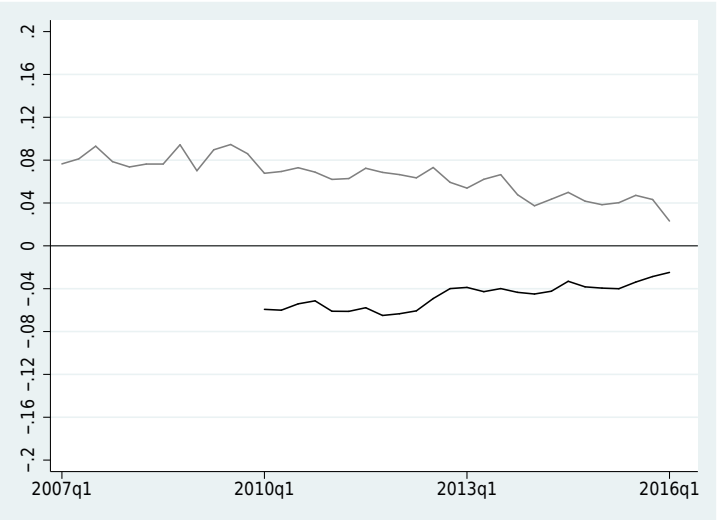

(a) Croatia

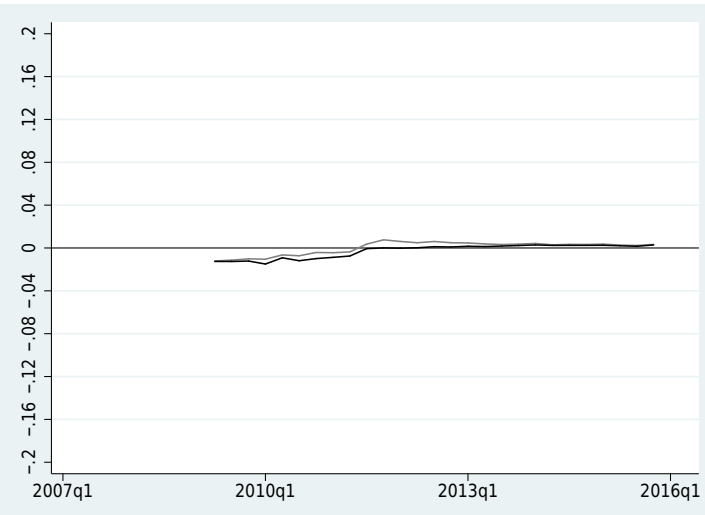

(c) Italy

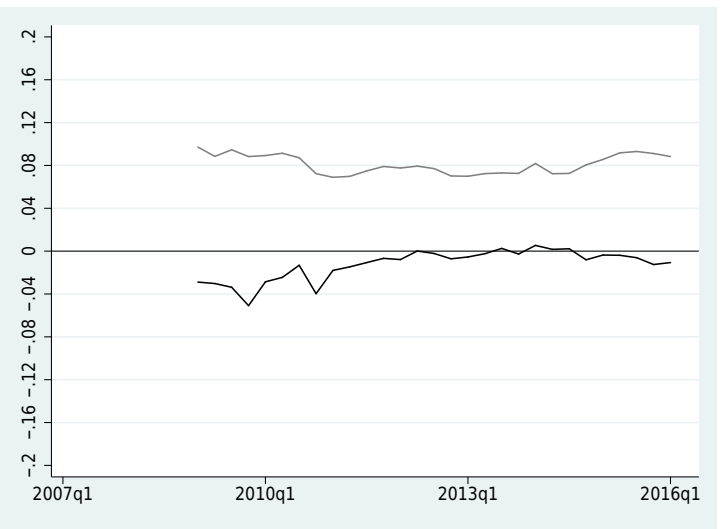

(e) Serbia

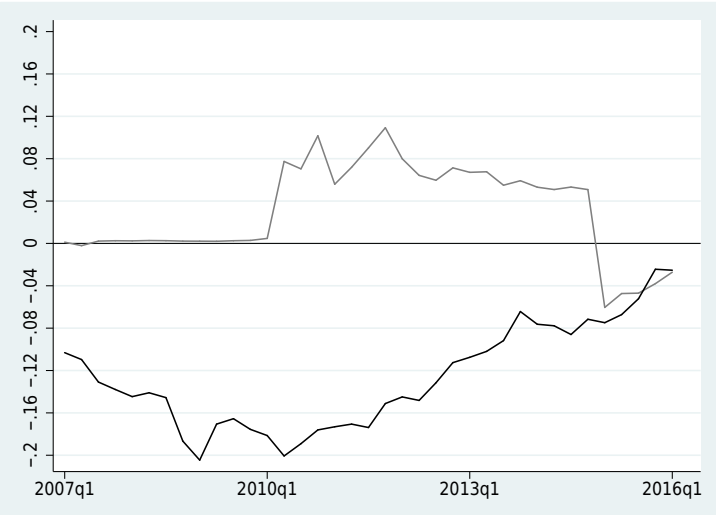

(b) Hungary

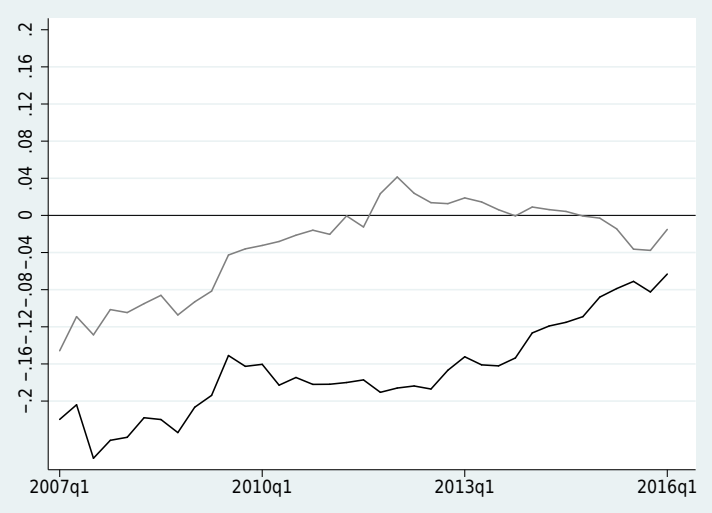

(d) Romania

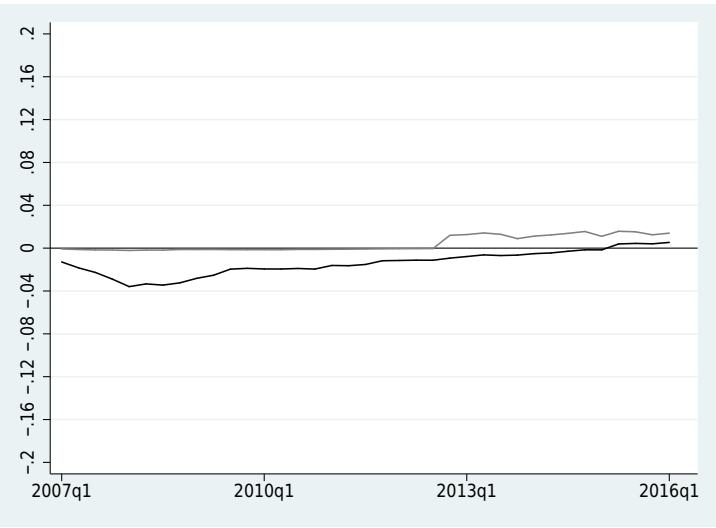

(f) Slovenia

Figure 9: Net foreign currency exposure.

The black line is the difference between foreign currency assets and foreign currency liabilities as a share of total bank assets. The gray line is foreign currency interbank cross border lending less similarly defined funding, as a share of total bank assets. Source: The Swiss Franc Lending Monitor, SNB. 


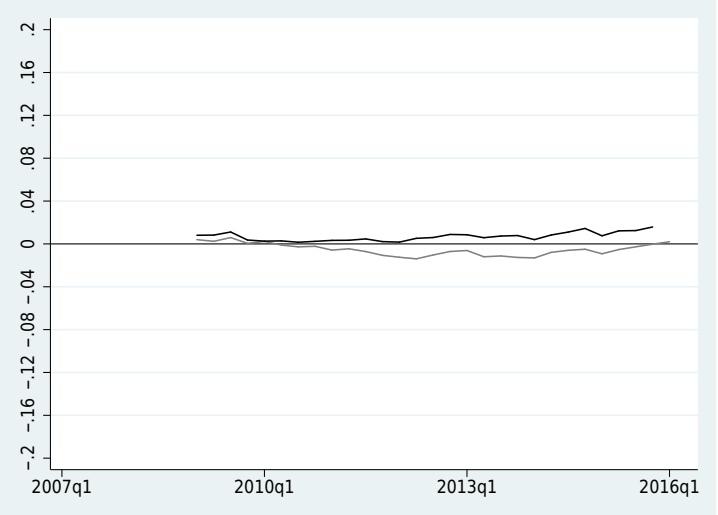

(a) Slovakia

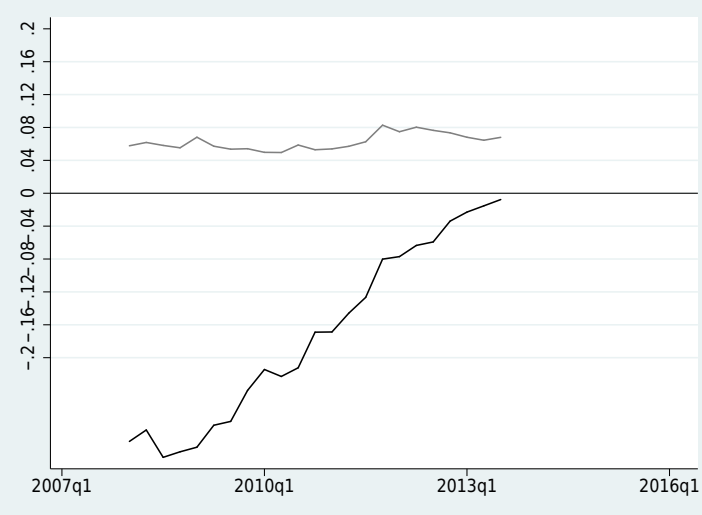

(c) Latvia

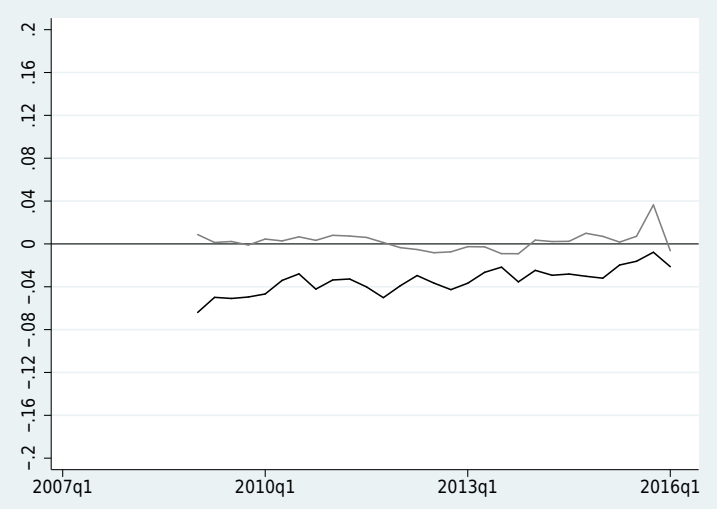

(b) United Kingdom

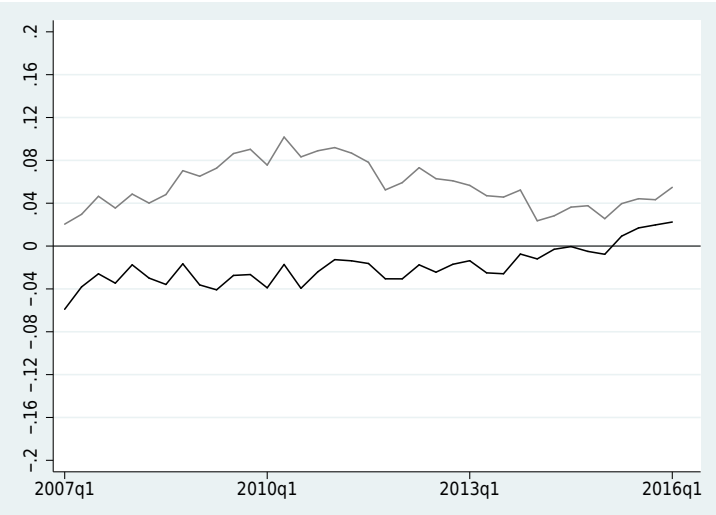

(d) Denmark

Figure 10: Net foreign currency exposure.

The black line is the difference between foreign currency assets and foreign currency liabilities as a share of total bank assets. The gray line is foreign currency interbank cross border lending less similarly defined funding, as a share of total bank assets. Source: The Swiss Franc Lending Monitor, SNB. 


\section{E Appendix tables}

\begin{tabular}{|c|c|c|c|}
\hline & I All & II Non-Euro & III Euro Area \\
\hline$g b d l_{-1}$ & -0.028 & -0.053 & 0.007 \\
\hline$N e t_{-1} \cdot g b d l_{-1}$ & $1.193^{* *}$ & $1.412^{* *}$ & -0.489 \\
\hline$l v o l_{-1}^{U S D}$ & -0.081 & -0.157 & -0.002 \\
\hline $\mathrm{Net}_{-1} \cdot \mathrm{lvol}_{-1}^{U S D}$ & 0.065 & 1.256 & 0.673 \\
\hline$d U S D_{-1}$ & -0.002 & -0.003 & -0.000 \\
\hline$N e t_{-1} \cdot d U S D_{-1}$ & $0.249^{* * *}$ & $0.182^{* * *}$ & 0.470 \\
\hline$N e t_{-1}^{2} \cdot d U S D_{-1}$ & $-1.961^{* * *}$ & $-1.136^{*}$ & -8.787 \\
\hline $\mathrm{Net}_{-1}$ & -5.310 & $-8.279^{* *}$ & 7.693 \\
\hline$N e t_{-1}^{2}$ & 4.836 & 35.314 & -145.412 \\
\hline$\tilde{C}_{-1}^{F X}$ & $0.177^{* *}$ & $0.163^{* *}$ & -0.081 \\
\hline$\tilde{D}_{-1}^{F X}$ & -0.006 & 0.026 & -0.017 \\
\hline $\mathrm{BG} d U I P_{-1}$ & -0.299 & -0.028 & \\
\hline HU & $-0.334^{*}$ & $-0.377^{*}$ & \\
\hline LV & -0.020 & $-0.026^{* *}$ & \\
\hline $\mathrm{RO}$ & $0.254^{*}$ & $0.366^{* *}$ & \\
\hline $\mathrm{RS}$ & 0.049 & 0.034 & \\
\hline $\mathrm{HR}$ & $-0.131^{* * *}$ & $-0.138^{* * *}$ & \\
\hline $\mathrm{CZ}$ & $0.580^{* * *}$ & $0.761^{* * *}$ & \\
\hline DK & $0.513^{* * *}$ & $0.636^{* * *}$ & \\
\hline GB & -0.150 & -0.054 & \\
\hline GR & $0.317^{*}$ & & -0.061 \\
\hline IT & $-0.298^{* * *}$ & & $-0.366^{* * *}$ \\
\hline SI & 0.007 & & $-0.335^{* * *}$ \\
\hline SK & -0.109 & & $0.278^{*}$ \\
\hline $\mathrm{AT}$ & $0.370^{* *}$ & & -0.032 \\
\hline $\mathrm{DE}$ & $0.268^{* *}$ & & 0.039 \\
\hline $\mathrm{EE}$ & $2.374^{* * *}$ & & \\
\hline $\mathrm{BG} d C I P_{-1}$ & $-1.690^{* * *}$ & $-1.696^{* * *}$ & \\
\hline $\mathrm{HU}$ & $0.453^{* *}$ & $0.601^{* *}$ & \\
\hline LV & -0.038 & -0.028 & \\
\hline $\mathrm{RO}$ & 0.019 & $0.112^{* *}$ & \\
\hline $\mathrm{RS}$ & $0.060^{* *}$ & $0.061^{* * *}$ & \\
\hline $\mathrm{HR}$ & $-0.381^{* * *}$ & $-0.400^{* * *}$ & \\
\hline $\mathrm{CZ}$ & $-0.896^{* *}$ & -0.489 & \\
\hline DK & 0.087 & 0.194 & \\
\hline GB & $1.477^{* * *}$ & $1.901^{* *}$ & \\
\hline GR & 0.103 & & $0.147^{* *}$ \\
\hline IT & $0.553^{* * *}$ & & $0.375^{* * *}$ \\
\hline SI & $-0.233^{* * *}$ & & $-0.204^{* * *}$ \\
\hline SK & $0.116^{*}$ & & $0.128^{* *}$ \\
\hline $\mathrm{AT}$ & $0.544^{* * *}$ & & $0.522^{* *}$ \\
\hline DE & $0.247^{* * *}$ & & $0.209^{* * *}$ \\
\hline $\mathrm{EE}$ & $1.516^{* * *}$ & & \\
\hline$R^{2}$ & 0.22 & 0.28 & 0.16 \\
\hline$R^{2}$ adjusted & 0.14 & 0.19 & 0.02 \\
\hline Nobs & 454 & 255 & 181 \\
\hline No.cross sections & 16 & 9 & 6 \\
\hline Sample period & Full & Full & Full \\
\hline Fixed effects & Yes & Yes & Yes \\
\hline
\end{tabular}

Table 6: Robustness to country specific cip and uip parameter estimates

The Table shows results from regressions of valuation adjusted bank net wholesale funding flows in percent of total assets, for the full sample of countries, the subsample of non-euro countries and the subsample of euro area countries. Specification III excludes Estonia. The sample period runs from Q1 2007 to Q1 2016. Asterisks *, ** and *** indicate significance at the 10, 5 percent and 1 percent levels, respectively, using white cross section standard errors and covariances. 


\begin{tabular}{|c|c|c|c|}
\hline & I All & II Non-Euro & III Euro Area \\
\hline$g b d l_{-1}$ & -0.007 & -0.000 & 0.006 \\
\hline Net $_{-1} \cdot g b d l_{-1}$ & $1.151^{* * *}$ & $1.145^{* *}$ & -0.116 \\
\hline $\operatorname{lvol}_{-1}^{U S D}$ & -0.159 & -0.257 & -0.028 \\
\hline Net $_{-1} \cdot l v o l_{-1}^{U S D}$ & 0.714 & 1.784 & 0.303 \\
\hline$d U S D_{-1}$ & 0.002 & -0.000 & 0.001 \\
\hline Net $_{-1} \cdot d U S D_{-1}$ & $0.330 * * *$ & $0.295^{* *}$ & 0.230 \\
\hline$N e t_{-1}^{2} \cdot d U S D_{-1}$ & $-3.035 * * *$ & $-2.690^{*}$ & -0.084 \\
\hline $\mathrm{Net}_{-1}$ & -2.721 & -4.054 & 5.432 \\
\hline$N e t_{-1}^{2}$ & 11.887 & 35.966 & -28.643 \\
\hline$\tilde{C}_{-1}^{F X}$ & $0.138^{* *}$ & $0.109^{* *}$ & -0.053 \\
\hline$\tilde{D}_{-1}^{F X}$ & -0.003 & 0.002 & -0.039 \\
\hline$d U I P_{-1}$ & 0.037 & 0.044 & -0.150 \\
\hline$d C I P_{-1}$ & -0.061 & -0.065 & -0.105 \\
\hline Inflation $_{-1}$ & 0.017 & 0.026 & 0.002 \\
\hline Growth $_{-1}$ & $0.057^{* *}$ & $0.068^{* *}$ & 0.022 \\
\hline$d U S_{T} S_{-1}$ & 0.061 & -0.040 & 0.082 \\
\hline$d U S_{R} R_{-1}$ & -0.097 & -0.195 & 0.011 \\
\hline$d U S_{R} E E R_{-1}$ & 0.011 & 0.017 & 0.001 \\
\hline$d U S_{M} 0_{-1}$ & -0.000 & -0.000 & -0.000 \\
\hline$d U S_{S} F F R_{-1}$ & -0.107 & -0.172 & 0.021 \\
\hline$R^{2}$ & 0.17 & 0.23 & 0.15 \\
\hline$R^{2}$ adjusted & 0.13 & 0.16 & 0.03 \\
\hline Nobs & 423 & 239 & 167 \\
\hline No.cross sections & 16 & 9 & 6 \\
\hline Sample period & Full & Full & Full \\
\hline Fixed effects & Yes & Yes & Yes \\
\hline
\end{tabular}

Table 7: Robustness to inclusion of additional controls

The Table shows results from regressions of valuation adjusted bank net wholesale funding flows in percent of total assets, for the full sample of countries, the sub-sample of non-euro countries and the sub-sample of euro area countries. Specification III excludes Estonia. The sample period runs from Q1 2007 to Q1 2016. Asterisks *, ** and *** indicate significance at the 10, 5 percent and 1 percent levels, respectively, using white cross section standard errors and covariances. 


\begin{tabular}{lccc}
\hline \hline & I All & II Non-Euro & III Euro Area \\
\hline$g b d l_{-1}$ & $-0.018^{*}$ & $-0.019^{* *}$ & -0.011 \\
$N e t_{-1} \cdot g b d l_{-1}$ & $0.399^{* *}$ & $0.462^{* * *}$ & 0.136 \\
$l v o l_{-1}^{U S D}$ & -0.030 & 0.019 & -0.054 \\
$N e t_{-1} \cdot l v o l_{-1}^{U S D}$ & $1.223^{* * *}$ & $0.943^{* * *}$ & $9.768^{* *}$ \\
$d U S D_{-1}$ & -0.001 & -0.001 & 0.005 \\
$N e t_{-1} \cdot d U S D_{-1}$ & -0.022 & -0.061 & 0.050 \\
$N e t_{-1}^{2} \cdot d U S D_{-1}$ & -0.126 & 0.461 & -3.762 \\
$N e t_{-1}$ & -2.275 & $-6.831^{*}$ & $30.590^{*}$ \\
$N e t_{-1}^{2}$ & 36.053 & $64.599^{* *}$ & 37.914 \\
$\tilde{C}_{-1}^{F X}$ & 0.026 & -0.015 & -0.180 \\
$\tilde{D}_{-1}^{F X}$ & -0.017 & 0.015 & 0.471 \\
$d U I P_{-1}$ & $-0.062^{*}$ & -0.020 & -0.669 \\
$d C I P_{-1}$ & 0.103 & 0.034 & $0.368^{* *}$ \\
\hline$R^{2}$ & 0.02 & 0.12 & 0.11 \\
$R^{2} a d j u s t e d$ & -0.01 & 0.07 & 0.04 \\
Nobs & 475 & 271 & 185 \\
No.cross sections & 16 & 9 & 6 \\
Sample period & Full & Full & Full \\
Fixed effects & Yes & Yes & Yes \\
\hline \hline
\end{tabular}

Table 8: Regression for total cross border flows denominated in domestic currency

The Table shows the results for regression with the alternative dependent variable that includes domestic currency denominated cross border flows to foreign banks. Column III excludes Estonia from the euro area sample. The sample runs from Q1 2007 to Q1 2016 and all regressions include country fixed effects as well as the three explanatory variables. Asterisks ${ }^{*}$, ** and *** indicate significance at the 10, 5 percent and 1 percent levels, respectively, using white cross section standard errors and covariances. 


\begin{tabular}{|c|c|c|c|c|c|c|c|c|c|c|}
\hline & $\overline{\mathrm{I}}$ & II & III & IV & $\overline{\mathrm{V}}$ & VI & VII & VIII & IX & $\mathrm{X}$ \\
\hline$g b d l_{-1}$ & -0.008 & -0.022 & $-0.027^{*}$ & -0.023 & -0.028 & -0.020 & -0.004 & & -0.007 & -0.022 \\
\hline$N e t_{-1} \cdot g b d l_{-1}$ & & $0.996 * *$ & $0.984^{* *}$ & $1.093^{* *}$ & $1.075^{*}$ & $0.993^{* *}$ & 0.514 & $1.174^{* *}$ & 0.531 & $1.460^{* *}$ \\
\hline $\operatorname{lvol}_{-1}^{F X}$ & & & -0.020 & -0.066 & -0.019 & -0.064 & -0.104 & -0.036 & -0.018 & 0.020 \\
\hline Net $_{-1}^{-1} \cdot \operatorname{lvol}_{-1}^{F X}$ & & & 1.066 & 1.287 & -0.191 & 1.360 & 1.734 & 1.228 & -0.400 & -1.577 \\
\hline$d F X_{-1}$ & & & 0.003 & 0.003 & 0.001 & 0.002 & 0.001 & 0.003 & 0.003 & 0.002 \\
\hline$N_{e} t_{-1} \cdot d F X_{-1}$ & & & $0.335^{* * *}$ & $0.298^{* *}$ & $0.439 * *$ & $0.328^{* *}$ & 0.524 & $0.228^{*}$ & 0.241 & $0.410^{* * *}$ \\
\hline$N e t_{-1}^{2} \cdot d F X_{-1}$ & & & $-7.222^{* * *}$ & $-7.112^{* * *}$ & $-9.400^{* * *}$ & $-6.978 * * *$ & $-10.436^{* *}$ & $-7.077^{* * *}$ & $-4.788^{* * *}$ & $-9.424^{* * *}$ \\
\hline Net-1 & -4.405 & -5.698 & -3.721 & -3.332 & 1.636 & -5.868 & -1.821 & -1.618 & -6.548 & -3.220 \\
\hline$N e t_{-1}^{2}$ & 4.106 & 0.478 & $62.023^{*}$ & 68.748 & -14.208 & $97.709^{* * *}$ & 91.412 & 62.631 & 16.003 & -67.429 \\
\hline$\tilde{C}_{-1}^{F X}$ & $0.215^{* * *}$ & $0.210^{* * *}$ & $0.242^{* * *}$ & $0.224^{* * *}$ & $0.128^{* * *}$ & $0.186^{* * *}$ & $0.184^{* * *}$ & $0.183^{* * *}$ & $0.235^{* * *}$ & $0.136^{* * *}$ \\
\hline$\tilde{D}_{-1}^{F X}$ & -0.049 & -0.052 & -0.055 & -0.068 & $-0.175^{* *}$ & -0.041 & -0.061 & -0.076 & -0.008 & -0.127 \\
\hline$d U^{-1} P_{-}^{F X}$ & -0.066 & -0.028 & -0.060 & -0.052 & -0.042 & -0.055 & -0.012 & -0.008 & -0.069 & -0.018 \\
\hline$d C I P_{-}^{\bar{F} X}$ & 0.039 & 0.011 & 0.008 & -0.005 & -0.103 & -0.001 & -0.088 & -0.024 & -0.013 & -0.091 \\
\hline Constant & -0.009 & 0.012 & -0.080 & -0.236 & -0.279 & -0.223 & -0.392 & 1.620 & -0.126 & -0.129 \\
\hline$R^{2}$ & 0.105 & 0.120 & 0.188 & 0.179 & 0.047 & 0.203 & 0.111 & 0.234 & 0.132 & 0.060 \\
\hline$R^{2}$ adjusted & 0.092 & 0.105 & 0.164 & 0.155 & 0.015 & 0.179 & 0.082 & 0.213 & 0.107 & 0.028 \\
\hline Nobs & 462 & 462 & 462 & 462 & 401 & 444 & 415 & 462 & 453 & 392 \\
\hline No.cross sections & 16 & 16 & 16 & 16 & 16 & 15 & 14 & 16 & 16 & 16 \\
\hline Sample period & Full & Full & Full & Full & $\mathrm{PC}$ & Full & Full & Full & Full & $\mathrm{PC}$ \\
\hline Fixed effects & Yes & Yes & No & Yes & Yes & Yes & Yes & Yes & Yes & Yes \\
\hline Time effects & No & No & No & No & No & No & No & Yes & No & No \\
\hline
\end{tabular}

\section{Table 9: Regression using EUR as foreign currency for non-euro countries}

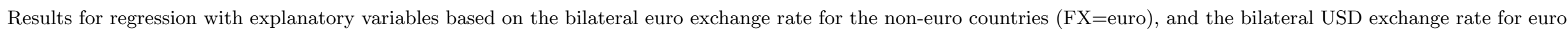

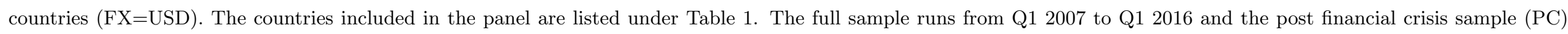

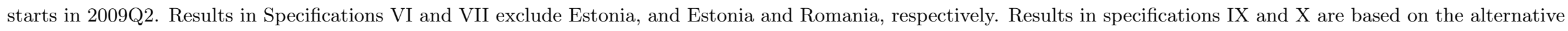

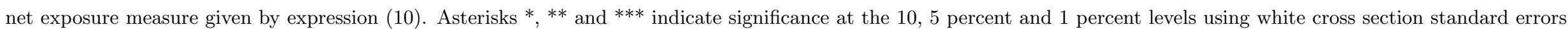
and covariances. 


\begin{tabular}{|c|c|c|c|c|c|c|}
\hline & $\overline{\mathrm{II}}$ & $\overline{\overline{\text { II }}}$ & III & IV & $\overline{\mathrm{V}}$ & $\overline{\mathrm{VI}}$ \\
\hline$g b d l_{-1}$ & -0.015 & -0.037 & -0.040 & $-0.068^{*}$ & -0.027 & $-0.068^{*}$ \\
\hline Net $_{-1} \cdot g b d l_{-1}$ & & $1.033^{* *}$ & $1.153^{* *}$ & $1.471^{*}$ & 0.798 & $1.567^{*}$ \\
\hline $\operatorname{lvol}_{-1}^{F X}$ & & & -0.083 & -0.035 & -0.083 & -0.040 \\
\hline Net $_{-1} \cdot \operatorname{lvol}_{-1}^{F X}$ & & & 1.162 & 0.550 & 1.028 & 0.448 \\
\hline$d F X_{-1}$ & & & 0.000 & -0.009 & -0.006 & -0.011 \\
\hline Net $_{-1} \cdot d F X_{-1}$ & & & $0.296^{*}$ & $0.694^{* *}$ & $0.749^{* *}$ & $0.827^{* *}$ \\
\hline$N e t_{-1}^{2} \cdot d F X_{-1}$ & & & $-7.244^{* * *}$ & $-11.094^{* *}$ & $-12.756^{* *}$ & $-12.170^{* *}$ \\
\hline Net $_{-1}$ & $-8.047^{* *}$ & $-9.125^{* *}$ & -7.053 & -5.463 & -1.200 & -6.796 \\
\hline$N e t_{-1}^{2}$ & 33.154 & 27.397 & $91.188^{* *}$ & 72.627 & 81.979 & 71.339 \\
\hline$\tilde{C}_{-1}^{F X}$ & $0.188^{* * *}$ & $0.186^{* * *}$ & $0.206^{* * *}$ & $0.147^{* * *}$ & $0.137^{* * *}$ & $0.168^{* * *}$ \\
\hline$\tilde{D}_{-1}^{F X}$ & -0.018 & -0.022 & -0.045 & -0.166 & -0.171 & $-0.235^{* *}$ \\
\hline$d U I P_{-}^{F X}$ & -0.077 & -0.036 & -0.063 & -0.095 & -0.020 & -0.106 \\
\hline$d C I P_{-}^{F X}$ & 0.034 & -0.017 & -0.036 & -0.030 & -0.151 & 0.081 \\
\hline$R^{2}$ & 0.14 & 0.16 & 0.23 & 0.11 & 0.05 & 0.13 \\
\hline$R^{2}$ adjusted & 0.12 & 0.14 & 0.19 & 0.05 & -0.01 & 0.08 \\
\hline Nobs & 263 & 263 & 263 & 225 & 201 & 207 \\
\hline No.cross sections & 9 & 9 & 9 & 9 & 8 & 8 \\
\hline Sample period & Full & Full & Full & $\mathrm{PC}$ & $\mathrm{PC}$ & $\mathrm{PC}$ \\
\hline Fixed effects & Yes & Yes & Yes & Yes & Yes & Yes \\
\hline
\end{tabular}

Table 10: Regression using EUR as foreign currency for non-euro countries

Results for regression with explanatory variables based on the bilateral euro exchange rate for the subsample of non-euro countries $(\mathrm{FX}=$ euro). The non-euro country sub-sample is listed under Table 1. The full sample runs from Q1 2007 to Q1 2016 and the post financial crisis sample (PC) starts in 2009Q2. Specifications V and VI exclude Romania and Latvia respectively. Asterisks $*{ }^{* *}$ and ${ }^{* * *}$ indicate significance at the 10,5 percent and 1 percent levels, respectively, using white cross section standard errors and covariances. 